\title{
A Density Functional Theory Investigation of Intramolecular Dispersion Forces in Buckyball-Buckybowl Complexes
}

Ivan Welsh

\section{VICTORIA UNIVERSITY OF WELLINGTON Te Whare Wananga o te Upoko o te Ika a Maui}

\section{Victoria UNIVERSITY OF WELLINGTON \\ Te Whare Wānanga o te Ūpoko o te Ika a Māui}

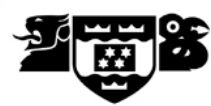

School of Chemical and Physical Sciences Te Wānanga Matū

A thesis

submitted to the Victoria University of Wellington in fulfilment of the requirements for the degree of

Master of Science in Chemistry.

Victoria University of Wellington 


\begin{abstract}
The electron-rich, concave face of corannulene makes it an ideal candidate to host electron-deficient fullerenes, such as $\mathrm{C}_{60}$. The host-guest system is dominated by weak van der Waals interactions. Modelling of the $\mathrm{C}_{60} @$ corannulene complex was carried out with nine different density functionals: B3LYP, B97-D, BP86, CAM-B3LYP, M06-2X, PW91, $\tau$-HCTH, $\omega \mathrm{B} 97 \mathrm{X}$, and $\omega \mathrm{B} 97 \mathrm{X}-\mathrm{D}$, using the 6-31G(d) basis set. Results indicated that the functionals including an empirical dispersion correction term, B97-D and $\omega \mathrm{B} 97 \mathrm{X}-\mathrm{D}$, gave the most reliable binding energy values when compared with $a b$ initio SCS-MP2 benchmark computations. Additionally, a number of complexes with functionalised corannulene bowls were modelled at the $\omega \mathrm{B} 97 \mathrm{X}-\mathrm{D} / 6-31 \mathrm{G}(\mathrm{d})$ level, with NMR calculations performed at the GIAO/ $\omega \mathrm{B} 97 \mathrm{X}-\mathrm{D} /$ dec-6-31G(d) level. A linear trend was revealed between the number of substituents on corannulene and the strength of binding within complex with $\mathrm{C}_{60}$. Calculated ${ }^{1} \mathrm{H}$ NMR $\Delta \delta$ values for methyl groups on methyl substituted corannulene bowls were also linearly dependent on binding energy. Further results are reported here.
\end{abstract}




\section{Acknowledgements}

It has been a long and interesting year working on this project. Doing a computational chemistry project started out a little difficult because it was not something I had done much of previously. I have really enjoyed it though. There are a few people I would like to thank for things over the year. Firstly, to the boss, Dr. Matthias Lein. He gets a big thanks for taking me on and guiding me over the course of the project. Emma Greenlees was a huge help in the early months, so big ups to her. Wong deserves a mention for being a sounding board for things and even being so kind as to read this thesis. Time to buy a giant gummi bear. To my other proofreaders, Steph Chee, Melanie Holzer (11.1.14. I be there), Jessica de Ruiter (you volunteered so yays for you), my dad Bruce Welsh (dimer $\neq$ dimmer) and especially Corrina Lines who took time out of her busy day proofreading things to proofread this. You're all awesome. Any bad English ain't their fault. Kevin Buckley of ECS has been keeping HPC more or less running well, so thanks for that. I would also like to acknowledge the awesomeness that is Sarah Hughes. An unexpected giant bag of candy goes so far. To my remaining office mates, Greenie, Jerry, Eldon, Andrea, Matthias and Steve. Thanks for putting up with me, and the fantastic whiteboard representation of my life. Flying elephants FTW. Lastly (and for a change leastly, just because I've been told to do it) Susan Welsh and Meghan Fraser for making my life interesting and stealing my candy so I don't get fat and generally being an annoyance. You're so nice. 


\section{Contents}

$1 \quad$ Introduction 1

1.1 Corannulene Derivatives . . . . . . . . . . . . . . . . . 2

1.2 Supramolecular Complexes . . . . . . . . . . . . . . . . . 3

$1.2 .1 \quad$ Experimental Results . . . . . . . . . . . . . . . 4

1.2 .2 Theoretical Investigations . . . . . . . . . . . . 10

1.3 Functionals . . . . . . . . . . . . . . . . . . . . 15

1.3 .1 GGA Functionals . . . . . . . . . . . . . . . . 16

1.3 .2 meta-GGA Functional . . . . . . . . . . . . . 17

1.3 .3 Hybrid Functional . . . . . . . . . . . . . . . . . 18

1.3 .4 Long-range Corrected Functionals . . . . . . . . . . . . . . 18

1.3 .5 ab initio Method . . . . . . . . . . . . . . . 22

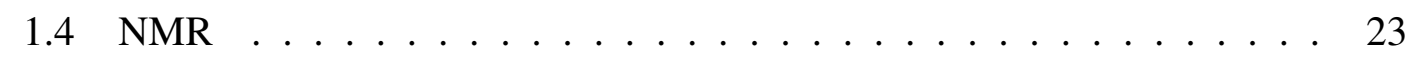

1.5 Research Aims . . . . . . . . . . . . . . . 23

2 Methodology 24

$2.1 \quad$ Functional Evaluation . . . . . . . . . . . . . . . . . . . . . . 24

$2.1 .1 \quad$ Functionals . . . . . . . . . . . . . . . . . . . . . 24

2.1 .2 Geometries . . . . . . . . . . . . . . . 25

2.1 .3 Energy Profiles . . . . . . . . . . . . . . 25

2.1 .4 Integration Grid . . . . . . . . . . . . . . . 25

2.2 Functionalised Bowls . . . . . . . . . . . . . . . . . . 26

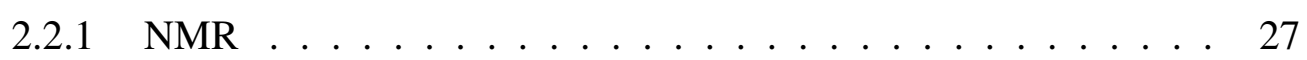

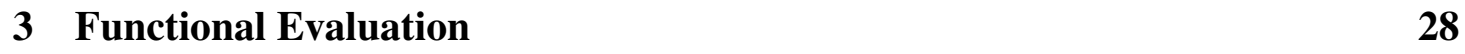

3.1 Results . . . . . . . . . . . . . . . . . . . . . . . 28

$3.1 .1 \quad$ Binding Energies . . . . . . . . . . . . . . . . . 28

3.1 .2 Fragment Separation $\ldots \ldots \ldots$. . . . . . . . . . . . . 29 
3.1 .3 Energy Profiles . . . . . . . . . . . . . . 30

3.1 .4 Integration Grid $\ldots \ldots \ldots . \ldots \ldots$

3.2 Discussion $\ldots \ldots \ldots \ldots \ldots \ldots$

$3.2 .1 \quad \mathrm{C}_{60} @$ corannulene Binding . . . . . . . . . . . . . . . 33

3.2 .2 Integration Grids $\ldots \ldots \ldots \ldots . \ldots \ldots 4$

4 Summary of Results 45

4.1 Functionals . . . . . . . . . . . . . . . . . . . . . . 45

4.2 Integration Grid $\ldots \ldots \ldots \ldots$. . . . . . . . . . . . . . 46

5 Functionalised Bowls $\quad 47$

5.1 Results . . . . . . . . . . . . . . . . . . . . . . . . 49

5.1 .1 Binding Energies . . . . . . . . . . . . . . . . . . 49

5.1 .2 Geometric Parameters . . . . . . . . . . . . . 51

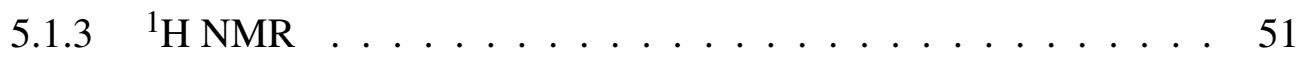

$5.1 .4{ }^{13} \mathrm{C} \mathrm{NMR} \ldots \ldots \ldots \ldots \ldots \ldots \ldots$

5.2 Discussion . . . . . . . . . . . . . . . . . 62

$5.2 .1 \quad$ Binding Energies $\ldots \ldots \ldots$. . . . . . . . . . . 62

$5.2 .2{ }^{1} \mathrm{H} \mathrm{NMR} \ldots \ldots \ldots \ldots \ldots \ldots \ldots$

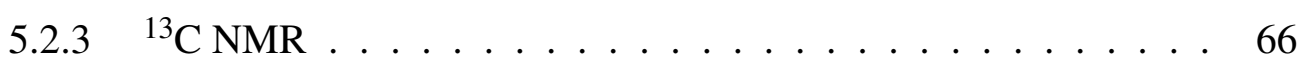

$\begin{array}{lll}6 & \text { Conclusions } & 67\end{array}$

$6.1 \quad$ Binding Energies . . . . . . . . . . . . . . . . . 67

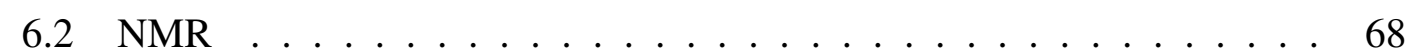

\begin{tabular}{lr}
\hline Glossary & 69
\end{tabular}

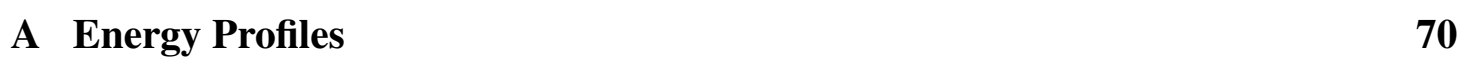

\begin{tabular}{lr}
\hline Bibliography & 78
\end{tabular} 


\section{List of Figures}

1.1 Corannulene . . . . . . . . . . . . . . . . . . . . . . . 1

1.2 Electrostatic potential of corannulene showing the electron-rich concave

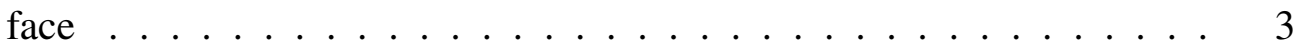

1.3 Sulfur containing derivatives of corannulene synthesised for complexation with fullerenes $\ldots \ldots \ldots \ldots \ldots \ldots$

$1.4 \mathrm{C}_{60} \mathrm{H}_{28}$ molecular tweezers $\ldots \ldots \ldots \ldots \ldots \ldots \ldots \ldots$

$1.5 \quad$ X-ray crystal structure of the $\mathrm{C}_{60} @ 1 \mathbf{1 . 4}$ complex $\ldots \ldots \ldots \ldots .7$

$1.6 \quad$ STM images of a $\mathrm{Cu}(110)$ surface-supported $\mathrm{C}_{60} @$ corannulene host-

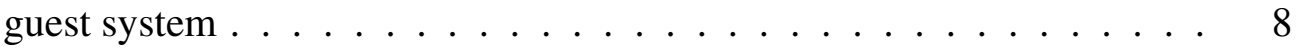

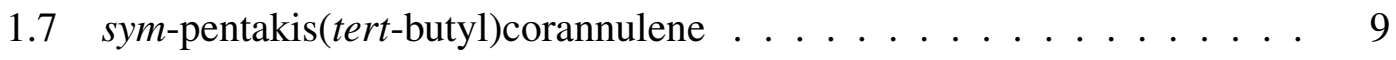

1.8 X-ray crystal structures of $\mathrm{C}_{60} @$ corannulene and $\mathrm{C}_{60} @ 1$ 1.7 $\mid$ complexes . 10

1.9 Sumanene and Pentaindenocorannulene $\ldots \ldots \ldots \ldots$

$2.1 \quad$ Geometries of the $\mathrm{C}_{60} @$ corannulene complex . . . . . . . . . . . 26

3.1 Definition of the $\mathrm{C}_{60}$-corannulene separation distance $\ldots \ldots \ldots \ldots .29$

3.2 An exemplar energy profile $\ldots \ldots \ldots \ldots \ldots \ldots \ldots$

3.3 MP2 energy profiles generated using the fine integration grid . . . . . 33

$3.4 \quad$ SCS-MP2 energy profiles generated using the fine integration grid . . . 34

$3.5 \quad$ BP86 energy profiles generated using the fine integration grid . . . . . 35

$3.6 \quad$ PW91 energy profiles generated using the fine integration grid . . . . 35

$3.7 \quad \tau$-HCTH energy profiles generated using the fine integration grid $\ldots .37$

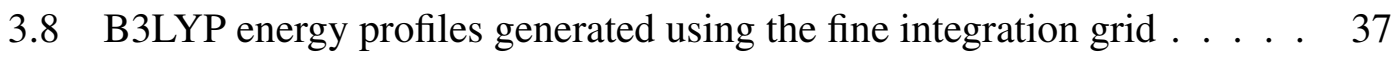

$3.9 \quad$ M06-2X energy profiles generated using the fine integration grid . . . . 39

3.10 CAM-B3LYP energy profiles generated using the fine integration grid . 39

$\begin{array}{lll}3.11 \omega \mathrm{B} 97 \mathrm{X} \text { energy profiles generated using the fine integration grid } \ldots & 40\end{array}$

3.12 B97-D energy profiles generated using the fine integration grid . . . . 42

$3.13 \omega \mathrm{B} 97 \mathrm{X}-\mathrm{D}$ energy profiles generated using the fine integration grid . . . 42 
3.14 PW91 energy profiles generated using the benchmark integration grid . 43

3.15 BP86 energy profiles generated using the benchmark integration grid. . 44

3.16 B3LYP energy profiles generated using the benchmark integration grid . 44

5.1 Structures of the functionalised bowls . . . . . . . . . . . . . . 47

5.2 Definition of the internal angle of a bowl-shaped molecule . . . . . . 50

$5.3 \quad$ Linear regression plot used to determine ${ }^{1} \mathrm{H}$ NMR scaling factor . . . . 55

5.4 Linear regression plot used to determine ${ }^{13} \mathrm{C}$ NMR scaling factor . . . . 62

A.1 B3LYP energy profiles generated using the ultrafine integration grid . . 70

A.2 B97-D energy profiles generated using the ultrafine integration grid . . 71

A.3 BP86 energy profiles generated using the ultrafine integration grid . . . 71

A.4 CAM-B3LYP energy profiles generated using the ultrafine integration grid . . . . . . . . . . . . . . . 72

A.5 M06-2X energy profiles generated using the ultrafine integration grid. . 72

A.6 PW91 energy profiles generated using the ultrafine integration grid . . . 73

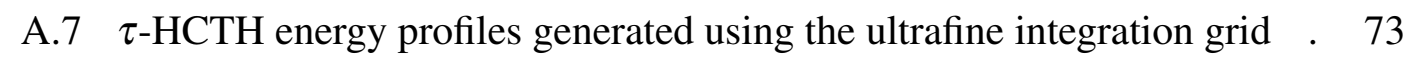

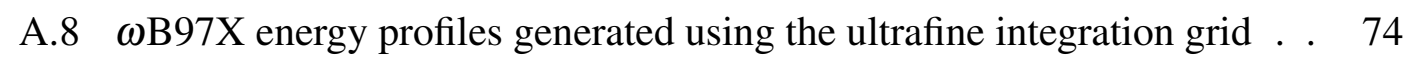

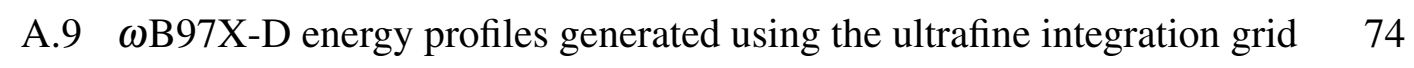

A.10 B97-D energy profiles generated using the benchmark integration grid . 75

A.11 CAM-B3LYP energy profiles generated using the benchmark integration grid . . . . . . . . . . . . . . . . 75

A.12 M06-2X energy profiles generated using the benchmark integration grid 76

A.13 $\tau$-HCTH energy profiles generated using the benchmark integration grid 76

$\begin{array}{ll}\text { A.14 } \omega \mathrm{B} 97 \mathrm{X} \text { energy profiles generated using the benchmark integration grid } & 77\end{array}$

A.15 $\omega$ B97X-D energy profiles generated using the benchmark integration grid 77 


\section{List of Tables}

$1.1 \quad K_{\text {assoc }}$ values for fullerenes complexed with sulfur containing corannulene derivatives . . . . . . . . . . . . . 6

1.2 Corannulene dimer binding energies reported in the literature . . . . . . 11

1.3 Homo and mixed dimer binding energies reported in the literature . . . 13

1.4 Binding energies of curved $\pi$-system complexes with $\mathrm{C}_{60}$ reported in the literature .................... 15

3.1 Calculated binding energies for $\mathrm{C}_{60} @$ corannulene . . . . . . . . . . . . 28

3.2 Calculated $\mathrm{C}_{60}$-corannulene fragment separation distances . . . . . . . 29

3.3 Binding energies of $\mathrm{C}_{60} @$ corannulene calculated with three different integration grid sizes $\ldots \ldots \ldots . \ldots \ldots 31$

$3.4 \quad \mathrm{C}_{60}$-corannulene separation distances calculated with three different integration grid sizes . . . . . . . . . . . . . 32

$5.1 \quad$ Calculated binding energies for functionalised bowl complexes with $\mathrm{C}_{60} \quad 50$

5.2 Geometric parameters for functionalised bowl complexes with $\mathrm{C}_{60}$. . . 51

\begin{tabular}{|lll}
5.3 & Calculated ${ }^{1} \mathrm{H}$ NMR shifts for the functionalised bowls and complexes & 52
\end{tabular}

\begin{tabular}{|lll}
5.4 & Calculated ${ }^{13} \mathrm{C}$ NMR shifts for the functionalised bowls and complexes & 55
\end{tabular} 


\section{Chapter 1}

\section{Introduction}

Dibenzo[ghi,mno]fluoranthene $\left(\mathrm{C}_{20} \mathrm{H}_{10}\right)$, trivially known as corannulene, is a moiety of $\mathrm{C}_{60}$ fullerene. The carbon framework consists of a $\mathrm{C}_{5}$ ring with phenyl groups fused to each edge (Figure 1.1). The presence of the five-membered ring surrounded by sixmembered rings forces the molecule out of the plane, forming a bowl-like structure with $\mathrm{C}_{5 \mathrm{v}}$ symmetry.

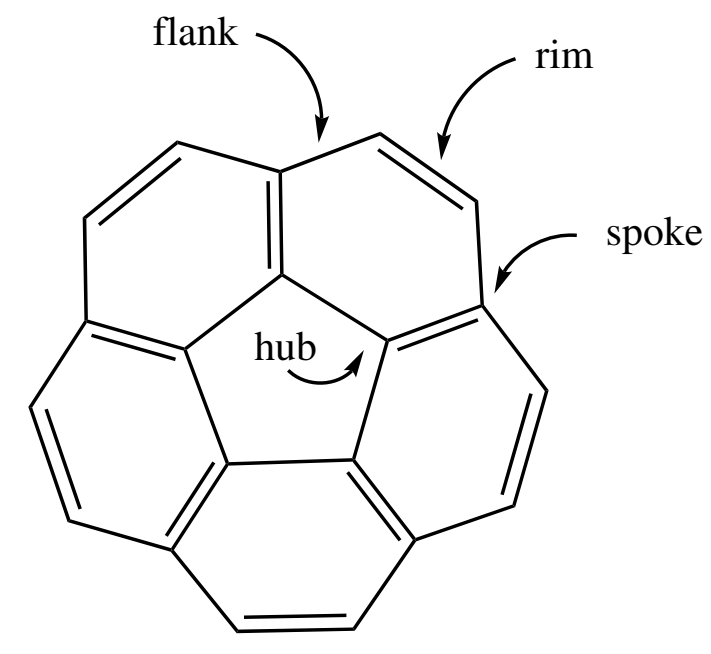

Figure 1.1. Corannulene $\left(\mathrm{C}_{20} \mathrm{H}_{10}\right)$.

Corannulene was first synthesised from acenaphthene via a 17 step process by Barth and Lawton in 1966. 11 Since then, several alternative synthetic methods have been produced, as well as methods to derivatise the corannulene framework in various manners. ${ }^{2}$ 


\subsection{Corannulene Derivatives}

Corannulene is the smallest and most studied bowl-shaped molecule. Functionalisation has provided a wide range of bowl-shaped molecules which could be used as host molecules in a host-guest system. A number of reviews of synthetic methods for the formation of corannulene derivatives have been published. ${ }^{[2]}$ There are two basic ideas for functionalisation of the corannulene: extending the rigid structure of the bowl and substituting functional groups onto the rim.

The most basic functionalisation of corannulene is the addition of alkyl chains to the rim. Seiders et al. have synthesised a number of methyl substituted corannulene derivatives. ${ }^{4} \mathrm{Di}$ - and tetra-substituted corannulenes were synthesised through use of carefully selected branched precursor materials. Mono-, sym-penta-, and deca-substituted corannulenes were produced from the corresponding selectively halogenated corannulenes. Grube et al. and Sevryugina et al. reported the synthesis of methyl, ethyl, octyl,,$\sqrt[5]{ }$ and tert-butyl ${ }^{6}$ sym-penta- substituted corannulenes.

Grube et al. also demonstrated the synthesis of aryl and alkynyl functionalised sympenta- corannulenes. ${ }^{5}$ Aryl substituents included phenyl, napthyl and $p$-octylphenyl with trimethylsilylacetylene as an alkynyl substituent. High molecular mass aryl substituted corannulenes have been prepared by Pappo et al. who have generated pentagonal dendrimers up to the third generation. ${ }^{7}$ Further examples of alkynyl substituted corannulenes were reported by Wu et al., who synthesised 1,6-di-, 1,2,5,6-tetra- and sym-pentasubstituted corannulenes. ${ }^{8}$ Their compounds contained a myriad of different functional groups attached to the free end of ethynyl, including trimethylsilane, phenyl, methyl benzanoate, and octoxynapthyalene. These results showed that it is possible to produce carbon substituted corannulenes where the attached carbon is either $\mathrm{sp}, \mathrm{sp}^{2}$ or $\mathrm{sp}^{3}$ hybridised.

Derivatives with heteroatoms in the 'ipso' position are a common occurrence. Thiolbased substituents have been reported by a number of groups,,$\frac{59-12}{12}$ as have ethers. .513 These come about because direct nucleophilic aromatic substitution of chloro- corannulenes is possible, and relatively easy, to achieve using good nucleophiles without the help of catalysts. The bowls produced containing these heteroatoms are generally expected to be better host molecules than their alkyl substituted relatives, as the electron 
donating groups will enhance the electron rich nature of the surface of the corannulene skeleton.

Another method of synthesising corannulene derivatives is through fusing additional rings directly onto various points of the corannulene skeleton. Commonly, this involves generating larger moieties of $\mathrm{C}_{60}$. For example, benzocorannulenes ${ }^{2[3 / 14}$ consist of phenyl groups fused to the rim of corannulene. With multiple phenyl groups fused, adjacent groups can be bonded together ${ }^{15}$ via their nearest carbon atoms, effectively increasing the curvature of the bowl through the creation of additional $\mathrm{C}_{5}$ rings. The family of indenocorannulenes $\frac{16,17}{}$ consists of indeno groups fused to the flanks of corannulene. Again, the addition of $\mathrm{C}_{5}$ rings to the structure increases the curvature of the system. Heteroatoms can also be used to increase the bowl area, either from being part of a bridging group between the 2 and 3 carbons of corannulene ${ }^{\frac{18}{18}}$ or fusing additional rings to the rim, as in the pentakis(1,4-benzodithiino)corannulene "fly-trap" synthesised by Bancu et al. 19

\subsection{Supramolecular Complexes}

Corannulene has an electron-rich concave surface (Figure 1.2), making it an ideal candidate to act as a host molecule for the electron-deficient convex $\mathrm{C}_{60}$ molecule. With this complementary electronic structure, there ought to exist a $\pi$-donor $\pi$-acceptor hostguest interaction with a significant binding constant. A significant amount of work has

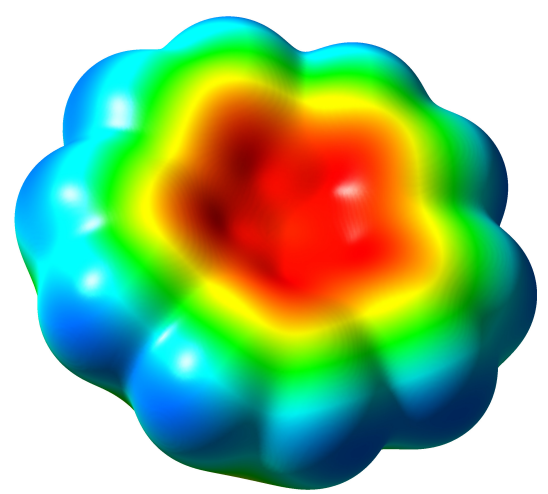

Figure 1.2. Electrostatic potential of corannulene showing the electron-rich concave face. The total SCF density has been mapped with the ESP at an isovalue of 0.0004 . 
been done, both experimentally and theoretically, into such supramolecular complexes using corannulene and derivatives thereof as host molecules.

\subsubsection{Experimental Results}

Complexation of $\mathrm{C}_{60}$ with conjugated $\pi$-systems has been extensively studied. Most of the work has involved traditional hosts, such as calix $[n]$ arenes, prophyrins, and belt shaped conjugated systems. $20-23$ Complexes with corannulene based bowl shaped host molecules have proved more difficult to obtain. The first observed evidence of complexation between corannulene and $\mathrm{C}_{60}$ was published by Becker et al. in 1993. Here, gas phase experiments with cationic corannulene and neutral $\mathrm{C}_{60}$ resulted in evidence of a $\left[\mathrm{C}_{60} @ \text { corannulene }\right]^{+}$complex being formed. ${ }^{24}$ These results were also obtained when the $\mathrm{C}_{60}$ was electronically charged and the corannulene neutral.

Although this was an important finding, neutral complexes in solution or solid state are more desirable. To this end, the first examples of complexation between corannulene derivatives and $\mathrm{C}_{60}$ were reported in 2001 by Mizyed et al. ${ }^{10}$ Several aryl thiol derivatised corannulene bowls were synthesised (Figures $1.3 \mathrm{a}-\mathrm{c}$ ) for complexation with $\mathrm{C}_{60}$. The addition of sulfur atoms to the rim of corannulene was expected to provide a positive mesomeric effect, releasing electron density into the aromatic systems, thereby enhancing the $\pi-\pi$ interactions between the electron-rich host and electron-deficient $\mathrm{C}_{60}$ guest. Using ${ }^{1} \mathrm{H}$ NMR techniques, the authors were able to determine that the complex formed with the expected 1:1 stoichiometry. Furthermore, $K_{\text {assoc }}$ values (upper portion of Table 1.1) were determined using two different treatments: the Benesi-Hildebrand (B-H) treatment ${ }^{[23 / 25}$ and the Foster-Fyfe (F-F) method. ${ }^{26}$ The relative values of $K_{\text {assoc }}$ give an indication of the strength of bonding within the complex, with larger $K_{\text {assoc }}$ values indicating more strongly bound systems. Investigation of the $\Delta \delta$ values for individual symmetry independent, hydrogens provided further evidence that $\mathrm{C}_{60} @ \mathbf{1 . 3 a}$ was the strongest bound complex. The protons on the corannulene moiety are less strongly shielded by the $\mathrm{C}_{60}$ in $\mathrm{C}_{60} @ \mathbf{1 . 3 b}$ and $\mathrm{C}_{60} @ \mathbf{1 . 3 c}$, possibly indicating that the $\mathrm{C}_{60}$ sits higher above the bowl in these complexes, suggesting weaker binding. A downfield shift in the ${ }^{1} \mathrm{H}$ NMR signal for the para-methoxy groups suggests that the attached arms swing up and embrace the $\mathrm{C}_{60}$, creating a large cavity in which the $\mathrm{C}_{60}$ sits.

Later work by the same group 9 aimed to determine whether the aryl groups were important for binding, how the number of sulfur atoms attached affects the strength of 


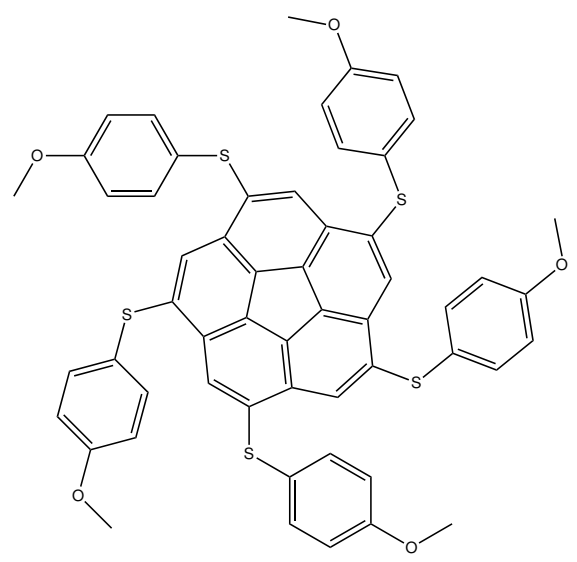

(a)

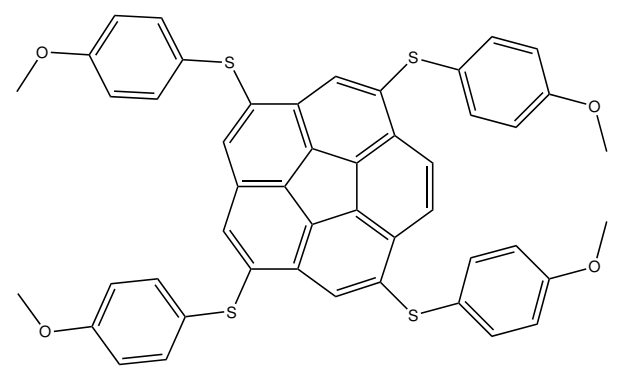

(c)

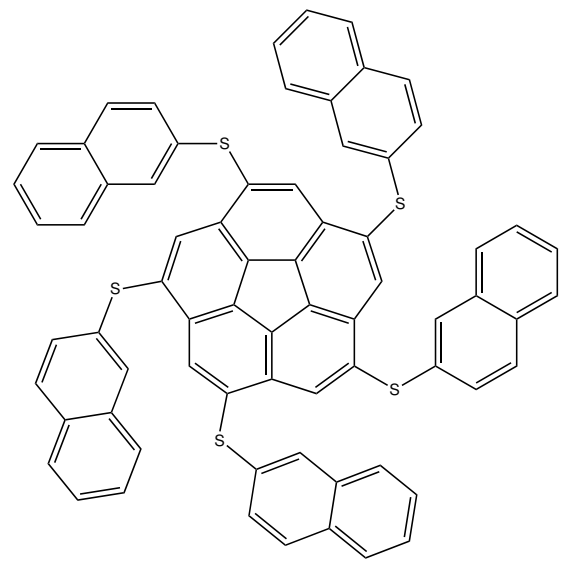

(b)

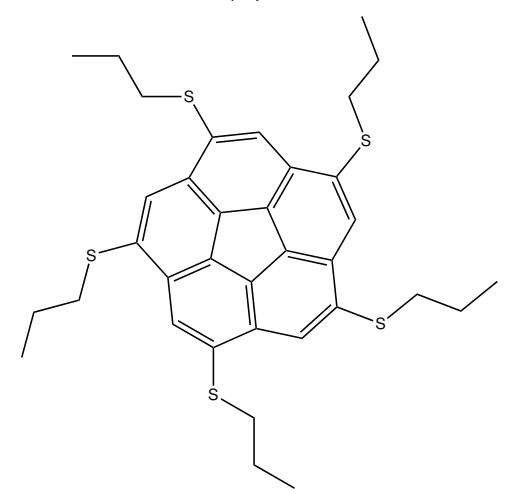

(d)

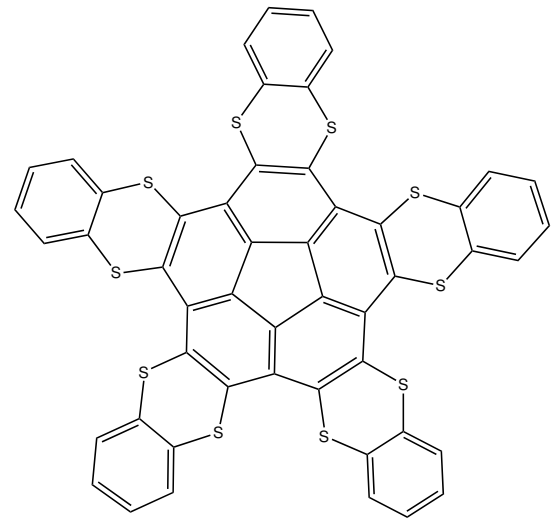

(e)

Figure 1.3. Sulfur containing derivatives of corannulene synthesised for complexation with fullerenes. They are: (a) sym-pentakis(4-methoxyphenylthio)corannulene, (b) sym-pentakis(2-naphthylthio)corannulene, (c) 1,4,6,9-tetrakis(4-methoxyphenylthio)corannulene, $\frac{10}{d \text { dd }}$ sym-pentakis(propylthio)corannulene, and (e) pentakis(1,4-benzodithiino)corannulene.9119 Decakis(4-methoxyphenylthio)corannulene ${ }^{10}$ and decakis(propylthio)corannulene ${ }^{9}$ were also synthesised but, along with unsubstituted corannulene, ${ }^{9}$ showed no evidence for complexation with $\mathrm{C}_{60}$ by ${ }^{1} \mathrm{H}$ NMR spectroscopy. 
Table 1.1. $K_{\text {assoc }}$ values $\left(\mathrm{M}^{-1}\right)$ for $\mathrm{C}_{60}$ complexes with 1.3a $1.3 \mathrm{~b}$, and $1.3 \mathrm{c}$ in toluene- $d_{8} \frac{10}{10}$ and $\mathrm{C}_{60}$ and $\mathrm{C}_{70}$ complexes with $\mathbf{1 . 3 b} \mathbf{1 . 3 d}$ and $\mathbf{1 . 3 e}$ in $\mathrm{CS}_{2} 9$ at $298 \mathrm{~K}$.

\begin{tabular}{|c|c|c|c|}
\hline Complex & Solvent & Method & Average \\
\hline $\mathrm{C}_{60} @ \mathbf{1 . 3 a}$ & \multirow{6}{*}{$\begin{array}{l}\overbrace{0}^{\infty} \\
\stackrel{1}{0} \\
\stackrel{0}{0}\end{array}$} & B-H & $454 \pm 30$ \\
\hline & & $\mathrm{F}-\mathrm{F}$ & $474 \pm 28$ \\
\hline$C_{60} @ 1.3 b$ & & B-H & $368 \pm 15$ \\
\hline & & $\mathrm{F}-\mathrm{F}$ & $358 \pm 27$ \\
\hline \multirow{2}{*}{$\mathrm{C}_{60} @ \mathbf{1 . 3 c}$} & & B-H & $280 \pm 28$ \\
\hline & & $\mathrm{F}-\mathrm{F}$ & $306 \pm 38$ \\
\hline \multirow[t]{2}{*}{$\mathrm{C}_{60} @ \mathbf{1 . 3 b}$} & & B-H & $320 \pm 25$ \\
\hline & & $\mathrm{F}-\mathrm{F}$ & $296 \pm 21$ \\
\hline \multirow{2}{*}{$\mathrm{C}_{60} @ \mathbf{1 . 3 d}$} & & B-H & $62 \pm 23$ \\
\hline & & $\mathrm{F}-\mathrm{F}$ & $53 \pm 6$ \\
\hline \multirow[t]{2}{*}{$\mathrm{C}_{60} @ \mathbf{1 . 3 e}$} & & B-H & $1420 \pm 64$ \\
\hline & $\tilde{s}^{2}$ & $\mathrm{~F}-\mathrm{F}$ & $1420 \pm 54$ \\
\hline \multirow[t]{2}{*}{$\mathrm{C}_{70} @ \mathbf{1 . 3 b}$} & U & B-H & $99 \pm 20$ \\
\hline & & $\mathrm{F}-\mathrm{F}$ & $97 \pm 11$ \\
\hline \multirow[t]{2}{*}{$\mathrm{C}_{70} @ \mathbf{1 . 3 d}$} & & B-H & $90 \pm 16$ \\
\hline & & $\mathrm{F}-\mathrm{F}$ & $94 \pm 19$ \\
\hline \multirow[t]{2}{*}{$\mathrm{C}_{70} @ \mathbf{1 . 3 e}$} & & B-H & $1110 \pm 92$ \\
\hline & & $\mathrm{F}-\mathrm{F}$ & $1060 \pm 24$ \\
\hline
\end{tabular}

the binding, and how $\mathrm{C}_{70}$ binds compared with $\mathrm{C}_{60}$. Two further corannulene derivatives (Figures $1.3 \mathrm{~d}$ and $\mathrm{e}$ ) were synthesised and complexed with $\mathrm{C}_{60}$ and $\mathrm{C}_{70}$. Additionally, because of the need to change NMR solvents, $\mathrm{C}_{60} @ \mathbf{1 . 3 \mathrm { b }}$ was reinvestigated to provide a comparison between the $K_{\text {assoc }}$ values obtained in the different solvents. In all cases, a Job plot was employed to determine the stoichiometry of guest to host as being 1:1. $\mathrm{C}_{60} @ 1.3 \mathrm{e}$ was found to be the strongest bound complex amongst the five investigated across the two papers. This could come about as (a) $\mathbf{1 . 3 e}$ has twice as many sulfur atoms as the other host molecules, $(b)$ these atoms are not encumbered with tetrahedral alkylthio carbon atoms, reducing the steric impedance, and $(c)$ the rigid nature of $\mathbf{1 . 3 e}$ means there are fewer degrees of freedom of motion resulting in a markedly smaller entropic cost to overcome for complexation to occur.

Sygula et al. provided the first evidence of $\mathrm{C}_{60}$ complexing with a heteroatom free corannulene based substrate. ${ }^{27}$ Their $\mathrm{C}_{60} \mathrm{H}_{28}$ molecular tweezers (Figure 1.4) consist of two corannulene subunits attached to a tether which enables them to be oriented such that they can embrace a $\mathrm{C}_{60}$ molecule, forming a 1:1 complex through "pure" concave-convex $\pi-\pi$ interactions. Complexation was confirmed both by NMR titration in toluene- $d_{8}$ and an x-ray structure determination of the complex. NMR titration results 


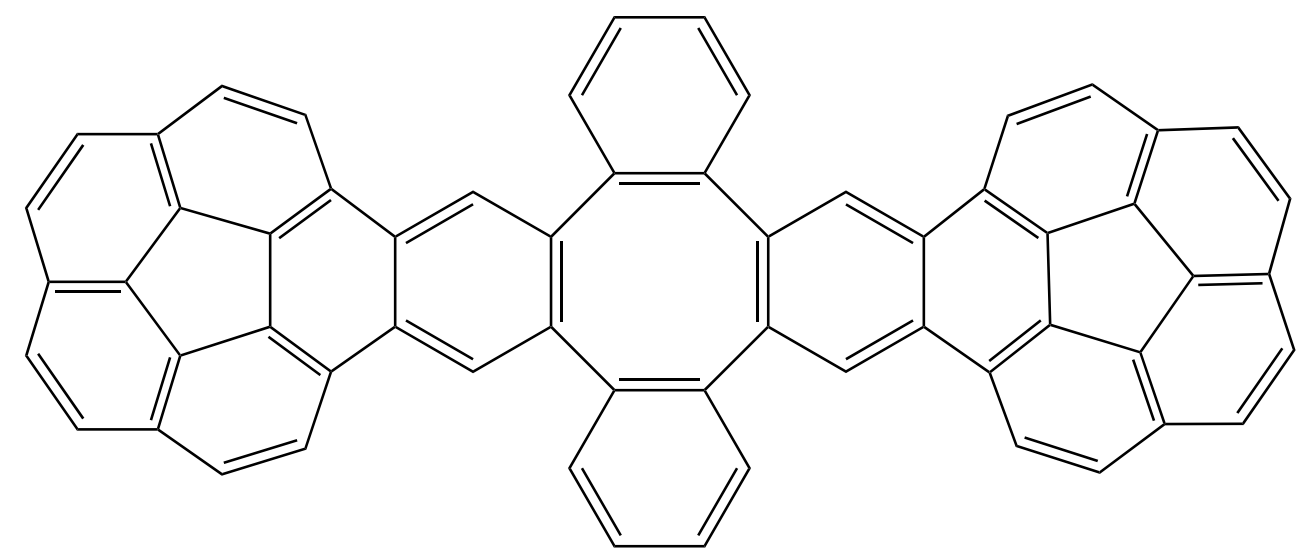

Figure 1.4. $\mathrm{C}_{60} \mathrm{H}_{28}$ molecular tweezers synthesised by Sygula et al. ${ }^{27}$

gave an average value for $K_{\text {assoc }}$ of $8600 \pm 500 \mathrm{M}^{-1}$, six times larger than that reported for $\mathrm{C}_{60} @ \mathbf{1 . 3 e}$. This value is at the upper limit of generally accepted reliability for NMR titrations. ${ }^{28}$ The crystal structure (Figure 1.5 ) clearly shows the $\mathrm{C}_{60}$ positioned between the concave faces of the corannulene subunits, confirming the formation of an inclusion complex. $\mathrm{C}_{60}$ molecules of individual complexes are packed in a linear columnar arrangement within the crystal structure. The shortest distance between carbons of the corannulene subunits and $\mathrm{C}_{60}$ is $3.128 \AA$.

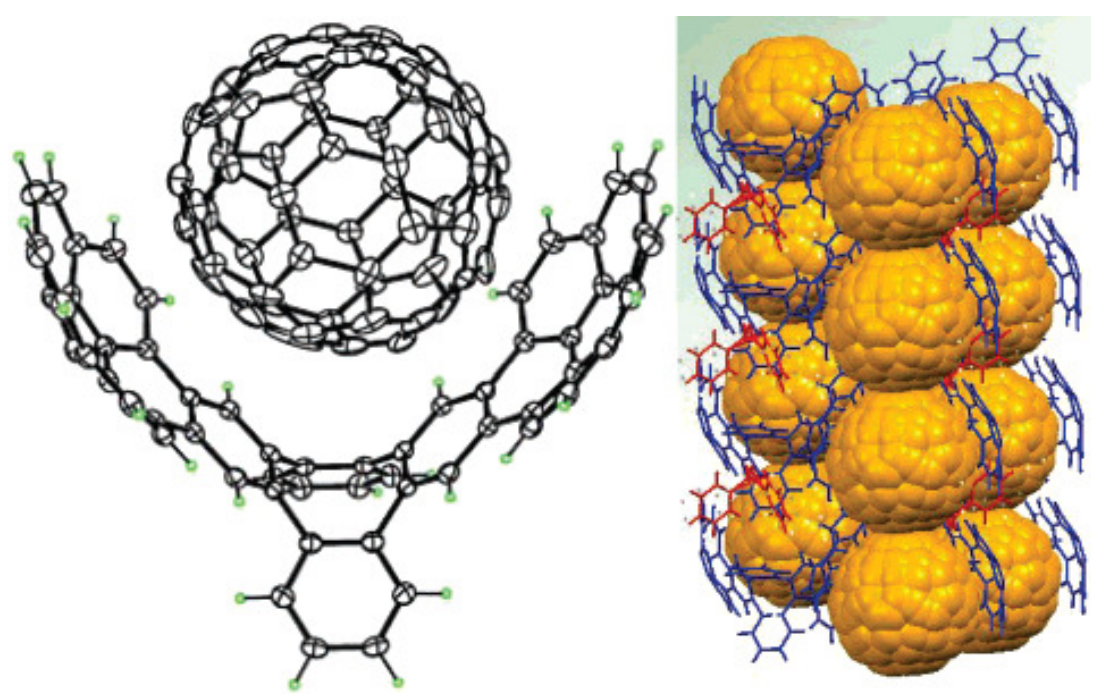

Figure 1.5. (left) Ortep representation of the crystal arrangement between $\mathrm{C}_{60}$ and molecular tweezers 1.4 Two toluene molecules are omitted for clarity. Only one of the two disordered orientation of $\mathrm{C}_{60}$ is shown. (right) Crystal packing pattern of $\mathrm{C}_{60}$ (gold) with $\mathbf{1 . 4}$ (blue) and toluene (red), showing a linear columnar arrangement of fullerene $\mathrm{C}_{60}$. Taken from Sygula et al. ${ }^{27}$ 

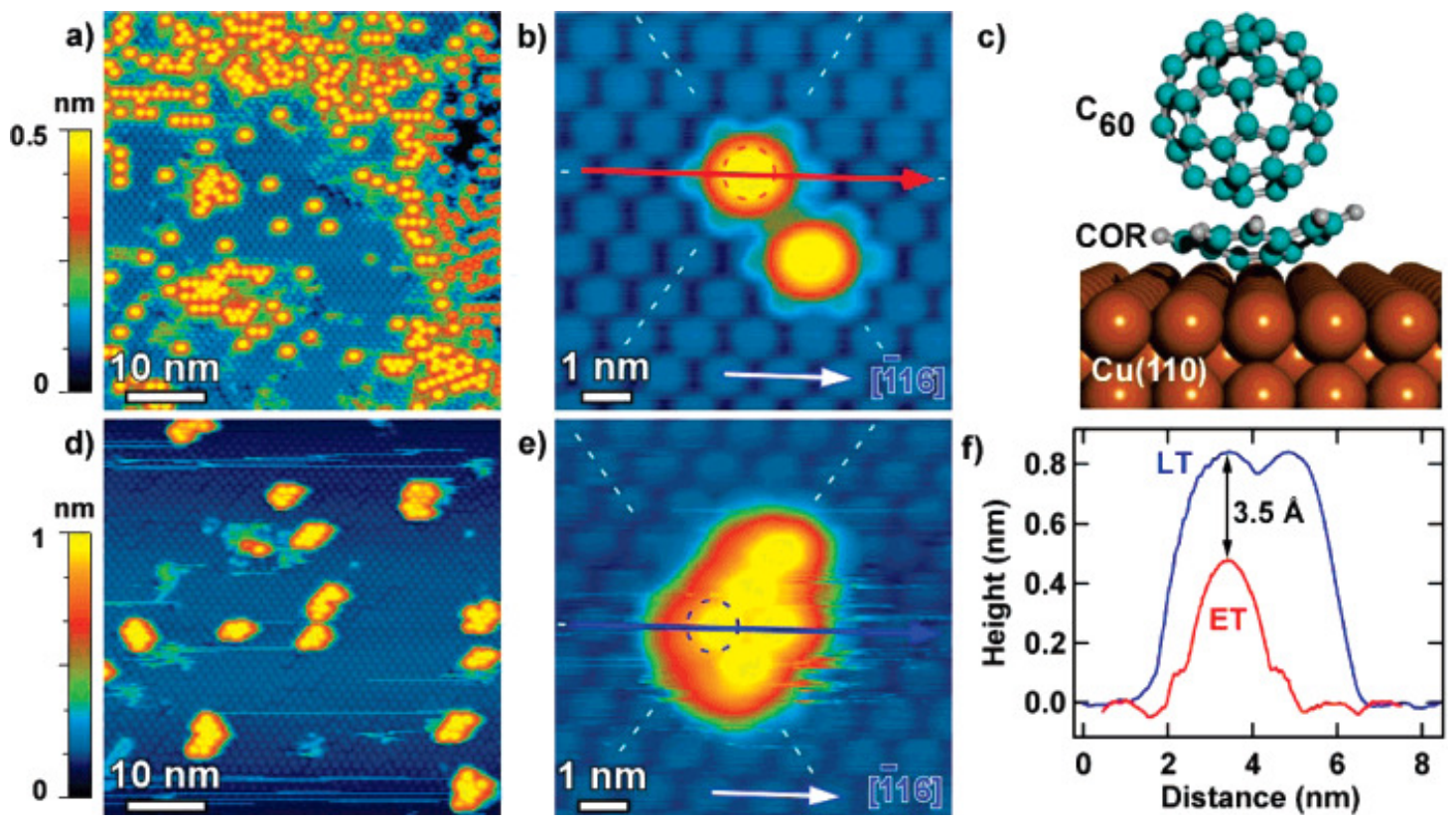

Figure 1.6. (a) Topographic STM image after the deposition of $\sim 0.15$ monolayer $\mathrm{C}_{60}$ on the corannulene lattice at elevated temperature. (b) Individual $\mathrm{C}_{60}$ molecules adsorbed on top of underlying corannulene bowls at elevated temperature. (c) Schematic representation of an individual $\mathrm{C}_{60} @$ corannulene host-guest complex on $\mathrm{Cu}(110)$. (d) STM image showing random distribution of small close-packed $\mathrm{C}_{60}$ clusters on the corannulene lattice after low temperature deposition of $\sim 0.05$ monolayer $\mathrm{C}_{60}$. (e) Close-up of a $\mathrm{C}_{60}$ cluster on the corannulene lattice at low temperature. (f) Line profiles across $\mathrm{C}_{60}$ molecules deposited at elevated and low temperatures, as indicated in b) and e). Taken from Xiao et al. 29

More recently, evidence has been obtained for complexation between neutral, unmodified $\mathrm{C}_{60}$ and corannulene. Xiao et al. reported the formation of a $\mathrm{Cu}(110)$ surfacesupported $\mathrm{C}_{60} @$ corannulene host-guest system. 29 Vapour deposition of corannulene onto the $\mathrm{Cu}(110)$ surface resulted in a close-packed monolayer with the bowl openings pointing away from the surface. $\mathrm{C}_{60}$ was evaporated onto the substrate at low $(\sim 100 \mathrm{~K})$, room, and elevated $(300-400 \mathrm{~K})$ temperatures. At room and elevated temperatures, analysis of close-up STM images (Figure 1.6p) showed that the $\mathrm{C}_{60}$ was located directly above the corannulene host. Verification of the $\mathrm{C}_{60}$ sitting above a corannulene bowl, and not just having displaced it within the underlying lattice, was performed by measuring the apparent heights of corannulene and $\mathrm{C}_{60}$ sitting directly on the $\mathrm{Cu}(110)$ surface, and with respect to it. The apparent height of $\mathrm{C}_{60}$ with respect to the corannulene substrate was much higher than what would have been expected if $\mathrm{C}_{60}$ had displaced a corannulene unit. Tip manipulation of individual $\mathrm{C}_{60}$ molecules on the corannulene substrate was difficult to achieve, indicating the formation of a strongly bound host-guest system. When it was achieved, the apparent heights of neighbour- 
ing $\mathrm{C}_{60}$ molecules were identical when measured with respect to either the tip-created vacancies or the original empty corannulene substrate, confirming that the $\mathrm{C}_{60}$ was indeed located above a corannulene bowl. At low temperature, a totally different situation was encountered. The $\mathrm{C}_{60}$ molecules were still positioned directly above an underlying corannulene bowl (Figure 1.6e), but the apparent heights were much higher than those at elevated temperature, $7.8 \pm 0.5 \AA$ compared with $4.5 \pm 0.2 \AA . \mathrm{C}_{60}$ was easy to displace from this position. Upon annealing the low temperature samples to room temperature, the apparent height and ease of manipulation decreased. This indicates that there is a weakly bound precursor state (low temperature) which can be thermally activated to form a strongly bound host-guest system.

Early in 2012, Dawe et al. reported the first successful crystallisation and subsequent X-ray structural determination of stable co-crystals of both $\mathrm{C}_{60}$ @corannulene and $\mathrm{C}_{60} @ \mathbf{1 . 7}^{30}$ The $\mathrm{C}_{60}$ molecule in $\mathrm{C}_{60} @$ corannulene (Figure $1.8 \mathrm{a}$ was disordered, crystallising in many different orientations, as too was the $\mathrm{C}_{60}$ molecule in $\mathrm{C}_{60} @ \mathbf{1 . 7}$ (Figure 1.8c), though to a lesser extent. This disorder points to an absence of a strong host-guest interaction for any particular orientation of $\mathrm{C}_{60}$ with respect to the corannulene host. In both cases, long-range packing of the $\mathrm{C}_{60}$ molecules was in a zigzag manner (Figures $1.8 \mathrm{~b}$ and $\mathrm{d}$ ). The shortest surface-to-surface distance in $\mathrm{C}_{60} @$ corannulene was measured at $3.75 \AA$, and in $\mathrm{C}_{60} @ \mathbf{1 . 7}$ as $3.30 \AA$. Along with the greater ordering of $\mathrm{C}_{60}$, this shorter molecular separation in the $\mathrm{C}_{60} @ \mathbf{1 . 7}$ indicates that $\mathbf{1 . 7}$ is a better host for $\mathrm{C}_{60}$ than pristine corannulene, probably due to the extra methyl- $\pi$ interactions that can take place between host and guest. There is also significant host-host interactions

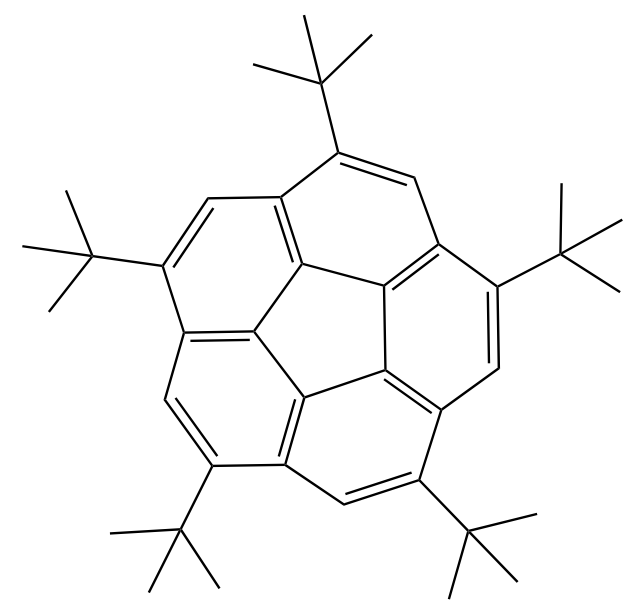

Figure 1.7. sym-pentakis(tert-butyl)corannulene 


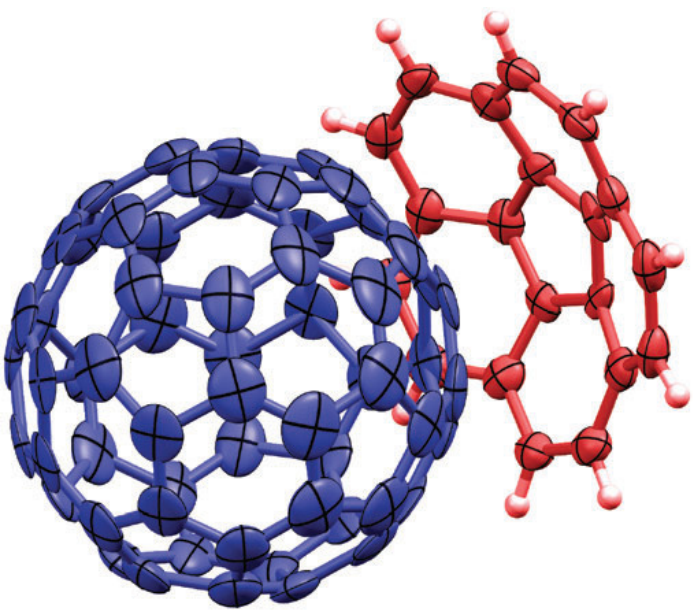

(a)

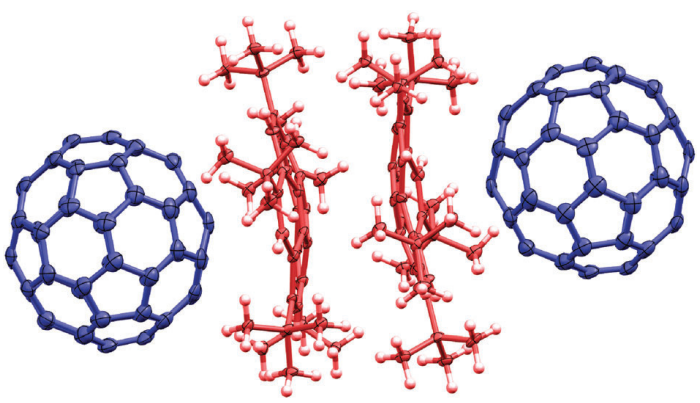

(c)

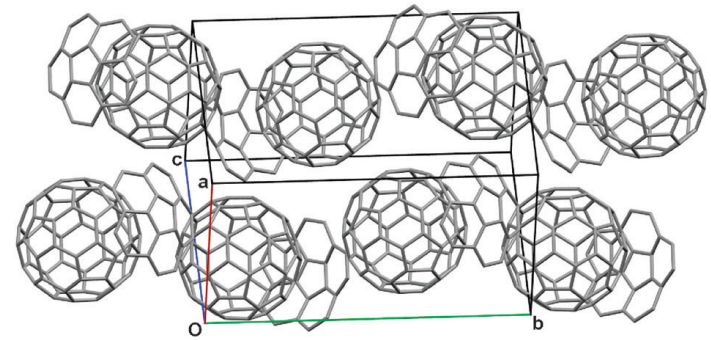

(b)

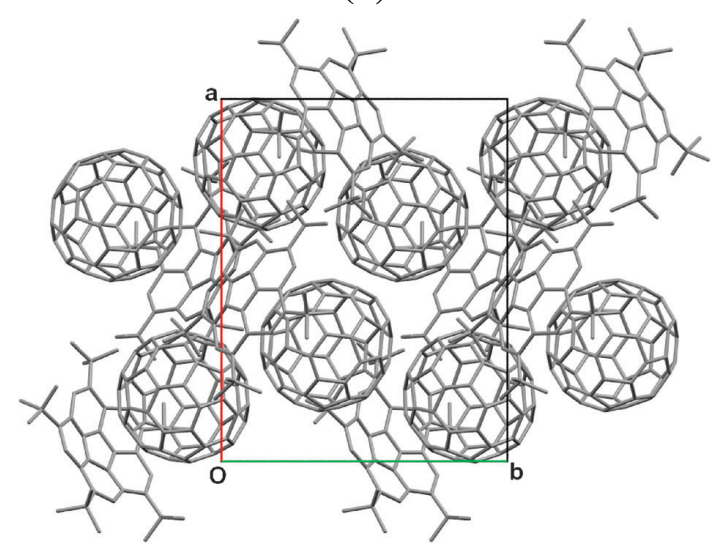

(d)

Figure 1.8. (a) $50 \%$ probability ellipsoid representation of the asymmetric unit of $\mathrm{C}_{60} @$ corannulene, with the minor disorder component of $\mathrm{C}_{60}$ omitted for clarity. (b) Capped stick representation of the extended packed unit cell for $\mathrm{C}_{60} @$ corannulene. Minor disorder components of $\mathrm{C}_{60}$ and $\mathrm{H}$-atoms omitted for clarity. (c) $30 \%$ probability ellipsoid representation of $\mathrm{C}_{60} @$ 1.7. with the minor disorder component of $\mathrm{C}_{60}$ omitted for clarity. (d) Capped stick representation of the extended packed unit cell for $\mathrm{C}_{60} @ 1 \mathbf{1 . 7}$, showing the zigzag motif with respect to $\mathrm{C}_{60}$. Minor disorder components of $\mathrm{C}_{60}$, $\mathrm{H}$-atoms and lattice solvent $\mathrm{C}_{6} \mathrm{H}_{4} \mathrm{Cl}_{2}$ omitted for clarity. Taken from Dawe et al. ${ }^{30}$

within the $\mathrm{C}_{60} @ \mathbf{1 . 7}$ crystal, unlike with $\mathrm{C}_{60} @$ corannulene. The host molecules are staggered with respect to their five-membered rings, with a separation of $3.30 \AA$ (Figure $1.8 \mathrm{c}$.

\subsubsection{Theoretical Investigations}

Computational investigations of non-covalent intermolecular interactions have faced increasing interest in recent years, particularly when $\pi$-systems are involved. Small pla- 
Table 1.2. Corannulene dimer binding energies $\left(\mathrm{kcal} \mathrm{mol}^{-1}\right)$ reported in literature. All values are for the eclipsed, concave-convex geometry.

\begin{tabular}{|c|c|c|}
\hline Method & Binding Energy & Ref. \\
\hline B97-D/TZVP & 17.0 & 34 \\
\hline B97-D/6-31+G(d) + BSSE & 15.2 & 35 \\
\hline$\omega \mathrm{B} 97 \mathrm{X}-\mathrm{D} / 6-31+\mathrm{G}(\mathrm{d})+\mathrm{BSSE}$ & 17.6 & 35 \\
\hline M06-2X/6-31+G(d) + BSSE & 13.3 & 35 \\
\hline B97-D/cc-pVQZ & 16.6 & 36 \\
\hline M06-2X/cc-pVQZ & 13.3 & 36 \\
\hline$\omega \mathrm{B} 97 \mathrm{X}-\mathrm{D} / \mathrm{cc}-\mathrm{pVQZ}$ & 18.5 & 36 \\
\hline M06-2X/6-31G & 15.1 & 37 \\
\hline M06-2X/6-31G + BSSE & 8.9 & 37 \\
\hline M06-2X/6-311G & 17.8 & 37 \\
\hline M06-2X/6-311G + BSSE & 14.1 & 37 \\
\hline MP2/6-31G + BSSE & 8.6 & 38 \\
\hline $\mathrm{MP} 2 / 6-31 \mathrm{G}(\mathrm{d})+\mathrm{BSSE}$ & 13.7 & 38 \\
\hline MP2/cc-pVDZ + BSSE & 19.5 & 38 \\
\hline MP2/cc-pVTZ + BSSE & 27.7 & 39 \\
\hline SCS-MP2/cc-pVTZ + BSSE & 17.2 & 39 \\
\hline MP2/aug-cc-pVDZ + BSSE & 26.8 & 36 \\
\hline SCS-MP2/aug-cc-pVDZ + BSSE & 18.1 & 36 \\
\hline CCSD/aug-cc-pVDZ + BSSE & 9.1 & 36 \\
\hline CCSD(T)/aug-cc-pVDZ + BSSE & 14.3 & 36 \\
\hline QCISD(T)/aug-cc-pVTZ + BSSE & 15.5 & 36 \\
\hline
\end{tabular}

nar systems, such as the benzene dimer, $\sqrt[21[1-33]{-3} \text { have been investigated extensively. Re- }$ cently, interest in curved $\pi$-systems has increased. The curved nature of the $\pi$-systems makes them ideal candidates for formation of inclusion complexes with other curved surfaces, such as fullerenes.

\subsubsection{Bowl Stacking}

A variety of different dimer bowl systems have been investigated, as both homo and mixed dimers. Probably the most extensively investigated system is the concave-convex corannulene dimer. There are a multitude of binding energy results available in the literature (Table 1.2), calculated at various levels of theory. In 2011, Janowski et al. provided the most reliable result. Their high level ab initio benchmark calculations at the QCISD(T)/aug-cc-pVTZ with BSSE correction level gave a binding energy of $15.5 \mathrm{kcal} \mathrm{mol}^{-1} .36$ In addition, they also investigated computationally cheaper alternatives, dispersion corrected density functionals, concluding that of the three functionals studied, B97-D reproduced the benchmark results best. M06-2X underestimates binding 
energy slightly, though this is known to occur. ${ }^{34|40| 41} \omega \mathrm{B} 97 \mathrm{X}-\mathrm{D}$ is found to overestimate the binding energy by $c a$. $20 \%$.

Earlier papers had relied on SCS-MP2 results to act as a benchmark. General MP2 methods are known to vastly overestimate dispersion type interactions; $\frac{32}{32}$ however, the use of spin-component-scaled MP2 (SCS-MP2) at no extra computational cost has been shown by Sygula and Saeb $\varnothing, \frac{39}{3}$ amongst others, to significantly improve the results. The best available SCS-MP2 calculation gives a binding energy of $17.2 \mathrm{kcal} \mathrm{mol}^{-1}$. ${ }^{39}$ With these SCS-MP2 results as a benchmark, Josa et al. showed that with the $6-31+\mathrm{G}(\mathrm{d})$ basis set, $\omega \mathrm{B} 97 \mathrm{X}-\mathrm{D}$ provided binding energies in close agreement $\left(17.55 \mathrm{kcal} \mathrm{mol}^{-1}\right), 35$ with the B97-D functional slightly underestimating the value $\left(15.18 \mathrm{kcal} \mathrm{mol}^{-1}\right)$ and M06-2X giving a large underestimation $\left(13.31 \mathrm{kcal} \mathrm{mol}^{-1}\right)$. When these results are compared with the high level ab initio results of Janowski et al. 36 it is the B97-D which provides the most accurate results. In either case, of the two approaches to calculating dispersion interactions: including an explicit empirical dispersion correction term as in B97-D and $\omega$ B97X-D, and developing new hybrid meta-GGA functionals like M06-2X, including empirical corrections provides the most reliable results.

Another commonly investigated system involves the $\mathrm{C}_{60}$-like corannulene monomer. In this monomer, the carbon atoms of the corannulene skeleton are fixed into the corresponding positions that they take in optimised $\mathrm{C}_{60}$. This imparts a greater degree of curvature to the monomer and is used as a simpler, less expensive model to the $\mathrm{C}_{60}$ molecule. At the SCS-MP2/cc-pVTZ + BSSE level, a binding energy of the $\mathrm{C}_{60}$-like@corannulene monomer is $17.0 \mathrm{kcal} \mathrm{mol}^{-1}, 39$ slightly weaker binding than the corresponding energy for corannulene dimer. This weaker binding is also noticed at the B97-D/6-31+G(d), $\omega$ B97X-D/6-31+G(d) and M06-2X/6-31+G(d) levels (binding energies $14.16,15.52$, and $11.70 \mathrm{kcal} \mathrm{mol}^{-1}$ respectively). ${ }^{35}$ Since the carbons of the $\mathrm{C}_{60}$-like monomer are held rigid, the binding energy obtained is lower than what would be expected for $\mathrm{C}_{60} @$ corannulene complex, where the $\mathrm{C}_{60}$ is allowed to relax.

Other curved hydrocarbon systems investigated include and homo and mixed dimers of corannulene, sumanene and pentaindenocorannulene. ${ }^{37 / 38}$ Sumanene, $\mathrm{C}_{21} \mathrm{H}_{12}$ (Figure 1.9a), is a $\mathrm{C}_{60}$ moiety similar to corannulene but where there is a $\mathrm{C}_{6}$ ring at the hub, with $3 \mathrm{C}_{6}$ and $3 \mathrm{C}_{5}$ rings fused at each edge. Pentaindenocorannulene, $\mathrm{C}_{50} \mathrm{H}_{20}$ (Figure $1.9 \mathrm{~b}$, takes the corannulene as a framework and fuses indeno groups to the flanks. General results indicate that larger contact areas between concave and convex surfaces 
Table 1.3. Binding energies $\left(\mathrm{kcal} \mathrm{mol}^{-1}\right)$ for a variety of homo and mixed dimers curved systems. Unless otherwise indicated all results include correction for BSSE.

\begin{tabular}{|c|c|c|c|}
\hline Dimer & Method & Binding Energy & Ref. \\
\hline Sumanene dimer & MP2/cc-pVDZ & 21.0 & 38 \\
\hline Sumanene dimer & M06-2X/6-311G & 17.8 & 37 \\
\hline Pentaindenocorannulene dimer & M06-2X/6-311G & 34.3 & 37 \\
\hline 1.9b@corannulene & M06-2X/6-311G & 13.5 & 37 \\
\hline Sumanene@corannulene & M06-2X/6-311G & 13.5 & 37 \\
\hline Corannulene@1.9b & M06-2X/6-311G & 22.2 & 37 \\
\hline Sumanene@1.9b & M06-2X/6-311G & 21.9 & 37 \\
\hline Corannulene@sumanene & M06-2X/6-311G & 14.6 & 37 \\
\hline 1.9b@sumanene & M06-2X/6-311G* & 18.9 & 37 \\
\hline $\mathrm{C}_{60}$-like@ corannulene & $\omega \mathrm{B} 97 \mathrm{X}-\mathrm{D} / 6-31+\mathrm{G}(\mathrm{d})$ & 15.5 & 35 \\
\hline $\mathrm{C}_{60}$-like@5Br-corannulene & $\omega \mathrm{B} 97 \mathrm{X}-\mathrm{D} / 6-31+\mathrm{G}(\mathrm{d})$ & 21.6 & 35 \\
\hline $\mathrm{C}_{60}$-like@5Cl-corannulene & $\omega \mathrm{B} 97 \mathrm{X}-\mathrm{D} / 6-31+\mathrm{G}(\mathrm{d})$ & 19.9 & 35 \\
\hline $\mathrm{C}_{60}$-like@5 $\mathrm{CH}_{3}$-corannulene & $\omega \mathrm{B} 97 \mathrm{X}-\mathrm{D} / 6-31+\mathrm{G}(\mathrm{d})$ & 20.1 & 35 \\
\hline $\mathrm{C}_{60}$-like@5 $\mathrm{C}_{2} \mathrm{H}$-corannulene & $\omega \mathrm{B} 97 \mathrm{X}-\mathrm{D} / 6-31+\mathrm{G}(\mathrm{d})$ & 19.3 & 35 \\
\hline $\mathrm{C}_{60}$-like@5CN-corannulene & $\omega \mathrm{B} 97 \mathrm{X}-\mathrm{D} / 6-31+\mathrm{G}(\mathrm{d})$ & 24.6 & 35 \\
\hline
\end{tabular}

${ }^{*}$ Does not include BSSE correction.

result in stronger binding, as would be expected, though there are some exceptions. For example, with the sumanene dimer, $\mathrm{CH}-\pi$ interactions become important, giving it stronger binding than the corannulene dimer even though the contact surface is lower. Also, the interactions are stronger when the surfaces can stack effectively, as shown in the corannulene@1.9b dimer where the corannulene can eclipse the corresponding

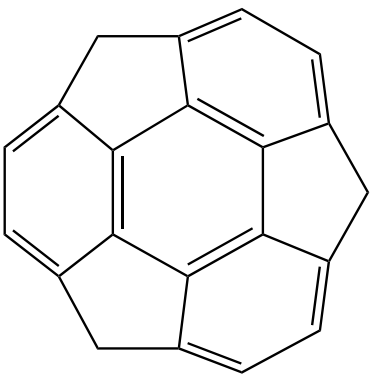

(a)

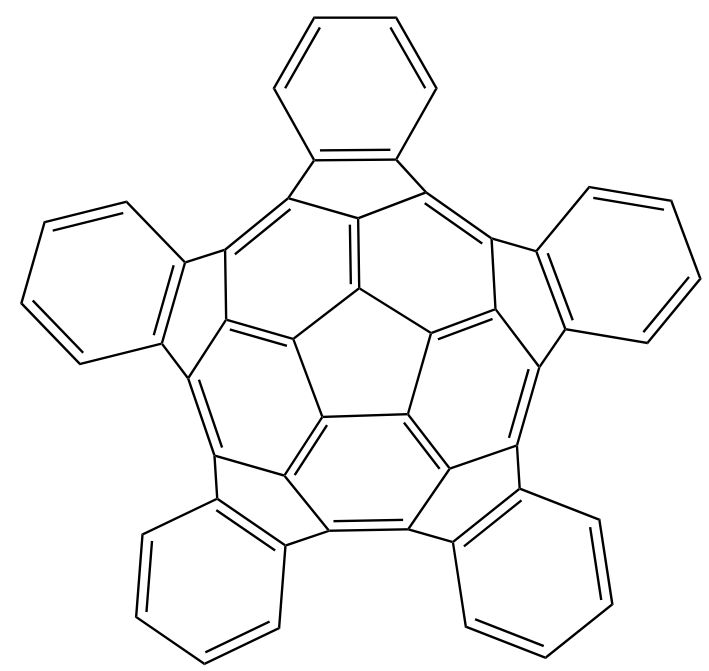

(b)

Figure 1.9. (a) Sumanene and (b) Pentaindenocorannulene. 
skeleton structure within 1.96 .

The effect of substituents on corannulene was investigated by Josa et al. ${ }^{35} \mathrm{C}_{60}$-like monomer complexes with sym-penta substituted corannulene, ${ }^{35}$ where the substituents are $\mathrm{Br}, \mathrm{Cl}, \mathrm{CH}_{3}, \mathrm{C}_{2} \mathrm{H}$, and $\mathrm{CN}$. They found that both electrostatic and dispersive interactions are important to account for the catching ability of bowls. From a purely electrostatic viewpoint, electron withdrawing groups would increase the positive charge on the concave surface of the bowl, making it more attractive to the negatively charged convex fullerene-like surface. Electron donating groups would have the opposite effect. This would indicate that ranking the substituents would be $\mathrm{CN}>\mathrm{Cl}>\mathrm{Br} \gg \mathrm{C}_{2} \mathrm{H} \gg \mathrm{H}$ $>\mathrm{CH}_{3}$. Both $\mathrm{Br}$ and $\mathrm{CH}_{3}$ have dispersion contributions of $\sim 22.5 \mathrm{kcal} \mathrm{mol}^{-1}$, which are large enough that electrostatic sensibilities are overpowered, giving the actual ranking as $\mathrm{CN}, \mathrm{Br}, \mathrm{Cl}, \mathrm{C}_{2} \mathrm{H}, \mathrm{CH}_{3}, \mathrm{H}$ (Table 1.3 ). In the case of $\mathrm{Br}$, the dispersion contribution came from the large diffuse nature of the bromine atom, and in $\mathrm{CH}_{3}$ it is mostly due to $\mathrm{CH}-\pi$ interactions between the $\mathrm{CH}_{3}$ groups and the $\pi$ system of the $\mathrm{C}_{60}$-like monomer.

\subsubsection{2 $\mathrm{C}_{60}$ complexes}

Computational studies of $\mathrm{C}_{60}$ complexed with corannulene based systems have focused on two main systems. The first is the $\mathrm{C}_{60} @$ corannulene complex. A wide range of binding energies have been reported for this complex (Table 1.4), from $12.4 \mathrm{kcal} \mathrm{mol}^{-1}$ by Zhao and Truhlar, ${ }^{43}$ to $24.7 \mathrm{kcal} \mathrm{mol}^{-1}$ by Xiao et al. ${ }^{29}$ These two extremes are generated by the M06-2X density functional and MP2, which are known to respectively underestimate and overestimate binding energies of non covalently bound systems. As such, the true binding energy is expected to be somewhere within this range. As Janowski et al. showed with their benchmark calculations on the corannulene dimer, the B97-D functional provides the best agreement with QCISD(T) level of theory. Thus, the "best estimate" of $\mathrm{C}_{60} @$ corannulene binding energy would be $19.5 \mathrm{kcal} \mathrm{mol}^{-1}$ as calculated at the B97-D/TZVP level. 34

The other major system studied is the complex between $\mathrm{C}_{60}$ and 1.4 the $\mathrm{C}_{60} \mathrm{H}_{28}$ buckycatcher synthesised by Sygula et al. ${ }^{[27}$ This molecule contains two corannulene subunits joined by a tether which can "grip" a $\mathrm{C}_{60}$ molecule between them. Because of the presence of these two units, the binding energy in $\mathrm{C}_{60} @ \mathbf{1 . 4}$ is expected to be approximately twice that of the $\mathrm{C}_{60} @$ corannulene complex. In the cases where the authors investigated both systems, the greater than double binding energy found was 
Table 1.4. Binding energies $\left(\mathrm{kcal} \mathrm{mol}^{-1}\right.$ ) of $\mathrm{C}_{60}$ complexed with curved $\pi$ systems.

\begin{tabular}{llcr}
\hline Complex & Method & Binding Energy & Ref. \\
\hline \hline $\mathrm{C}_{60} @$ corannulene & M06-2X/6-31+G(d,p)+ BSSE & 12.4 & 43 \\
$\mathrm{C}_{60} @$ corannulene & M06-2X/6-311G + BSSE & 14.0 & 37 \\
$\mathrm{C}_{60} @$ corannulene & B97-D/TZVP & 19.5 & $\underline{34}$ \\
$\mathrm{C}_{60} @$ corannulene & MP2/6-31G + BSSE & 16.1 & 29 \\
$\mathrm{C}_{60} @$ corannulene & MP2/6-31G(d,p) + BSSE & 17.5 & 29 \\
$\mathrm{C}_{60} @$ corannulene & MP2/cc-pVDZ + BSSE & 24.7 & 29 \\
$\mathrm{C}_{60} @ \mathbf{1 . 4}$ & M06-2X/6-31+G(d,p) + BSSE & 26.4 & 43 \\
$\mathrm{C}_{60} @ \overline{\mathbf{1 . 4}}$ & M05-2X/6-311G(d,p) + BSSE & 20.7 & 42 \\
$\mathrm{C}_{60} @ \mathbb{\mathbf { 1 . 4 }}$ & $\mathrm{B} 97-\mathrm{D} / \mathrm{TZVP}$ & 43.1 & 34 \\
$\mathrm{C}_{60} @ \overline{\mathbf{1 . 9}}$ & M06-2X/6-311G + BSSE & 27.5 & 37 \\
$\mathrm{C}_{60} @$ sumanene & M06-2X/6-311G + BSSE & 16.4 & 37 \\
\hline
\end{tabular}

attributed to the additional interaction between the $\mathrm{C}_{60}$ and the tether part of 1.4. Again, B97-D/TZVP provides the "best estimate" of the binding energy of $43.1 \mathrm{kcal} \mathrm{mol}^{-1}$, far greater than that estimated using the M06-2X and M05-2X functionals.

Other systems have also been investigated, namely where the bowl is sumanene or pentaindenocorannulene, both by Denis. ${ }^{37}$ In the case of $\mathrm{C}_{60} @$ sumanene, the binding energy is slightly higher than that of $\mathrm{C}_{60} @$ corannulene, even though the interaction surface between the two molecules is smaller. This is attributed to $\mathrm{CH}-\pi$ interactions as sumanene has hydrogens which point up with the curve of the bowl. Pentaindenocorannulene is a much larger bowl than corannulene and would be expected to provide a better host environment. This was indeed shown to be true as the binding energy was found to be nearly twice that of the $\mathrm{C}_{60} @$ corannulene complex.

\subsection{Functionals}

A wide range of functionals are available for use, each with their own advantages and disadvantages. In this project, nine functionals of various types were chosen for evaluation of their performance in computing the energetics of the $\mathrm{C}_{60} @$ corannulene complex. They were B3LYP, ${ }^{44}$ B7 B97-D, ${ }^{48}$ BP86, ${ }^{4950}$ CAM-B3LYP, ${ }^{51}$ M06-2X, 52 PW91, ${ }^{5354} \tau$-HCTH, ${ }^{55} \omega \mathrm{B} 97 \mathrm{X}^{56}$ and $\omega \mathrm{B} 97 \mathrm{X}-\mathrm{D} . \underline{57}$

These functionals can be arranged into four different groups, based on the type of functional they are. At the lowest level, BP86 and PW91 are GGA functionals. Above these, there is the meta-GGA functional, $\tau$-HCTH, which includes an evaluation of 
kinetic energy density. B3LYP is a hybrid functional, combining exact Hartree-Fock exchange with GGA exchange and correlation. The final tier comprises the long-range corrected functionals. These account for long-range effects either through direct longrange correction, CAM-B3LYP and $\omega \mathrm{B} 97 \mathrm{X}$, or empirical dispersion corrections, B97-D and $\omega \mathrm{B} 97 \mathrm{X}-\mathrm{D}$. The remaining functional, M06-2X is a hybrid meta-GGA functional, which includes properties of both hybrid and meta-GGA functionals. It has been specially designed to accommodate long range interactions and, as such, it is included in that group.

\subsubsection{GGA Functionals}

\subsubsection{BP86}

BP86 4950 is an exchange-correlation functional, utilising Becke's 1988 exchange functional ${ }^{49}$ and Perdew's 1986 correlation functional. ${ }^{50}$ This gives an overall functional form of

$$
E_{x c}^{\mathrm{BP} 86}=E_{x}^{\mathrm{B} 88}+E_{c}^{\mathrm{P} 86}
$$

To account for the well known underestimation of exchange energies by the exchange functional, $E_{x}^{\mathrm{B} 88}$ is given by a gradient correction to the local-spin-density approximation exchange energy, $E_{x}^{\mathrm{LSDA}}$,

$$
E_{x}^{\mathrm{B} 88}=E_{x}^{\mathrm{LSDA}}-\beta \sum_{\sigma} \int \rho_{\sigma}^{4 / 3} \frac{x_{\sigma}^{2}}{1+6 \beta x_{\sigma} \sinh ^{-1} x_{\sigma}} d^{3} \mathbf{r}
$$

where $\beta=0.0042, \rho_{\sigma}$ is the spin density, $x_{\sigma}$ is the reduced spin density gradient

$$
x_{\sigma}=\frac{\left|\nabla \rho_{\sigma}\right|}{\rho_{\sigma}^{4 / 3}}
$$

and $E_{x}^{\mathrm{LSDA}}$ is the local-spin density approximation for exchange energy given by

$$
E_{x}^{\mathrm{LSDA}}=-c_{x} \sum_{\sigma} \int \rho_{\sigma}^{4 / 3} d^{3} \mathbf{r} ; \quad c_{x}=\frac{3}{2}\left(\frac{3}{4 \pi}\right)^{1 / 3}
$$

\subsubsection{PW91}

PW91 takes both the exchange and correlation components of the 1991 functional developed by Perdew and Wang. ${ }^{53 \mid 54}$ They both have had gradient corrections applied. 
The exchange energy functional is

$$
E_{x}^{\mathrm{PW} 91}=A_{x} \int d^{3} \mathbf{r} F_{x}(s) \rho_{\sigma}^{4 / 3}
$$

where $A_{x}=-\frac{3}{4}\left(\frac{3}{\pi}\right)^{1 / 3}$,

$$
s=\frac{\left|\nabla \rho_{\sigma}\right|}{2\left(3 \pi^{2}\right)^{1 / 3} \rho_{\sigma}^{4 / 3}}
$$

is a scaled density gradient, and the function $F(s)$ is

$$
F(s)=\frac{1+\alpha s \sinh ^{-1}(\beta s)+\left(\gamma s-\delta e^{-100 s^{2}}\right) s^{2}}{1+\alpha s \sinh ^{-1}(\beta s)+0.004 s^{4}}
$$

with $\alpha, \beta, \gamma$ and $\delta$ optimised as $0.19645,7.7956,0.2743$ and 0.1508 respectively. A full breakdown of the correlation functional can be found in Perdew et al. ${ }^{53}$

\subsection{2 meta-GGA Functional}

\subsubsection{1 $\tau$-HCTH}

$\tau$-HCTH ${ }^{55}$ is a meta-GGA exchange-correlation functional. It takes the HCTH/407 58 functional, a modification to Becke's 1997 functional,, 59 and adds in the kinetic-energy density, $\tau$, to simulate delocalised exchange, ie it adds a non-local term. The functional form is thus given as

$$
E_{x c}^{\tau \mathrm{HCTH}}=E_{x}^{\text {local }}+E_{x}^{\text {non-local }}+E_{c}
$$

The form of both the local and non-local exchange energies are as usual, ie taking the local-spin density approximation energy with a gradient correction, except the non-local exchange takes an additional term, $f_{x \sigma}\left(w_{\sigma}\right)$

$$
f_{x \sigma}\left(w_{\sigma}\right)=w_{\sigma}-2\left(w_{\sigma}\right)^{3}+w_{\sigma}^{5}
$$

where $w_{\sigma}$ is a function of $t_{\sigma}$ which is a function of the spin kinetic energy density $\tau_{\sigma}$ and spin density $\rho_{\sigma}$.

$$
w_{\sigma}=\frac{t_{\sigma}-1}{t_{\sigma}+1} ; \quad t_{\sigma}=\frac{\tau_{\sigma}^{\mathrm{LSDA}}}{\tau_{\sigma}} ; \quad \tau_{\sigma}^{\mathrm{LSDA}} \equiv \frac{3}{10}\left(6 \pi^{2}\right)^{2 / 3} \rho_{\sigma}^{5 / 3}
$$

The correlation energy form is identical to that of HCTH. 


\subsubsection{Hybrid Functional}

\subsubsection{B3LYP}

B3LYP is the most popular functional and has been used in a wide variety of applications. It is a hybrid functional, combining components of exact Hartree-Fock exchange with the local and gradient-corrected exchange and correlation terms. First utilised by Stephens et al. ${ }^{47}$ it is based on Becke's three-parameter functional form. ${ }^{44}$ However, instead of using the PW91 correlation functional, it uses the LYP functional. ${ }^{45}$ This gives the functional form

$$
E_{x c}^{\mathrm{B} 3 \mathrm{LYP}}=(1-a) E_{x}^{\mathrm{LSDA}}+a E_{x}^{\mathrm{HF}}+b \Delta E_{x}^{\mathrm{B} 88}+c E_{c}^{\mathrm{LYP}}+(1-c) E_{c}^{\mathrm{VWN}}
$$

where $a, b$ and $c$ are coefficients taking the values suggested by Becke; 0.2, 0.72 and 0.81 respectively, ${ }^{44} E_{x}^{\mathrm{LSDA}}$ is as defined by Equation $1.4, E_{x}^{\mathrm{HF}}$ is the exact Hartree-Fock exchange energy, $\Delta E_{x}^{\mathrm{B} 88}$ is Becke's gradient correction to the exchange energy, ${ }^{49}$ and $E_{c}^{\mathrm{LYP}}$ is the Lee-Yang-Parr correlation functional. ${ }^{45}$ Since LYP does not have an easily separable local component, $E_{c}^{\mathrm{VWN}}$ the VWN local correlation expression, 46 is used to provide the different coefficients of local and gradient corrected correlation functionals.

\subsubsection{Long-range Corrected Functionals}

\subsubsection{M06-2X}

M06-2X is part of the M06 suite of density functionals. ${ }^{52}$ It is a hybrid meta-GGA exchange-correlation functional, as it incorporates the electron spin density $\left(\rho_{\sigma}\right)$, reduced spin density gradient $\left(x_{\sigma}\right)$, kinetic energy density $\left(\tau_{\sigma}\right)$ and non-local Hartree-Fock exchange. The functional form can be written as

$$
E_{x c}^{\mathrm{M} 06-2 \mathrm{X}}=a E_{x}^{\mathrm{HF}}+(1-a) E_{x}^{\mathrm{M} 06-2 \mathrm{X}}+E_{c}^{\mathrm{M} 06-2 \mathrm{X}}
$$

where $a$ controls the percentage of Hartree-Fock exchange in the hybrid functional and is optimised to 0.54 . The exchange functional is given by

$$
E_{x}^{\mathrm{M} 06-2 \mathrm{X}}=\sum_{\sigma} \int \mathrm{d} r\left[F_{x \sigma}^{\mathrm{PBE}}\left(\rho_{\sigma}, \nabla \rho_{\sigma}\right) f\left(w_{\sigma}\right)\right]
$$

where $F_{x \sigma}^{\mathrm{PBE}}\left(\rho_{\sigma}, \nabla \rho_{\sigma}\right)$ is the exchange energy density of the PBE exchange model 60 
and $f\left(w_{\sigma}\right)$ is the spin kinetic-energy density enhancement factor

$$
f\left(w_{\sigma}\right)=\sum_{i=\sigma}^{m} a_{i} w_{\sigma}^{i}
$$

where $w_{\sigma}$ is as in equation 1.10

The correlation functional, $E_{c}^{\mathrm{M} 06-2 \mathrm{X}}$ takes the same form as that of the M06-HF functional. $\underline{61}$

\subsubsection{2 $\omega \mathrm{B97X}$}

$\omega \mathrm{B} 97 \mathrm{X}$ is a long-range corrected hybrid density functional developed by Chai and Head-Gordon. It incorporates some short-range Hartree-Fock exchange in addition to the short-range density functional exchange as a means to improve thermochemistry performance and provide non-local correction to the short-range exchange. ${ }^{\sqrt[56]{6}}$ This gives the overall functional form,

$$
E_{x c}^{\omega \mathrm{B} 97 \mathrm{X}}=E_{x}^{\mathrm{LR}-\mathrm{HF}}+c_{x} E_{x}^{\mathrm{SR}-\mathrm{HF}}+E_{x}^{\mathrm{SR}-\mathrm{B} 97}+E_{c}^{\mathrm{B} 97}
$$

where $E_{x}^{\mathrm{LR}-\mathrm{HF}}$ and $E_{x}^{\mathrm{SR}-\mathrm{HF}}$ are the long- and short- range components of Hartree-Fock exchange, $E_{x}^{\mathrm{SR}-\mathrm{B} 97}$ is the exchange portion of Becke's 1997 functional ${ }^{59}$ modified for short-range exchange and $E_{c}^{\mathrm{B} 97}$ is the unmodified correlation portion of the same functional. $c_{x}$ is a dimensionless constant optimised as 0.157706 .

In such long-range corrected schemes, defining what is long-range and what is shortrange plays an important role in the performance of the functional. In this instance, Chai and Head-Gordon use the popular standard error function (erf, Equation 1.17),

$$
\begin{gathered}
\frac{1}{r_{12}}=\frac{\operatorname{erf}\left(\omega r_{12}\right)}{r_{12}}+\frac{1-\operatorname{erf}\left(\omega r_{12}\right)}{r_{12}} \\
\operatorname{erf}(x)=\frac{2}{\sqrt{\pi}} \int_{0}^{x} e^{-t^{2}} \mathrm{~d} t
\end{gathered}
$$

where $r_{12} \equiv\left|\mathbf{r}_{12}\right|=\left|\mathbf{r}_{1}-\mathbf{r}_{2}\right|$, the modulus of the difference between the atomic radii vectors of a pair of atoms, and $\omega$ is a parameter used to define the range of these operators, optimised as $0.3 \mathrm{bohr}^{-1}$. The first term on the right hand side of equation 1.16 is long ranged and the second is short ranged. 
The long and short-range operators are incorporated into the Hartree-Fock exchange components by factoring them directly into the computation. However, the short-range modification to the density functional component is performed by using an attenuation function $F\left(a_{\sigma}\right)$, giving

$$
\begin{gathered}
E_{x}^{\mathrm{SR}-\mathrm{B} 97}=\sum_{\sigma} \int e_{x \sigma}^{\mathrm{B} 97} F\left(a_{\sigma}\right) d \mathbf{r} \\
F\left(a_{\sigma}\right)=1-\frac{8}{3} a_{\sigma}\left[\sqrt{\pi} \operatorname{erf}\left(\frac{1}{2 a_{\sigma}}\right)-3 a_{\sigma}+4 a_{\sigma}^{3}+\left(2 a_{\sigma}-4 a_{\sigma}^{3}\right) \exp \left(-\frac{1}{4 a_{\sigma}^{2}}\right)\right]
\end{gathered}
$$

where $e_{x \sigma}^{\mathrm{B} 97}$ is the exchange energy density for $\sigma$-spin of the B97 functional and includes the required inhomogeneity correction factor, $a_{\sigma}$ is a dimensionless parameter controlling the values of the attenuation function and is equivalent to $\omega /\left(2 k_{F \sigma}\right)$, with $k_{F \sigma} \equiv\left(6 \pi^{2} \rho_{\sigma}(\mathbf{r})\right)^{1 / 3}$ the local Fermi wave vector.

\subsubsection{CAM-B3LYP}

CAM-B3LYP 51 is a long-range correction modification to the B3LYP functional. Yanai et al. used a modified version of the long-range-correction scheme of Tawada et al. ${ }^{62}$ where the Ewald split is generalised to include two extra parameters $\alpha$ and $\beta$, becoming

$$
\frac{1}{r_{12}}=\frac{\alpha+\beta \operatorname{erf}\left(\mu r_{12}\right)}{r_{12}}+\frac{1-\left[\alpha+\beta \operatorname{erf}\left(\mu r_{12}\right)\right]}{r_{12}}
$$

where $\alpha=0.19, \alpha+\beta=0.65$ and $\mu$ takes the value of Tawada et al. of 0.33 .62 This approach is termed the 'Coulomb-attenuating method' (CAM).

Within the long-range correction scheme, the different halves of the Ewald splitting are applied to long-range Hartree-Fock exchange and short-range density functional exchange. In the CAM method, this is not the case. The first term on the right side of equation 1.20 is applied to the Hartree-Fock exchange and the second to the density functional exchange, in this case Becke's 1988 exchange functional. This gives an overall functional where there is 0.19 Hartree-Fock exchange at short-range and 0.65 at long-range. Conversely, there is $0.81 \mathrm{~B} 88$ exchange at short-range and 0.35 at longrange. The B3LYP correlation functional is used without modification. 


\subsubsection{B97-D}

B97-D ${ }^{48}$ is based on Becke's 1997 GGA functional, B97. ${ }^{59}$ It takes the basic form of the B97 functional and reoptimises some parameters to include empirical atom-atom dispersion corrections. The linear parameters of the gradient correction factors are redetermined by a least-squares fit to include van der Waals corrections, and an additional dispersion energy correction is added, to give the final functional form

$$
\begin{gathered}
E_{\mathrm{B} 97-\mathrm{D}}=E_{\mathrm{B} 97}+E_{\mathrm{disp}} \\
E_{\mathrm{disp}}=-s_{6} \sum_{i=1}^{N-1} \sum_{j=i+1}^{N} \frac{C_{6}^{i j}}{R_{i j} 6} f_{\mathrm{dmp}}\left(R_{i j}\right)
\end{gathered}
$$

where $N$ is the number of atoms in the system, $C_{6}^{i j}$ denotes the dispersion coefficient for atom pair $i j, s_{6}$ is a global scaling factor chosen to be 1.25 and $R_{i j}$ is an interatomic distance. A damping function, $f_{\mathrm{dmp}}$, is used to avoid near-singularities for small $R$ and is given by

$$
f_{\mathrm{dmp}}\left(R_{i j}\right)=\frac{1}{1+e^{-d\left(R_{i j} / R_{r}-1\right)}}
$$

where $R_{r}$ is the sum of atomic van der Waals radii and $d=20$.

In previous DFT-D functionals, there is an issue where too much weight is given to the lighter atom when determining the dispersion coefficient for an atom pair. Grimme overcomes this by using a geometric mean of the form

$$
C_{6}^{i j}=\sqrt{C_{6}^{i} C_{6}^{j}}
$$

with the $C_{6}$ coefficient (in $\mathrm{J} \mathrm{nm}^{6} \mathrm{~mol}^{-1}$ ) for a given atom $a$ being determined based on DFT/PBE0 calculations of atomic ionisation potentials $\left(I_{p}\right)$ and static dipole polarizabilites $\alpha$

$$
C_{6}^{a}=0.05 N I_{p}^{a} \alpha^{a}
$$

where $N$ takes the values $2,10,18,36$ and 54 for atoms from rows $1-5$ of the periodic table. 


\subsubsection{5 $\omega$ B97X-D}

In a similar manner to the $\mathrm{B} 97-\mathrm{D}$ functional $(\$ 1.3 .4 .4), \omega \mathrm{B} 97 \mathrm{X}-\mathrm{D}^{57}$ is a reoptimisation of an existing functional to include empirical atom-atom dispersion corrections. In this case, Chai and Head-Gordon have taken their own $\omega$ B97X long-range corrected hybrid density functional $(\$ 1.3 .4 .2)$ as the starting point. Except for the use of a different damping function (Equation 1.27) and constraining for correct asymptotic behaviour, Grimme's work ${ }^{48}(\S 1.3 .4 .4$ is followed for computing the empirical dispersion corrections

$$
\begin{gathered}
E_{\omega \mathrm{B} 97 \mathrm{X}-\mathrm{D}}=E_{\omega \mathrm{B} 97 \mathrm{X}}-\sum_{i=1}^{N-1} \sum_{j=i+1}^{N} \frac{C_{6}^{i j}}{R_{i j}^{6}} f_{\mathrm{dmp}}\left(R_{i j}\right) \\
f_{\mathrm{dmp}}\left(R_{i j}\right)=\frac{1}{1+a\left(R_{i j} / R_{r}\right)^{-12}}
\end{gathered}
$$

where $a=6.0$.

The parameters of the $\omega \mathrm{B} 97 \mathrm{X}$ functional have been reoptimised to account for the additional dispersion correction term, to give $c_{x}=0.222036$ and $\omega=0.2 \mathrm{Bohr}^{-1}$.

\subsection{5 ab initio Method}

\subsubsection{SCS-MP2}

Møller-Plesset correlation energy correction calculations, truncated at second-order (MP2) $\sqrt{63-68}$ are known to severely overestimate the interaction energies of $\pi-\pi$ stacked complexes. ${ }^{32}$ However, small basis sets, such as the $6-31 \mathrm{G}(\mathrm{d})$ basis set used here, can give reasonable results due to the cancellation of two errors: the overestimation of attraction due to the MP2 approach, and the underestimation due to the small basis set. MP2 results can be further improved by using Grimme's SCS-MP2 (spin-componentscaled) method ${ }^{69}$ at no additional computational cost. This method takes the total MP2 correlation energy and partitions it into parallel- and antiparallel-spin components which are separately scaled. The SCS-MP2 energy is given by

$$
E_{\mathrm{SCS}-\mathrm{MP} 2}=\frac{6}{5} E_{\alpha \beta}+\frac{1}{3}\left(E_{\alpha \alpha}+E_{\beta \beta}\right)+E_{\mathrm{HF}}
$$

where $E_{\alpha \beta}$ is the correlation energy contribution from antiparallel-spin pairs of electrons, $E_{\alpha \alpha}$ and $E_{\beta \beta}$ are the contributions from parallel-spin pairs and $E_{\mathrm{HF}}$ is the HartreeFock exchange energy. 


\subsection{NMR}

Nuclear magnetic resonance (NMR) is a powerful technique used by experimentalists to obtain mainly three-dimensional structures of organic compounds. Because of its power, a number of computational techniques have been developed to provide a theoretical aid in these endeavours. One of these techniques is the gauge independent atomic orbital (GIAO) method. The GIAO method is especially useful as it has been shown to converge faster than other methods, ${ }^{70 \mid 71}$ meaning smaller basis sets can be used to obtain high levels of accuracy, making it ideal for large systems. The GIAO method was developed by Ditchfield in $1974^{72}$ as an ab initio alternative to the semi-empirical approaches available at the time. Since then, the GIAO method has been applied with density functionals, firstly by Friedrich et al. ${ }^{73}$ and later by other groups ${ }^{70 \mid 74}$ using different functionals and larger basis sets.

A number of studies have looked at the effect of density functional ${ }^{75-178}$ and basis set $\frac{75-77}{7-70}$ on calculated NMR shifts. With density functionals, the general consensus is that hybrid functionals perform better than pure functionals. Larger basis sets do provide better results, as would be expected, though their improvement over modest basis sets is minor and the performance enhancement obtained with smaller basis sets is more enticing. Solvent inclusion, through the use of SCRF (placing the solute in a cavity within the solvent reaction field) or similar method, leads to additional improvements. However, the magnitude of these improvements can vary greatly depending on the system and are most noticeable for a few difficult cases.

\subsection{Research Aims}

This research aimed to investigate nine different density functionals (B3LYP, B97-D, BP86, CAM-B3LYP, M062X, PW91, $\tau$-HCTH, $\omega$ B97X and $\omega$ B97X-D) for their suitability in modelling the $\mathrm{C}_{60} @$ corannulene complex. With a suitable density functional determined, a number of functionalised corannulene bowls were to be generated and their complex formation with $\mathrm{C}_{60}$ investigated. Additionally, computational NMR techniques were to be used to determine the viability of experimentally investigating those complexes. 


\section{Chapter 2}

\section{Methodology}

Throughout this project, all calculations were performed using the Gaussian 09 Revision B.01 ${ }^{79}$ program. Optimisations, single point, and NMR calculations were performed on a combination of the Victoria University of Wellington School of Chemical and Physical Sciences' Heisenberg cluster, consisting of eight processing nodes with two $2.53 \mathrm{GHz}$ Xeon X3440 quad-core processors per node and $1 \mathrm{~GB}$ of memory per core, and the Victoria University of Wellington Science Faculty HPC facility, consisting of 22 processing nodes with two 2.2 GHz AMD Opteron 6174 (12-core) processors per node and $2.6 \mathrm{~GB}$ of memory per core.

\subsection{Functional Evaluation}

\subsubsection{Functionals}

Nine density functionals were chosen for evaluation of their suitability in modelling the $\mathrm{C}_{60} @$ corannulene complex. They were B3LYP, ${ }^{44}$,47 B97-D, ${ }^{48}$ BP86, ${ }^{4950}$ CAM-

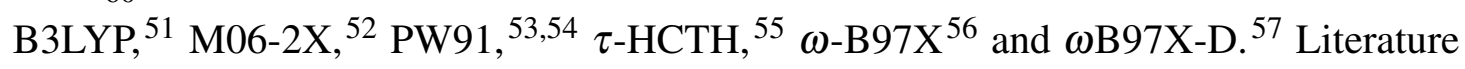
results indicate that smaller basis sets can provide resonable approximations for binding energies at a fraction of the cost of larger basis sets. ${ }^{38}$ As the aim of this project was to determine which functionals were suitable for modelling non-bonding complex systems, Pople's 6-31G(d) basis set was chosen for use due to the computational efficiency afforded by its small size. Geometries were optimised at the $\omega$ B97X-D/6-31G(d) level, and then reoptimised using the various functionals. In addition to the density functional methods, optimisations were also performed at the MP2/6-31G(d) level, with the energy of the optimised structure being calculated with SCS-MP2 to act as a reference. 


\subsubsection{Geometries}

Five different geometries of the $\mathrm{C}_{60} @$ corannulene complex were investigated (Figure 2.1). Two have $\mathrm{C}_{5 v}$ symmetry. These are such that the five carbons forming the hub of corannulene are eclipsed by $(\mathrm{C} 5 \mathrm{e}, \mathrm{a})$ or staggered with respect to a $\mathrm{C}_{5}$ ring $(\mathrm{C} 5 \mathrm{~s}, \mathrm{~b})$ from $\mathrm{C}_{60}$. The remaining three have $\mathrm{C}_{s}$ symmetry. (C6C6e, c), where a bond joining two $\mathrm{C}_{6}$ rings within $\mathrm{C}_{60}$ is positioned such that it is eclipsed by the bond between two hub carbons of the corannulene. (C6C6t, d), where a bond joining two $\mathrm{C}_{6}$ rings is positioned such that it lies along the plane of reflection of the complex. (C5C6e, e), where a bond joining a $\mathrm{C}_{6}$ ring with a $\mathrm{C}_{5}$ ring within $\mathrm{C}_{60}$ is positioned such that it is eclipsed by the bond between two hub carbons of the corannulene, with the $\mathrm{C}_{6}$ ring overlapping the $\mathrm{C}_{5}$ ring at the hub of corannulene.

\subsubsection{Energy Profiles}

Rigid energy profiles were generated for the 55 possible functional-geometry combinations, including the perturbation methods. In each case, the optimised geometry was taken as a starting point. The $\mathrm{C}_{60}$-corannulene fragment separation was decreased by $1.75 \AA$, then from this a series of single-point calculations were performed. Starting at the reduced fragment separation, the fragments were separated by $0.2 \AA$ for 5 steps, followed by 30 steps of $0.05 \AA, 15$ steps of $0.1 \AA$ and 9 of $0.5 \AA$, for a total of 59 points.

\subsubsection{Integration Grid}

Energy profiles were created with three different integration grid sizes: fine, ultrafine and benchmark. All optimisations were performed with the default "fine" Gaussian grid size. The single point calculations to generate the rigid energy profiles were then performed at the three levels of integration grid size for each density functional (MP2 was excluded). The grids are as follows:

(a) Fine: a pruned $(75,302)$ grid, with 75 radial shells and 302 angular points per shell, giving 22650 points per atom.

(b) Ultrafine: a pruned $(99,590)$ grid, with 99 radial shells and 590 angular points per shell, giving 58410 points per atom.

(c) Benchmark: a full $(96,32,64)$ grid with 96 radial shells, each containing a spherical product grid of dimension $32 \times 64$ points for a total of 196608 points per atom. 


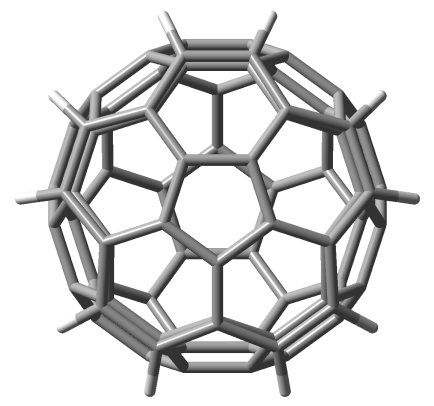

(a) $\mathrm{C} 5 \mathrm{e}\left(\mathrm{C}_{5 v}\right.$ symmetry $)$

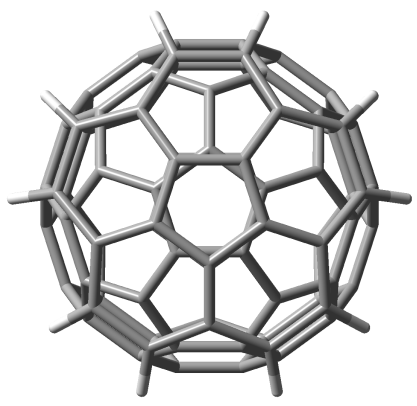

(b) $\mathrm{C} 5 \mathrm{~s}\left(\mathrm{C}_{5 v}\right.$ symmetry)

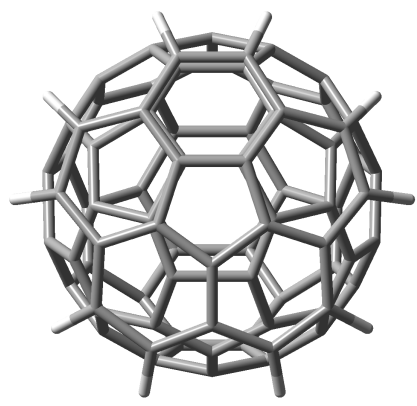

(c) $\mathrm{C} 6 \mathrm{C} 6 \mathrm{e}\left(\mathrm{C}_{s}\right.$ symmetry $)$

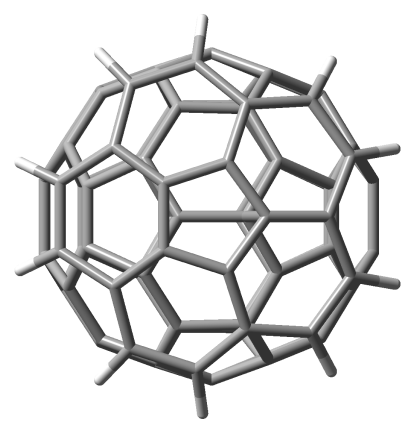

(d) C6C6t ( $\mathrm{C}_{s}$ symmetry)

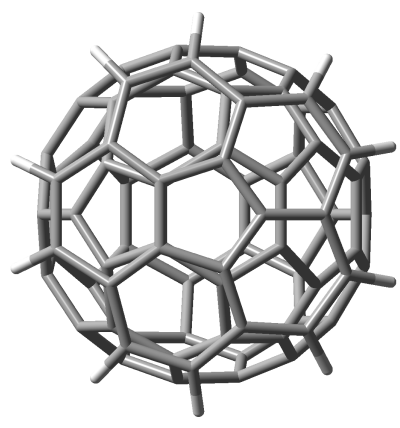

(e) $\mathrm{C} 5 \mathrm{C} 6 \mathrm{e}\left(\mathrm{C}_{s}\right.$ symmetry $)$

Figure 2.1. The five geometries of the $\mathrm{C}_{60} @$ corannulene complex. They are $(\mathrm{a}) \mathrm{C}$ e where the $\mathrm{C}_{5}$ ring of corannulene is eclipsed by a $\mathrm{C}_{5}$ ring of the $\mathrm{C}_{60}$; (b) $\mathrm{C} 5 \mathrm{~s}$ where the $\mathrm{C}_{5}$ ring of corannulene is staggered with respect to a $\mathrm{C}_{5}$ ring of the $\mathrm{C}_{60}$; (c) $\mathrm{C} 6 \mathrm{C} 6 \mathrm{e}$ where the bond between two adjacent $\mathrm{C}_{6}$ rings of the $\mathrm{C}_{60}$ are eclipsed by a hub bond of the corannulene; (d) C6C6t where the bond between two adjacent $\mathrm{C}_{6}$ rings of the $\mathrm{C}_{60}$ lies along the mirror plane of the complex; and (e) C5C6e where the bond between a $\mathrm{C}_{5}$ and $\mathrm{C}_{6}$ ring of the $\mathrm{C}_{60}$ is eclipsed by a hub bond on the corannulene.

\subsection{Functionalised Bowls}

Functionalised bowls were optimised at the $\omega \mathrm{B} 97 \mathrm{X}-\mathrm{D} / 6-31 \mathrm{G}(\mathrm{d})$ level, using the fine grid. Five input geometries $(\$ 2.1 .2)$ were used and optimisation was allowed to proceed without any further restrictions. In cases where the functional group attachments could be positioned either pointing up (-U) with the curvature of the corannulene skeleton, or down (-D) against it, both positions were optimised. 


\subsubsection{NMR}

${ }^{13} \mathrm{C}$ and ${ }^{1} \mathrm{H}$ NMR calculations were performed on the optimised geometries of both $\mathrm{C}_{60} @$ corannulene and $\mathrm{C}_{60} @$ functionalised-bowls gas-phase complexes. In all cases, the geometries were those as calculated at the $\omega \mathrm{B} 97 \mathrm{X}-\mathrm{D} / 6-31 \mathrm{G}(\mathrm{d})$ level. The NMR calculations themselves were performed at the GIAO/ $\omega \mathrm{B} 97 \mathrm{X}-\mathrm{D} / \mathrm{dec}-6-31 \mathrm{G}(\mathrm{d})$ level. TMS was optimised and NMR calculations performed at the same levels for use as an NMR reference compound. Basis sets are designed for systems where the valence electrons are important. NMR calculations require good representation of the core electrons, so the core orbitals of the 6-31G(d) basis set were decontracted. Decontraction was performed for hydrogen and carbon. For carbon, the core s-type orbital consisting of six gaussians was decontracted by separating the gaussians to give six s-type orbitals consisting of one gaussian each. Hydrogen was decontracted by separating the triple gaussian 'core' s-type orbital into three individual s-type orbitals of one gaussian.

As the $\omega \mathrm{B} 97 \mathrm{X}-\mathrm{D}$ functional does not contain any experimental NMR parametrisation, scaling of calculated shifts by linear regression parameters was included. Calculated relative NMR shifts were plotted against their respective experimental values for several of the uncomplexed bowls. A linear least squares fit was performed to determine a scaling factor which could be used to relate the calculated shift values to what would be expected experimentally.

As suggested by Jain et al. ${ }^{77}$ NMR shifts relative to the TMS reference for the complexes were thermally weighted to obtain an average value. The weighting was based on the binding energies of each geometry and was given by

$$
W_{n}=\frac{e^{-E_{\text {bind }}^{n} / k_{\mathrm{B}} \mathrm{T}}}{\sum_{n=1}^{5} e^{-E_{\text {bind }}^{n} / k_{\mathrm{B}} \mathrm{T}}}
$$

where $W_{n}$ is the fraction of the $n$-th geometry to use, $E_{\text {bind }}^{n}$ is the binding energy of the $n$-th geometry in kcal mol ${ }^{-1}, k_{\mathrm{B}}$ is Boltzmann's constant in $\mathrm{kcal} \mathrm{mol}^{-1} \mathrm{~K}^{-1}$ and $\mathrm{T}=298 \mathrm{~K}$. These weighted results were then scaled by the appropriate scaling factor. $\Delta \delta$ values were calculated as the difference between the thermally weighted average NMR values of the complexes and their component fragments. ${ }^{*}$

\footnotetext{
*Fragment NMR values were used instead of the optimised bowl values. This was so that any changes in the calculated $\delta$ values were purely due to shielding or deshielding effects caused upon complexation of the bowl with $\mathrm{C}_{60}$, and not influenced by possible changes in the bowl structure.
} 


\section{Chapter 3}

\section{Functional Evaluation}

\subsection{Results}

\subsubsection{Binding Energies}

Binding energy is defined as the energy difference between the calculated energy of the complex and the calculated energy of the fragments which make up the complex;

$$
E_{\text {binding }}=E_{\text {complex }}-E_{\mathrm{C}_{60}}-E_{\text {corannulene }}
$$

A negative binding energy represents an attractive interaction, and a positive binding energy represents a repulsive interaction. The results are presented in Table 3.1. Frequency calculations indicated that some of the structures were transition states.

Table 3.1. Binding energies from the optimised structures for the various functionals. All values are in $\mathrm{kcal} \mathrm{mol}^{-1}$.

\begin{tabular}{l|rrrrr}
\hline Functional & \multicolumn{1}{|c}{ C5e } & \multicolumn{1}{c}{ C5s } & \multicolumn{1}{c}{ C6C6e } & \multicolumn{1}{c}{ C6C6t } & \multicolumn{1}{c}{ C5C6e } \\
\hline \hline B3LYP & -0.216 & -0.197 & -0.385 & -0.470 & -0.280 \\
B97-D & -21.784 & -18.909 & -21.724 & -21.286 & -21.871 \\
BP86 & 0.047 & 0.081 & -0.218 & 0.121 & -0.163 \\
CAM-B3LYP & -2.161 & -1.529 & -2.287 & -2.394 & -2.354 \\
M06-2X & -15.172 & -11.049 & -15.238 & -14.857 & -14.878 \\
MP2 & -35.275 & -29.809 & -36.016 & -34.371 & -36.030 \\
PW91 & -3.111 & -2.629 & -3.440 & -3.490 & -3.212 \\
SCS-MP2 & -23.504 & -19.601 & -24.019 & -22.920 & -24.041 \\
$\tau$-HCTH & -1.510 & -1.523 & -1.462 & -1.624 & -1.853 \\
$\omega B 97 X$ & -9.119 & -6.955 & -9.507 & -9.229 & -9.451 \\
$\omega$ B97X-D & -21.172 & -18.036 & -21.256 & -20.912 & -21.299
\end{tabular}




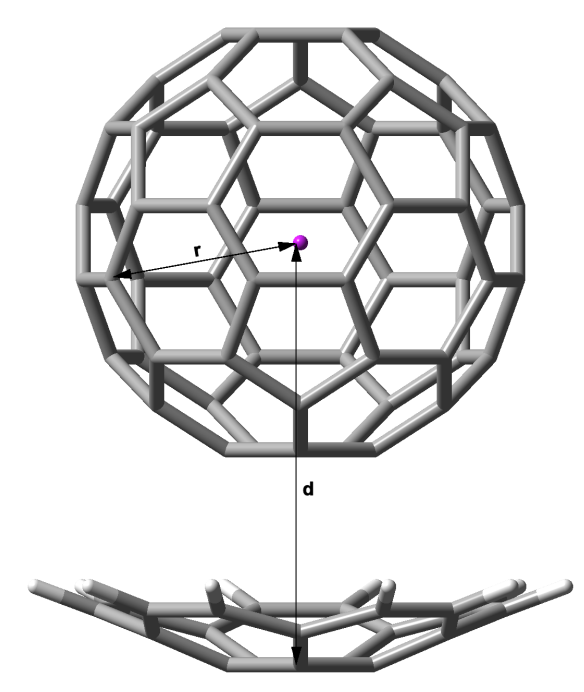

Figure 3.1. The separation of the $\mathrm{C}_{60}$ and corannulene is defined as: $s=d-r$.

\subsubsection{Fragment Separation}

The fragment separation is defined as the distance between the centre of the $\mathrm{C}_{5}$ hub ring of corannulene and the centre of the $\mathrm{C}_{60}$ in the optimised structure, less the radius of $\mathrm{C}_{60}$ as optimised with the required functional (Figure 3.1). The results are presented in Table 3.2

Table 3.2. $\mathrm{C}_{60}$-corannulene fragment separation distances for the various functionals. All values are measured in $\AA$.

\begin{tabular}{l|ccccc}
\hline Functional & C5e & C5s & C6C6e & C6C6t & C5C6e \\
\hline \hline B3LYP & 4.092 & 4.278 & 4.116 & 4.117 & 4.125 \\
B97-D & 3.169 & 3.206 & 3.160 & 3.188 & 3.153 \\
BP86 & 5.432 & 6.159 & 6.656 & 6.132 & 6.168 \\
CAM-B3LYP & 3.741 & 3.891 & 3.728 & 3.728 & 3.723 \\
M06-2X & 3.208 & 3.326 & 3.216 & 3.247 & 3.254 \\
MP2 & 2.926 & 2.985 & 2.917 & 2.963 & 2.914 \\
PW91 & 3.865 & 3.950 & 3.782 & 3.759 & 3.807 \\
SCS-MP2 & 3.076 & 3.135 & 3.067 & 3.113 & 3.064 \\
$\tau$-HCTH & 4.298 & 4.346 & 4.285 & 4.263 & 4.336 \\
$\omega$ B97X & 3.412 & 3.563 & 3.434 & 3.478 & 3.421 \\
$\omega B 97 X-D$ & 3.247 & 3.324 & 3.251 & 3.290 & 3.252
\end{tabular}




\subsubsection{Energy Profiles}

Rigid body energy profiles were generated for each functional-geometry pair. An example result for the B97-D functional is shown in Figure 3.2

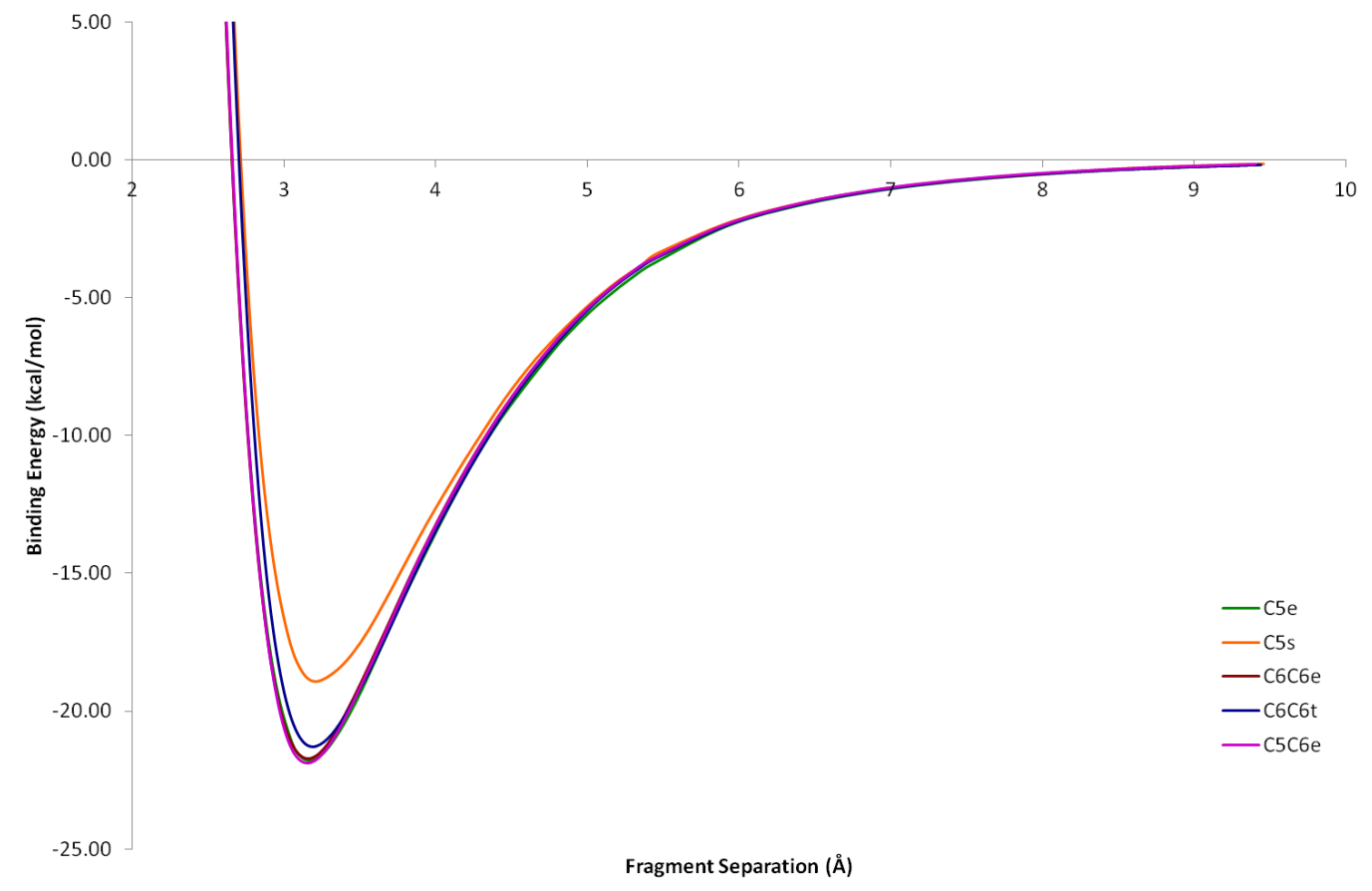

Figure 3.2. Example of the energy profiles generated showing the B97-D functional result.

\subsubsection{Integration Grid}

The effect of increasing the size of the integration grid was investigated to see whether or not it could reduce or outright remove unphysical "spiking" observed in several energy profiles, particularly with the B3LYP and BP86 functionals.

Because the ultrafine and benchmark grid calculations were performed on structures optimised with the fine grid, the binding energies (Table 3.3) and separation distances (Table 3.4 are determined through a quadratic least-squares fit to the seven data points around the minimum energy for each set of calculations. In the interests of comparability, the binding energies and separation distances for the fine grid were also determined using the same method. 
Table 3.3. Binding energies for all nine density functionals at the three different integration grid sizes. The values are determined from the minimum of a quadratic least-squares fit to the seven points around the minimum energy value. All values are in $\mathrm{kcal} \mathrm{mol}^{-1}$.

\begin{tabular}{|c|c|c|c|c|c|c|}
\hline & Functional & $\mathrm{C} 5 \mathrm{e}$ & $\mathrm{C} 5 \mathrm{~s}$ & С6C6e & C6C6t & C5C6e \\
\hline \multirow{9}{*}{ 跬 } & B3LYP & -0.218 & -0.197 & -0.391 & -0.469 & -0.280 \\
\hline & B97-D & -21.810 & -18.927 & -21.735 & -21.303 & -21.889 \\
\hline & BP86 & -0.104 & 0.076 & -0.225 & 0.112 & -0.176 \\
\hline & CAM-B3LYP & -2.163 & -1.531 & -2.289 & -2.396 & -2.355 \\
\hline & M06-2X & -15.188 & -11.435 & -15.237 & -14.859 & -15.008 \\
\hline & PW91 & -3.109 & -2.633 & -3.441 & -3.499 & -3.212 \\
\hline & $\tau$-НCТН & -1.510 & -1.521 & -1.463 & -1.624 & -1.851 \\
\hline & $\omega \mathrm{B} 97 \mathrm{X}$ & -9.117 & -6.954 & -9.506 & -9.233 & -9.451 \\
\hline & $\omega B 97 X-D$ & -21.187 & -18.047 & -21.255 & -20.923 & -21.307 \\
\hline \multirow{9}{*}{ 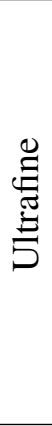 } & B3LYP & -0.231 & -0.184 & -0.309 & -0.418 & -0.311 \\
\hline & B97-D & -21.979 & -18.892 & -21.807 & -21.285 & -21.979 \\
\hline & BP86 & -0.037 & 0.044 & -0.011 & -0.048 & -0.018 \\
\hline & CAM-B3LYP & -2.191 & -1.562 & -2.336 & -2.381 & -2.319 \\
\hline & M06-2X & -15.252 & -11.332 & -15.180 & -14.479 & -15.247 \\
\hline & PW91 & -3.122 & -2.684 & -3.321 & -3.378 & -3.209 \\
\hline & $\tau$-HCТH & -1.607 & -1.526 & -1.694 & -1.836 & -1.611 \\
\hline & $\omega \mathrm{B} 97 \mathrm{X}$ & -9.150 & -7.082 & -9.336 & -9.253 & -9.321 \\
\hline & $\omega \mathrm{B} 97 \mathrm{X}-\mathrm{D}$ & -21.300 & -18.260 & -21.292 & -20.864 & -21.318 \\
\hline \multirow{9}{*}{ 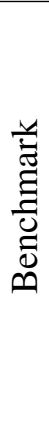 } & B3LYP & -0.274 & -0.151 & -0.336 & -0.393 & -0.333 \\
\hline & B97-D & -21.765 & -18.863 & -21.798 & -21.374 & -21.966 \\
\hline & BP86 & -0.043 & -0.010 & -0.001 & -0.006 & -0.003 \\
\hline & CAM-B3LYP & -2.175 & -1.569 & -2.341 & -2.386 & -2.305 \\
\hline & M06-2X & -15.230 & -11.350 & -15.178 & -14.554 & -15.176 \\
\hline & PW91 & -3.126 & -2.701 & -3.321 & -3.369 & -3.230 \\
\hline & $\tau$-НCТН & -1.611 & -1.505 & -1.686 & -1.807 & -1.605 \\
\hline & $\omega \mathrm{B} 97 \mathrm{X}$ & -9.172 & -7.104 & -9.365 & -9.271 & -9.326 \\
\hline & $\omega \mathrm{B} 97 \mathrm{X}-\mathrm{D}$ & -21.317 & -18.255 & -21.347 & -20.872 & -21.308 \\
\hline
\end{tabular}


Table 3.4. $\mathrm{C}_{60}$-corannulene separation distances for all nine density functionals at the three different integration grid sizes. The values are determined from the separation at which the minimum of a quadratic least-squares fit to the seven points around the minimum energy value occurs. All values are in $\AA$.

\begin{tabular}{|c|c|c|c|c|c|c|}
\hline & Functional & $\mathrm{C} 5 \mathrm{e}$ & $\mathrm{C} 5 \mathrm{~s}$ & C6C6e & C6C6t & C5C6e \\
\hline \multirow{9}{*}{ 急 } & B3LYP & 4.115 & 4.287 & 4.127 & 4.119 & 4.125 \\
\hline & B97-D & 3.184 & 3.232 & 3.173 & 3.206 & 3.169 \\
\hline & BP86 & 6.708 & 6.374 & 7.498 & 6.656 & 6.739 \\
\hline & CAM-B3LYP & 3.751 & 3.907 & 3.742 & 3.744 & 3.734 \\
\hline & M06-2X & 3.222 & 3.295 & 3.224 & 3.265 & 3.210 \\
\hline & PW91 & 3.896 & 3.978 & 3.803 & 3.793 & 3.815 \\
\hline & $\tau$-HCTH & 4.302 & 4.350 & 4.303 & 4.273 & 4.333 \\
\hline & $\omega \mathrm{B} 97 \mathrm{X}$ & 3.423 & 3.566 & 3.440 & 3.479 & 3.427 \\
\hline & $\omega \mathrm{B} 97 \mathrm{X}-\mathrm{D}$ & 3.261 & 3.344 & 3.267 & 3.306 & 3.258 \\
\hline \multirow{9}{*}{ 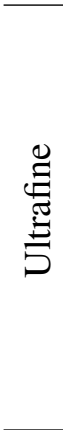 } & B3LYP & 4.152 & 4.293 & 4.121 & 4.081 & 4.121 \\
\hline & B97-D & 3.185 & 3.240 & 3.175 & 3.211 & 3.171 \\
\hline & BP86 & 6.801 & 6.942 & 7.472 & 6.686 & 6.968 \\
\hline & CAM-B3LYP & 3.749 & 3.914 & 3.745 & 3.756 & 3.739 \\
\hline & M06-2X & 3.225 & 3.315 & 3.231 & 3.276 & 3.215 \\
\hline & PW91 & 3.837 & 4.004 & 3.849 & 3.853 & 3.827 \\
\hline & $\tau$-НCТН & 4.313 & 4.359 & 4.304 & 4.270 & 4.326 \\
\hline & $\omega \mathrm{B} 97 \mathrm{X}$ & 3.425 & 3.556 & 3.440 & 3.475 & 3.429 \\
\hline & $\omega \mathrm{B} 97 \mathrm{X}-\mathrm{D}$ & 3.261 & 3.350 & 3.271 & 3.311 & 3.261 \\
\hline \multirow{9}{*}{ 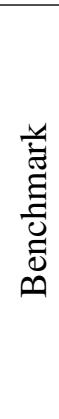 } & B3LYP & 4.147 & 4.291 & 4.123 & 4.080 & 4.121 \\
\hline & B97-D & 3.185 & 3.240 & 3.175 & 3.211 & 3.171 \\
\hline & BP86 & 6.594 & 6.876 & 7.459 & 6.659 & 7.016 \\
\hline & CAM-B3LYP & 3.746 & 3.912 & 3.746 & 3.756 & 3.739 \\
\hline & M06-2X & 3.224 & 3.310 & 3.231 & 3.276 & 3.216 \\
\hline & PW91 & 3.837 & 4.007 & 3.856 & 3.852 & 3.826 \\
\hline & $\tau$-HCTH & 4.312 & 4.361 & 4.301 & 4.271 & 4.327 \\
\hline & $\omega \mathrm{B} 97 \mathrm{X}$ & 3.425 & 3.558 & 3.441 & 3.475 & 3.428 \\
\hline & $\omega B 97 X-D$ & 3.260 & 3.350 & 3.271 & 3.311 & 3.261 \\
\hline
\end{tabular}




\subsection{Discussion}

\subsection{1 $\mathrm{C}_{60} @$ corannulene Binding}

Using the SCS-MP2 calculations as a benchmark, the nine different density functionals had a wide range of performance in respect to the binding energies and separation distances obtained. As would be expected, the functionals implementing some form of long-range correction had superior results when compared to those that do not. In particular, the inclusion of empirical corrections for dispersion, as in B97-D and $\omega$ B97X-D, provided the most reliable results.

\subsubsection{MP2 and SCS-MP2}

MP2 calculations resulted in binding energies in excess of $150 \%$ of the magnitude of the nearest density functional binding energies. This was expected as MP2 is known to overestimate the binding energies involved in non covalent interactions. ${ }^{32}$ With the use of SCS-MP2, the binding energies obtained were still slightly overestimated relative to the density functionals, but provided a more reasonable upper bound to the expected binding energy. The lowest energy geometry was C5C6e, which was isoenergetic with

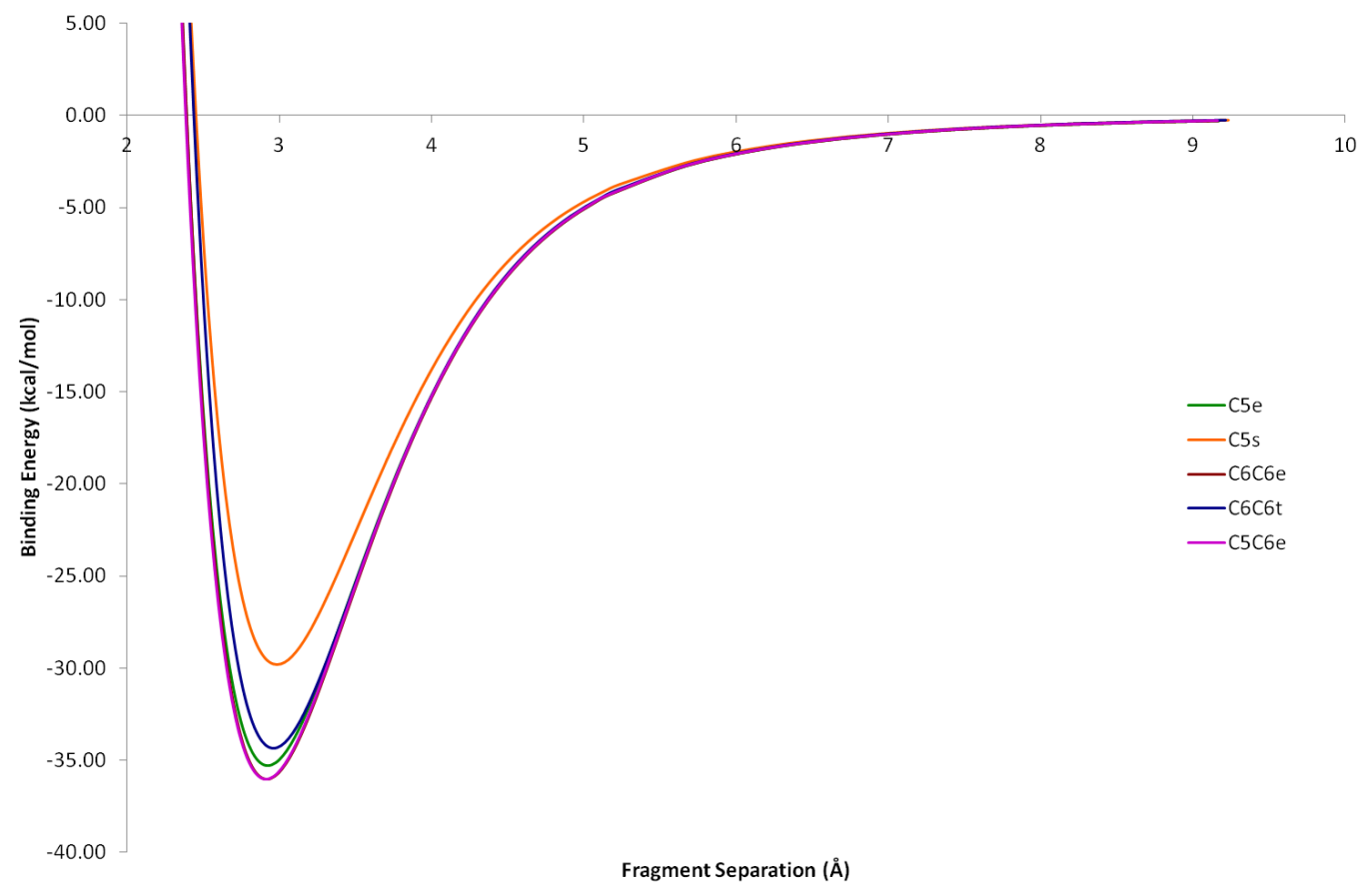

Figure 3.3. Energy profiles generated using MP2 perturbation theory with the fine integration grid. 


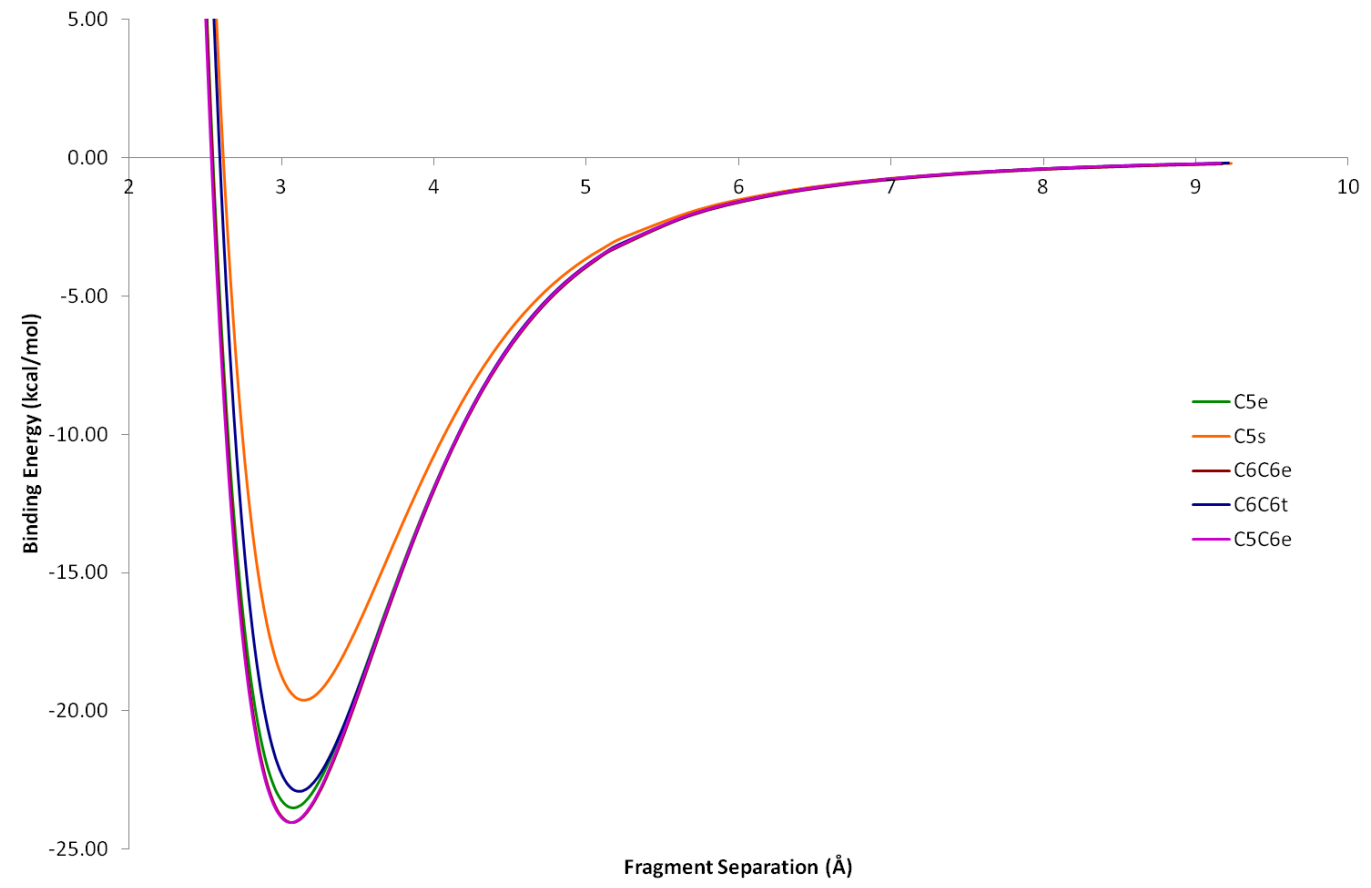

Figure 3.4. Energy profiles generated using SCS-MP2 perturbation theory with the fine integration grid.

C6C6e within the bounds of numerical accuracy. Interaction energy showed exponential decay converging to zero as fragment separation was increased (Figures 3.3 and 3.4), as was expected for a system dominated by dispersion interactions.

\subsubsection{GGA Functionals}

The two GGA functionals investigated, BP86 and PW91, performed very differently, though neither provided reliable results. In both cases, frequency calculations resulted in all geometries having imaginary frequencies, indicating that none were true minima. In the $\mathrm{C} 5 \mathrm{e}, \mathrm{C} 5 \mathrm{~s}$ and $\mathrm{C} 6 \mathrm{C} 6 \mathrm{t}$ geometries, the converged BP86 calculations gave repulsive interactions between the $\mathrm{C}_{60}$ and corannulene. This was the only functional in which repulsive interactions were obtained. The magnitude of attractive interactions in the C6C6e and C5C6e geometries was approximately $0.2 \mathrm{kcal} \mathrm{mol}^{-1}$, which are very minor energies. Additionally, the fragment separation distance was far greater than in any other functional. Energy profiles generated with the BP86 functional (Figure 3.5) revealed that attractive interactions for the $\mathrm{C} 5 \mathrm{e}$ and $\mathrm{C} 5 \mathrm{~s}$ geometries were obtained at separations greater than those calculated with the converged optimisation structures. Unexpectedly, long-range energies failed to converge to zero, with deviations of the or- 


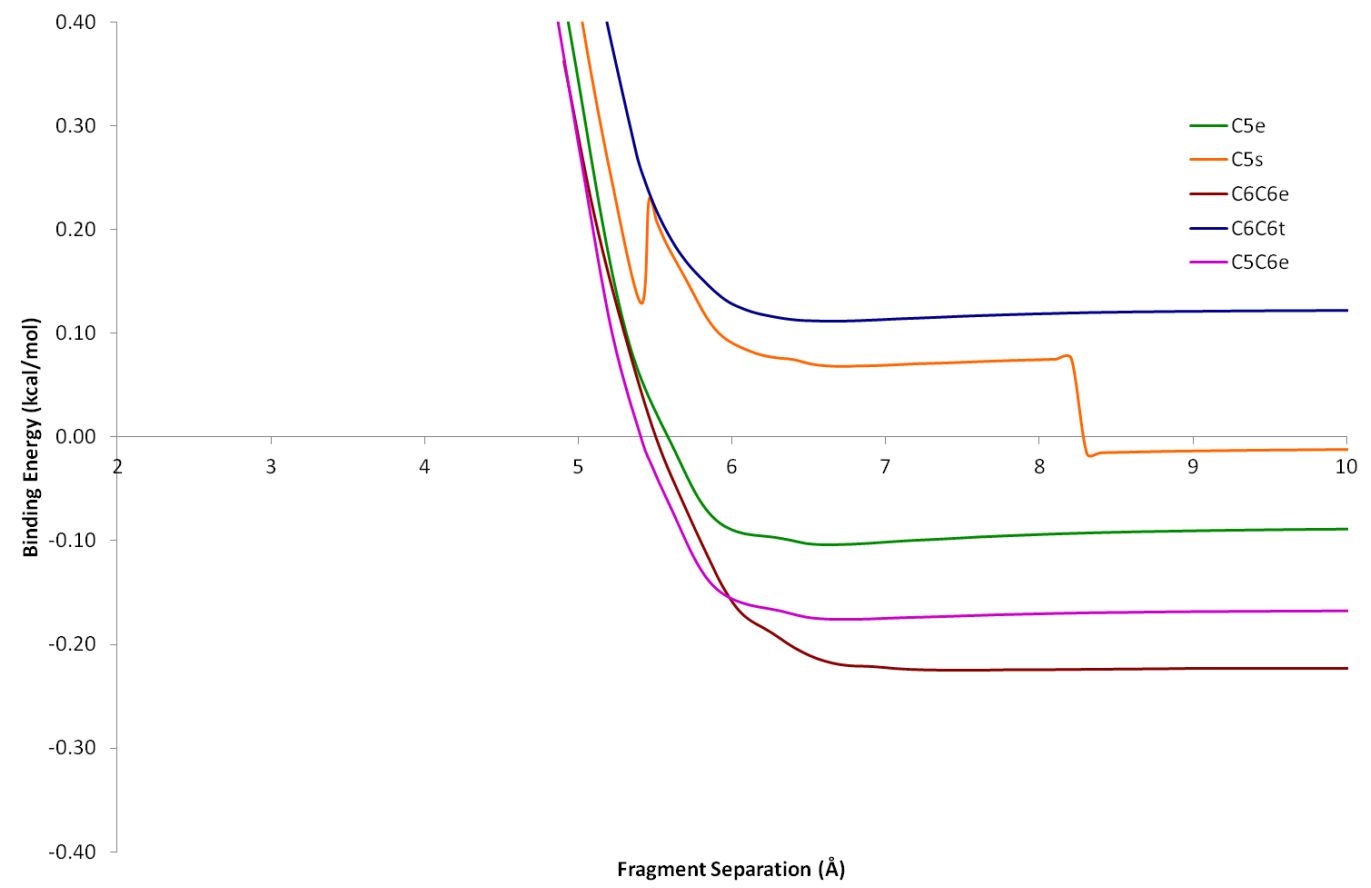

Figure 3.5. Energy profiles generated using the BP86 functional with the fine integration grid. Spikes in the C5s geometry were smoothed out when ultrafine and benchmark-sized grids are used.

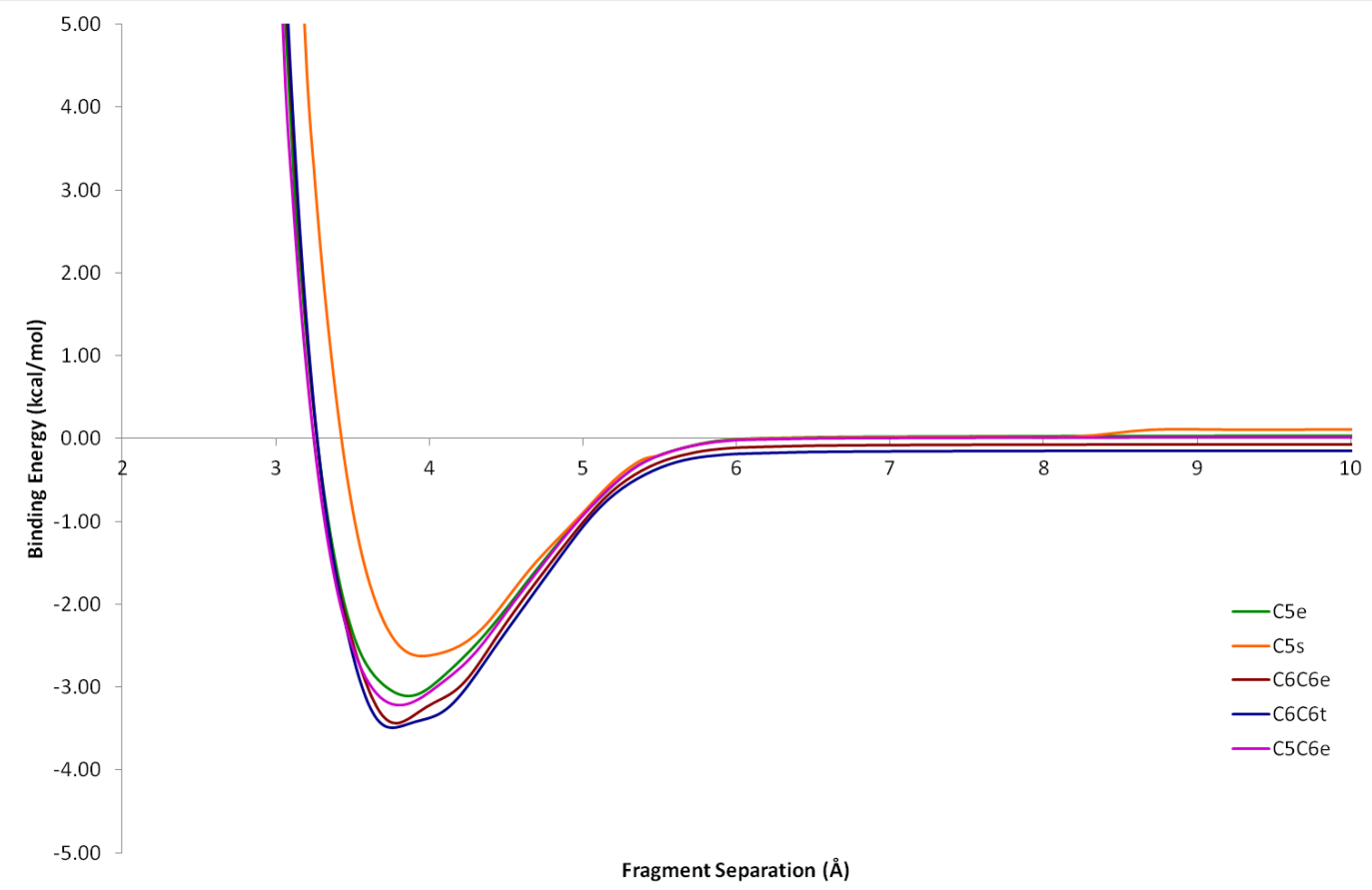

Figure 3.6. Energy profiles generated using the PW91 functional with the fine integration grid. 
der of the binding energies. Along with the nonphysical spikes seen in the C5s plot, this indicated that there may be numerical inaccuracies strongly influencing the results obtained, thus necessitating calculations using finer integration grids.

PW91 provided attractive interactions of between 2.6 and $3.5 \mathrm{kcal} \mathrm{mol}^{-1}$, along with fragment separations of 3.75 to $3.95 \AA$. The binding energies obtained were underestimated relative to the expected range of values. Fragment separation was on par with the distances obtained by Dawe et al. in their crystal structure. ${ }^{[30}$ However, those measurements were made in the solid state and calculations were performed in gas phase, which was expected to give shorter separation distances. PW91 energy profiles (Figure 3.6 revealed relatively broad minima, indicating a relatively flat potential energy surface. Long range decay was modelled reasonably well, though due to the small binding energies obtained, it did not extend as long as was expected. Again, there was slight deviation from zero in the long-range limit, which was of the same magnitude as the BP86 results.

BP86 proved to be inadequate for use in dispersion dominated systems. Despite the lack of true minima, PW91 was more promising. Even though the absolute energies obtained were unreliable, PW91 was able to model long-range effects to some degree, indicating that it could be used to study trends. However, PW91 was negligibly more computationally efficient than B97-D, so using it to study trends was deemed unproductive.

\subsubsection{3 meta-GGA Functional}

$\tau$-HCTH calculations resulted in binding energies of approximately $1.5 \mathrm{kcal} \mathrm{mol}^{-1}$, with fairly large fragment separation distances of around 4.3 A. Frequency calculations showed that the lowest energy geometry, C5C6e, was a true minimum. Crossover of the energy profiles (Figure 3.7) of the other geometries indicated that they were transition states. Including the kinetic energy density did provide some decay characteristics. Interaction energy decay as the fragments were separated was modelled to a small degree. The decay was initially too rapid, which resulted in only a short range effect being modelled. 


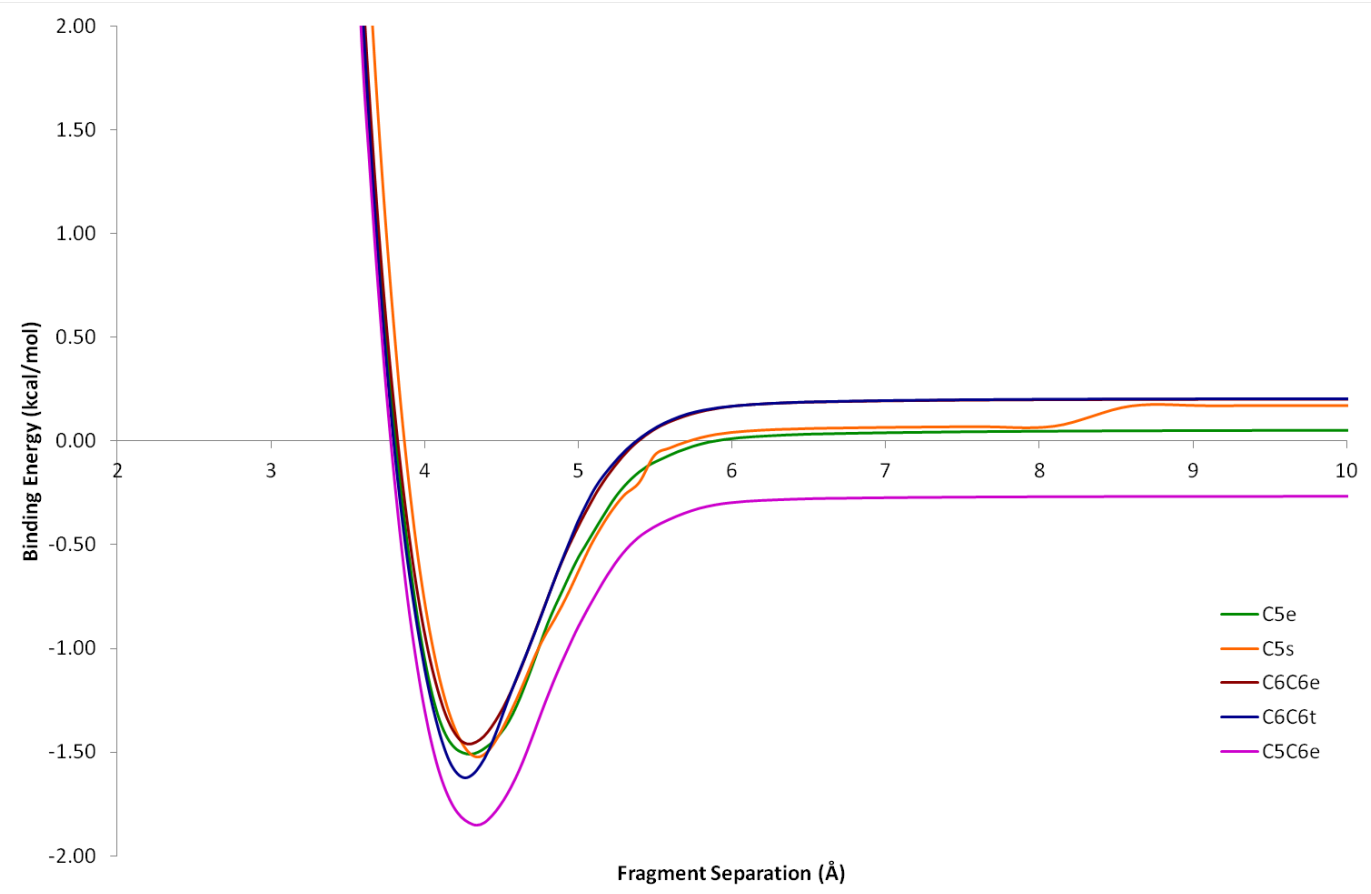

Figure 3.7. Energy profiles generated using the $\tau$-HCTH functional with the fine integration grid.

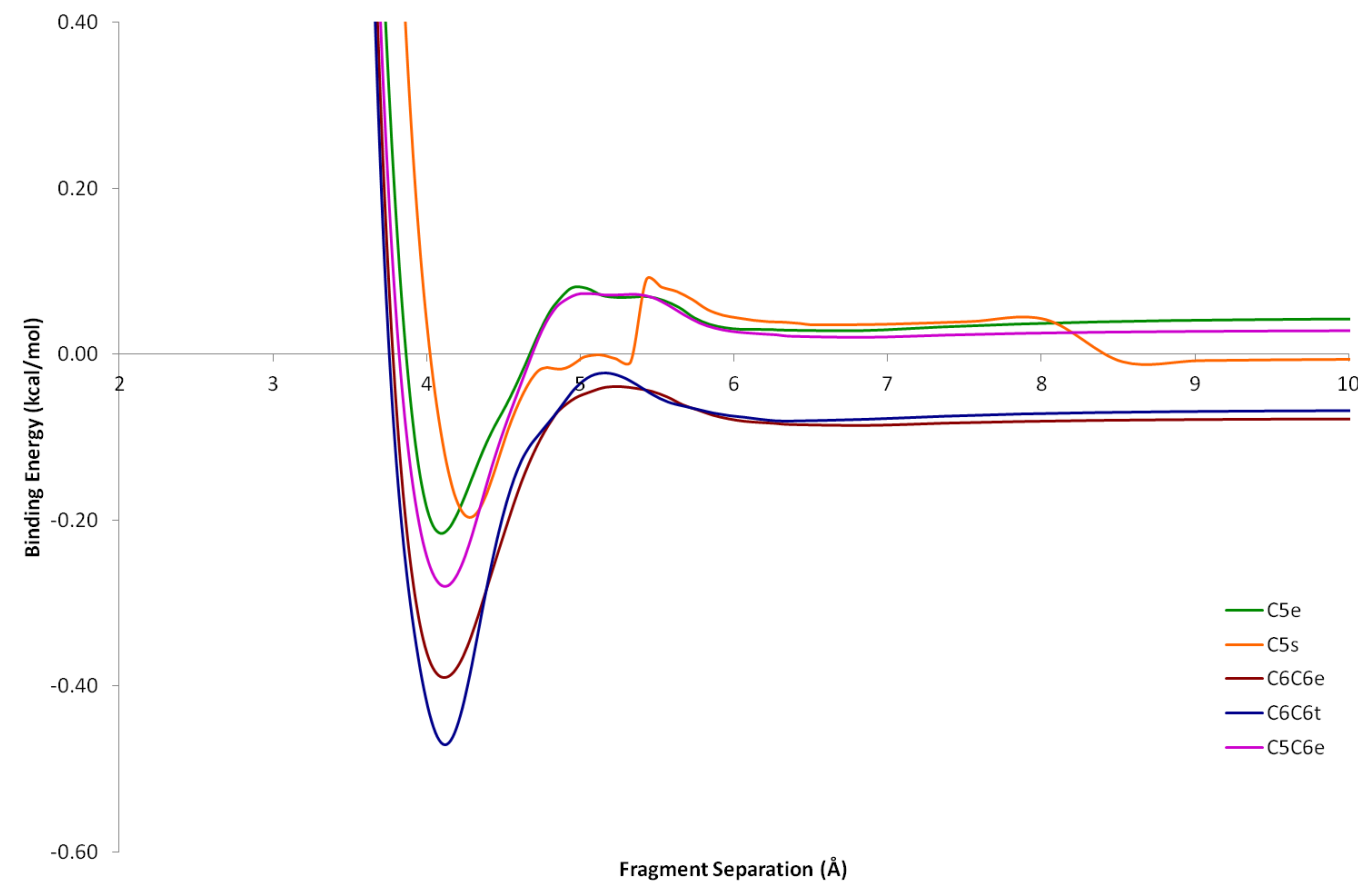

Figure 3.8. Energy profiles generated using the B3LYP functional with the fine integration grid. Spikes in several of the plots were smoothed out when ultrafine and benchmark size grids are used. 


\subsubsection{Hybrid Functional}

Binding energies of between 0.2 and $0.5 \mathrm{kcal} \mathrm{mol}^{-1}$ were obtained with the popular B3LYP functional, though frequency analysis indicated that none of the geometries were true minima. These minor binding energies indicated that B3LYP was unsuitable for systems involving dispersion interactions. Fragment separation was around $4.1 \AA$, which was longer than was expected. In addition to the numerical error induced fluctuations, energy profiles (Figure 3.8) revealed a nonphysical hump at around $5 \AA$. This was a clear sign that the functional was failing to model long range interactions adequately.

\subsubsection{Long-range corrected Functionals}

Long-range corrected functionals gave the most reliable results. The hybrid metaGGA functional M06-2X, was specifically designed for use in modelling non-bonding, $\pi-\pi$ stacking interactions. Binding energies of around $15 \mathrm{kcal} \mathrm{mol}^{-1}$ for four of the geometries were obtained, with the C5s geometry being noticeably weaker bound, as was the case for all long-range corrected functionals. Binding energy was around $65 \%$ that of the benchmark SCS-MP2 results, showing the underestimation expected from the M06-2X functional due to the lack of dispersion inclusion. The lowest energy geometry was C6C6e but frequency calculations showed that this geometry had an imaginary frequency, indicating that there may be additional geometries with lower energies which were not investigated. Fragment separation distances of between 3.2 and $3.3 \AA$ were obtained. Experimental results indicate that the fragment separation distance in solid state crystals of the $\mathrm{C}_{60} @$ corannulene complex was $3.75 \AA .30$ Gas phase results were expected to be slightly shorter than this, so the results obtained were a reasonable representation of the expected value. Energy profiles (Figure 3.9 showed a failure of some geometries to converge to the expected zero value at long range, due to the small integration grid size used. Decay as fragment separation distance was increased was slightly too rapid at short ranges when compared with the MP2 and SCS-MP2 results. M06-2X was found to be acceptable for studying trends in energies; however, the underestimation of binding energies meant that it was inadequate for absolute energies.

CAM-B3LYP was the weakest of the long-range corrected functionals, giving binding energies of less than $2.5 \mathrm{kcal} \mathrm{mol}^{-1}$ and fragment separation distances around $3.75 \AA$, slightly larger than was expected. Frequency calculations showed that none of the geometries were minima. However, energy profiles (Figure 3.10) were vastly improved with regards to the B3LYP functional. The nonphysical hump at around $5 \AA$ present 


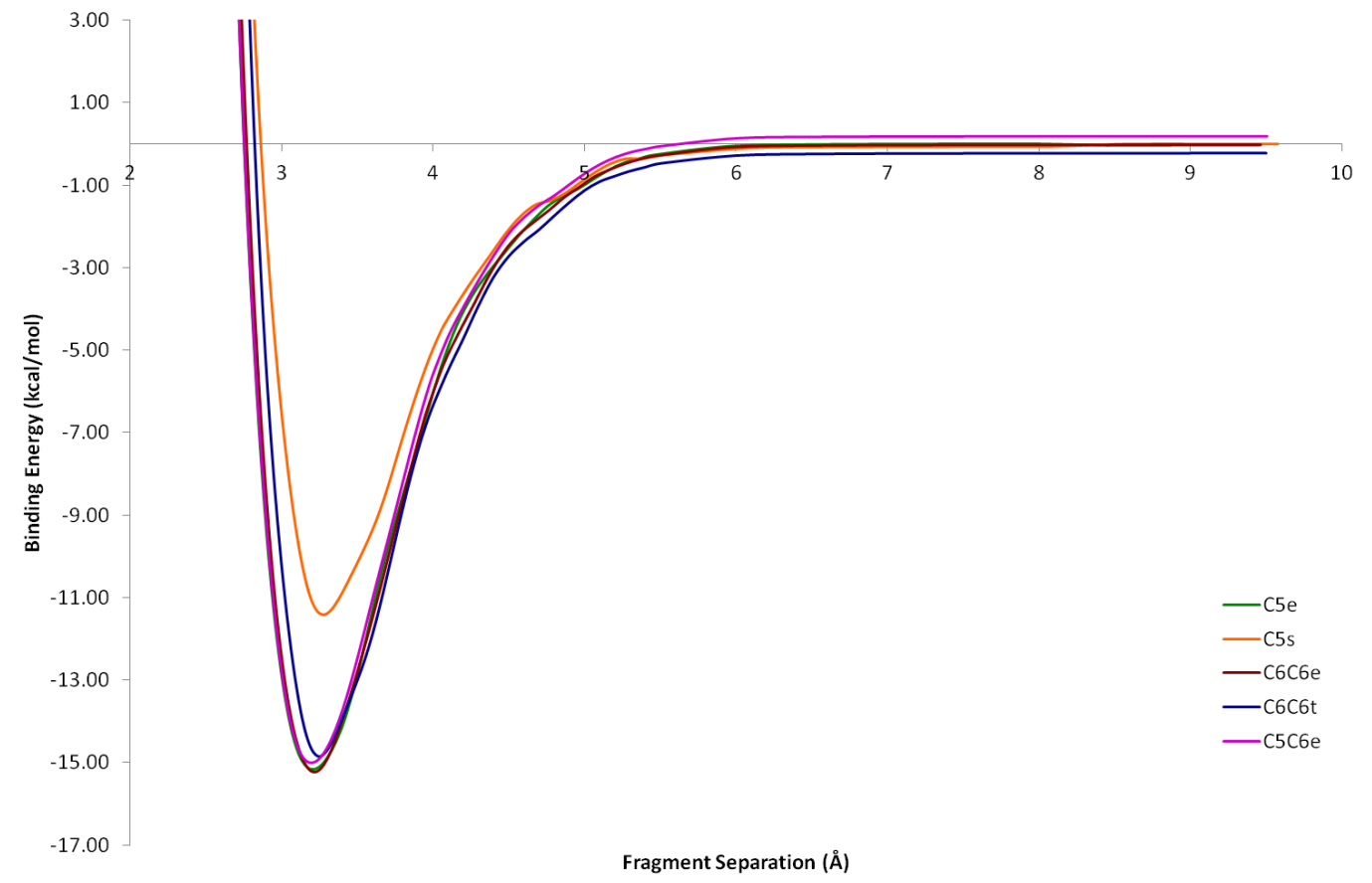

Figure 3.9. Energy profiles generated using the M06- $2 \mathrm{X}$ functional with the fine integration grid.

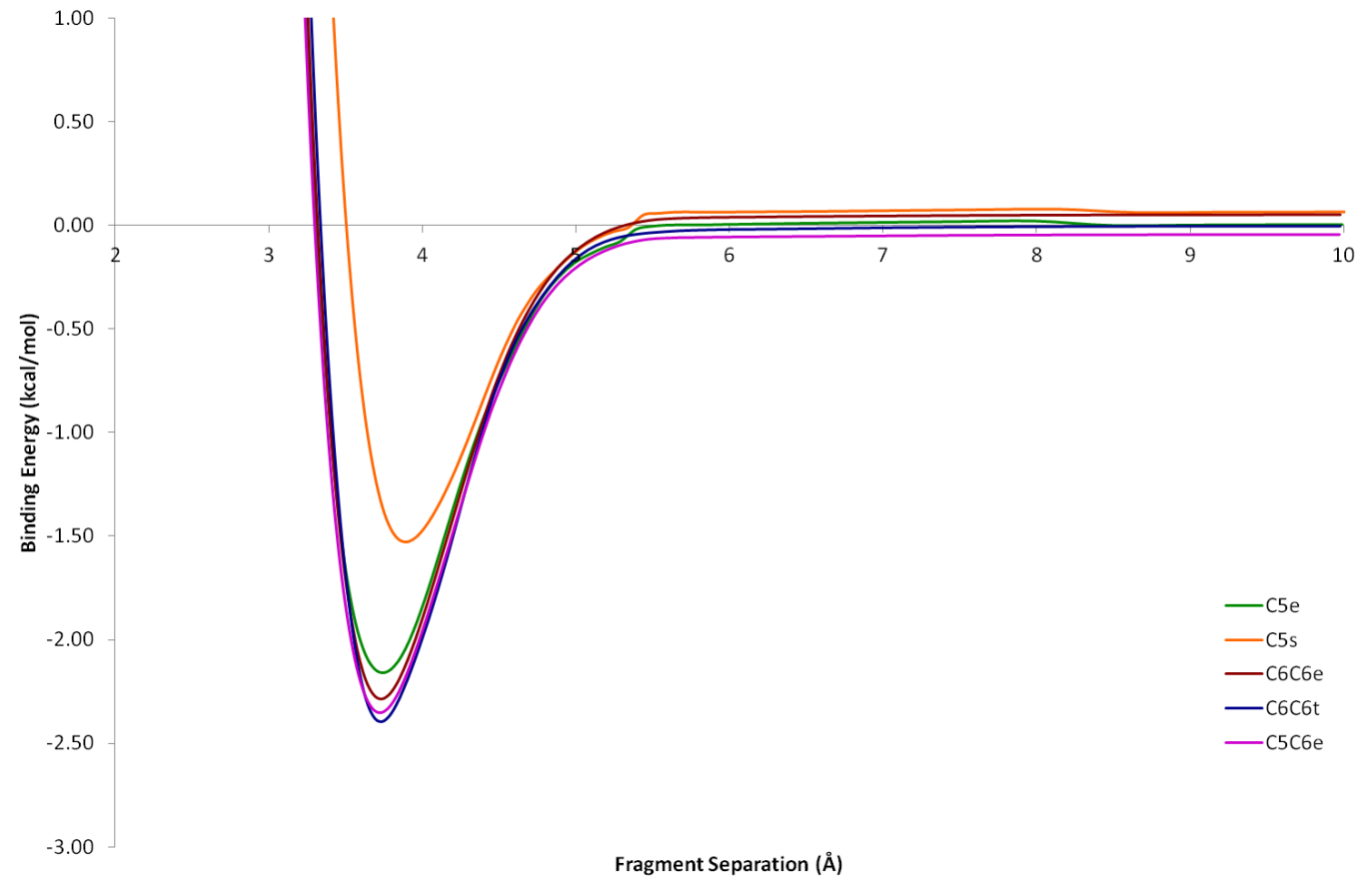

Figure 3.10. Energy profiles generated using the CAM-B3LYP functional with the fine integration grid. 
with the B3LYP functional was removed and replaced with better modelling of the energy decay characteristics. Several geometries failed to converge to zero in the longrange limit.

$\omega \mathrm{B} 97 \mathrm{X}$ calculated that all geometries except $\mathrm{C} 5 \mathrm{~s}$ were local minima. Weaker than expected binding energies of around $9.3 \mathrm{kcal} \mathrm{mol}^{-1}$ were obtained. Fragment separation distances, at $3.4 \AA$, were slightly longer than expected. Interaction energy decay was shown by energy profiles (Figure 3.11) to be too rapid at short range.

B97-D and $\omega$ B97X-D provided the most reliable and similar results. Binding energies were slightly lower than the corresponding SCS-MP2 results, which was expected as these were still slightly overestimated. $\omega \mathrm{B} 97 \mathrm{X}-\mathrm{D}$ binding energies were $3 \%$ to $5 \%$ lower than the corresponding B97-D geometries. In both cases C5C6e was the lowest energy minimum and C5s was a high energy transition state. Though C5C6e was the lowest energy geometry, thermal energy at room temperature $\left(0.59 \mathrm{kcal} \mathrm{mol}^{-1}\right)$ is sufficient to allow free rotation between the geometries investigated. This means that there would not be a preferred orientation in a crystal structure, which was found by Dawe et al. in the disorder of $\mathrm{C}_{60}$ and modelling of four different geometries of their

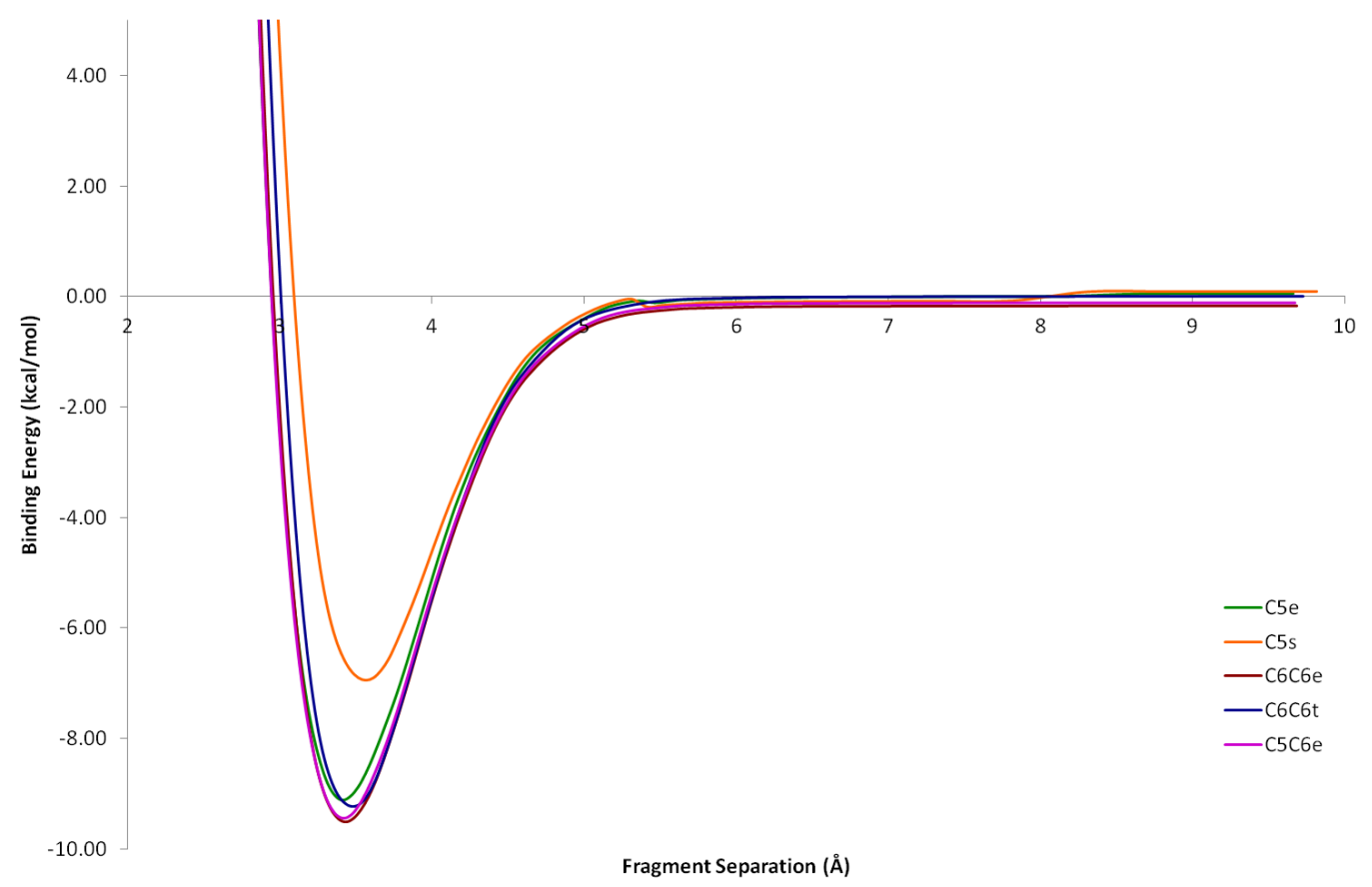

Figure 3.11. Energy profiles generated using the $\omega \mathrm{B} 97 \mathrm{X}$ functional with the fine integration grid 
$\mathrm{C}_{60} @$ corannulene complex crystal structure. $\frac{30}{30}$ Energy profiles generated using the B97-D and $\omega$ B97X-D functionals (Figures 3.12 and 3.13 respectively) showed smooth exponential decay of interaction energy as fragment separation increases converging to zero as was expected.

\subsubsection{Integration Grids}

Several of the functionals investigated showed one or both of two types of numerically induced errors in their energy profiles. They were non convergence to zero in the longrange limit and unexplained spiking seen in some of the energy profiles. The long-range limit had a deviation from zero of up to $0.2 \mathrm{kcal} \mathrm{mol}^{-1}$. As the magnitude was similar across the various functionals, this was ascribed to numerical inaccuracies. Decreasing the integration grid size attempted to account for this. Concurrent work within the group had shown similar spiking evident in rotation of $\mathrm{a}_{60}$ molecule on a graphene flake. .80 Decreasing the integration grid size was able to remove the effect, so the method was applied in this instance.

The increase in integration grid size had only a minor effect on the binding energies and fragment separation distances of the complexes. Changes in binding energy were generally less than $1 \%$. The minor energy differences between the different geometries meant that there was some variation in their relative energies. For example, $\omega$ B97X-D showed C5C6e as the most stable geometry with the fine grid, but C6C6e with the benchmark grid. BP86 gave attractive interactions with all geometries when using the benchmark grid, though the magnitudes were so minor they effectively showed no interaction between the fragments. Fragment separation distances had only negligible changes.

\subsubsection{Convergence Error}

Decreasing the grid size from fine to ultrafine resulted in a 50\% or greater decrease in the deviation from zero for those functionals in which it was most noticeable: B3LYP, BP86 and $\tau$-HCTH (see Appendix A for ultrafine grid energy profiles). Other functionals had the convergence error effectively removed, though there was still some slight deviation. The final benchmark grid size eliminated all deviation for the functionals which showed only slight effects, eg PW91 (Figure 3.14). BP86 (Figure 3.15) and B3LYP (Figure 3.16) had convergence errors eliminated for four of the five geometries. 


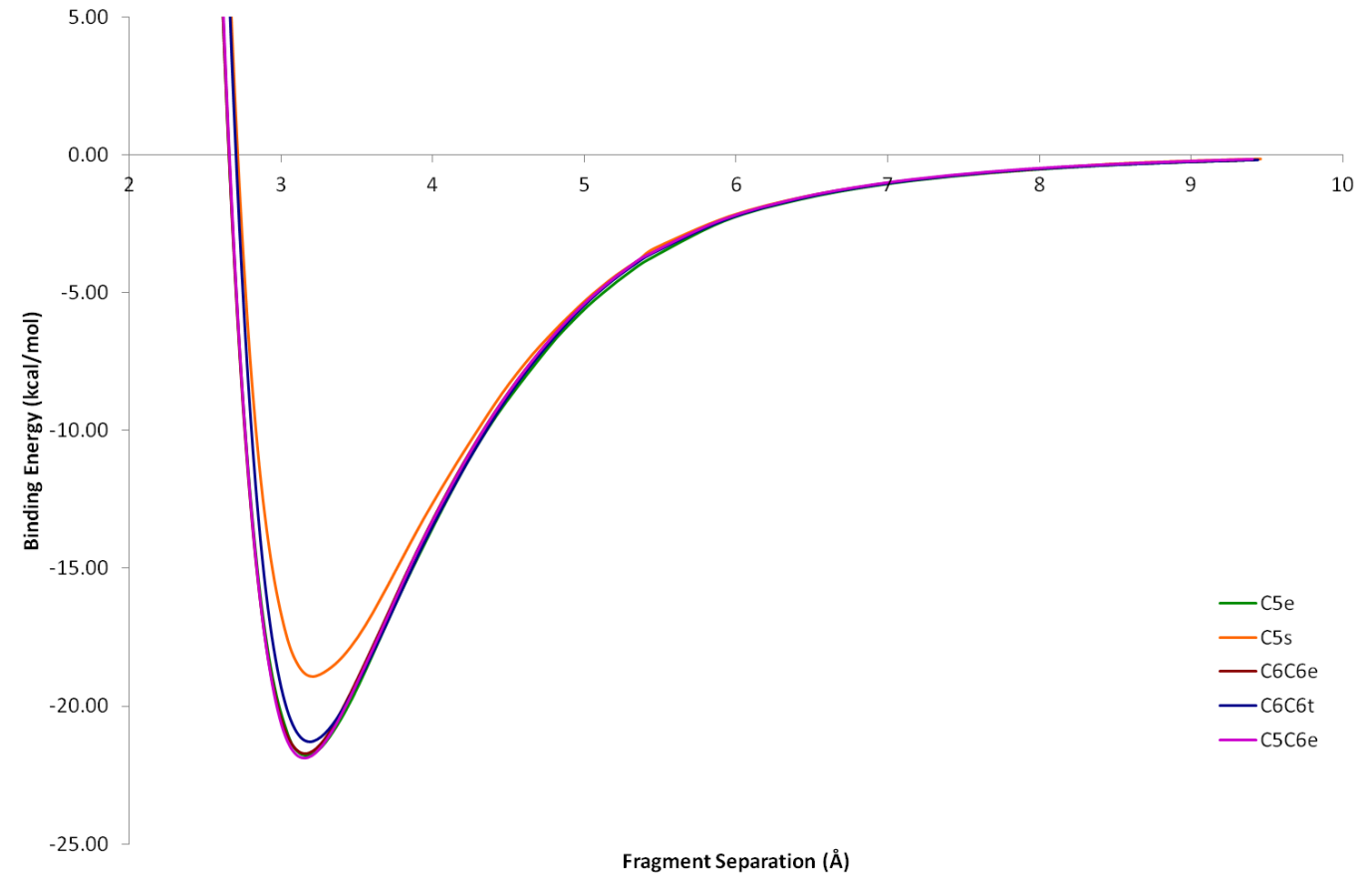

Figure 3.12. Energy profiles generated using the B97-D functional with the fine integration grid.

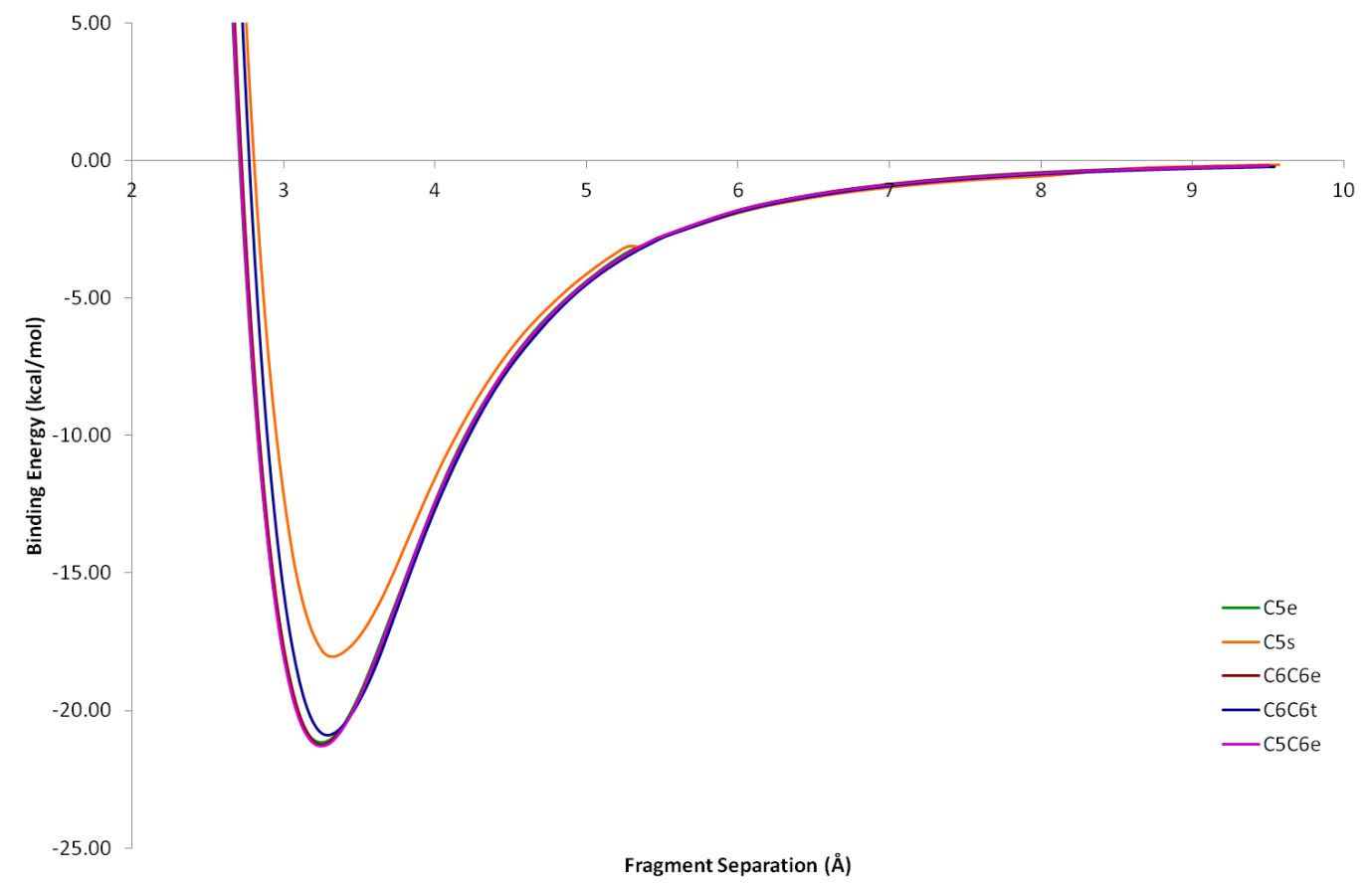

Figure 3.13. Energy profiles generated using the $\omega \mathrm{B} 97 \mathrm{X}-\mathrm{D}$ functional with the fine integration grid. 
The inability to eliminate all convergence errors for these functionals was interesting, but because they were clearly inadequate for use in modelling these systems, they were deemed unimportant and were not investigated further.

\subsubsection{Energy Profile Spiking}

Spiking in the energy profiles was most noticeable with the C5s geometry of the B3LYP and BP86 functionals. Use of the ultrafine grid significantly diminished the size of the spikes. The ultrafine grid was sufficient to effectively eliminate the minor spiking noticed in the CAM-B3LYP, $\tau$-HCTH and $\omega$ B97X functionals. Benchmark grid was required to eliminate the spiking observed with the BP86 (Figure 3.15) and B3LYP (Figure 3.16) functionals.

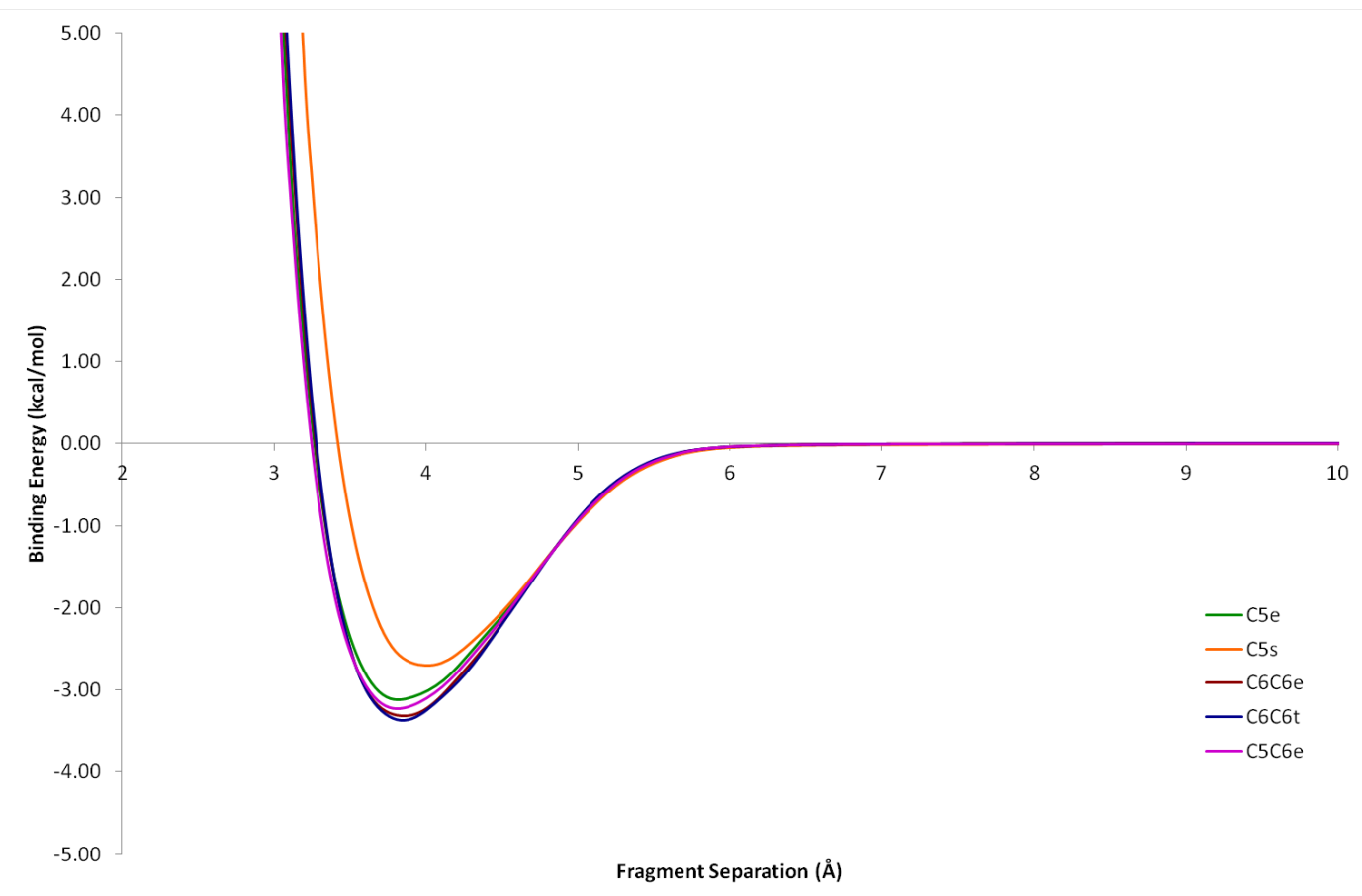

Figure 3.14. Energy profiles generated using the PW91 functional with the benchmark integration grid. Convergence errors present in the coarser grids have been eliminated. 


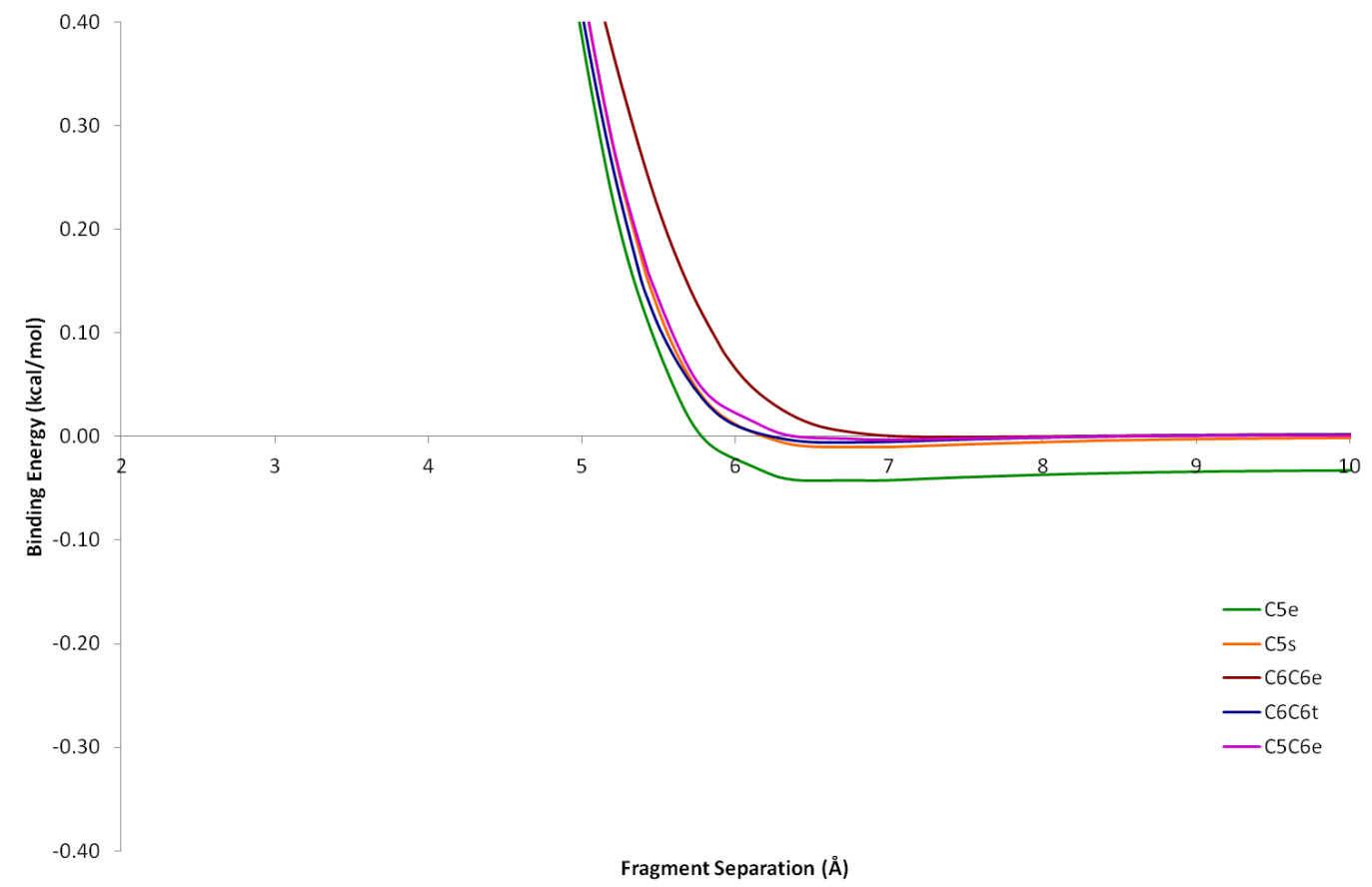

Figure 3.15. Energy profiles generated using the BP86 functional with the benchmark integration grid. Convergence errors present in the coarser grids have been eliminated for four of the geometries but are still present for C5e.

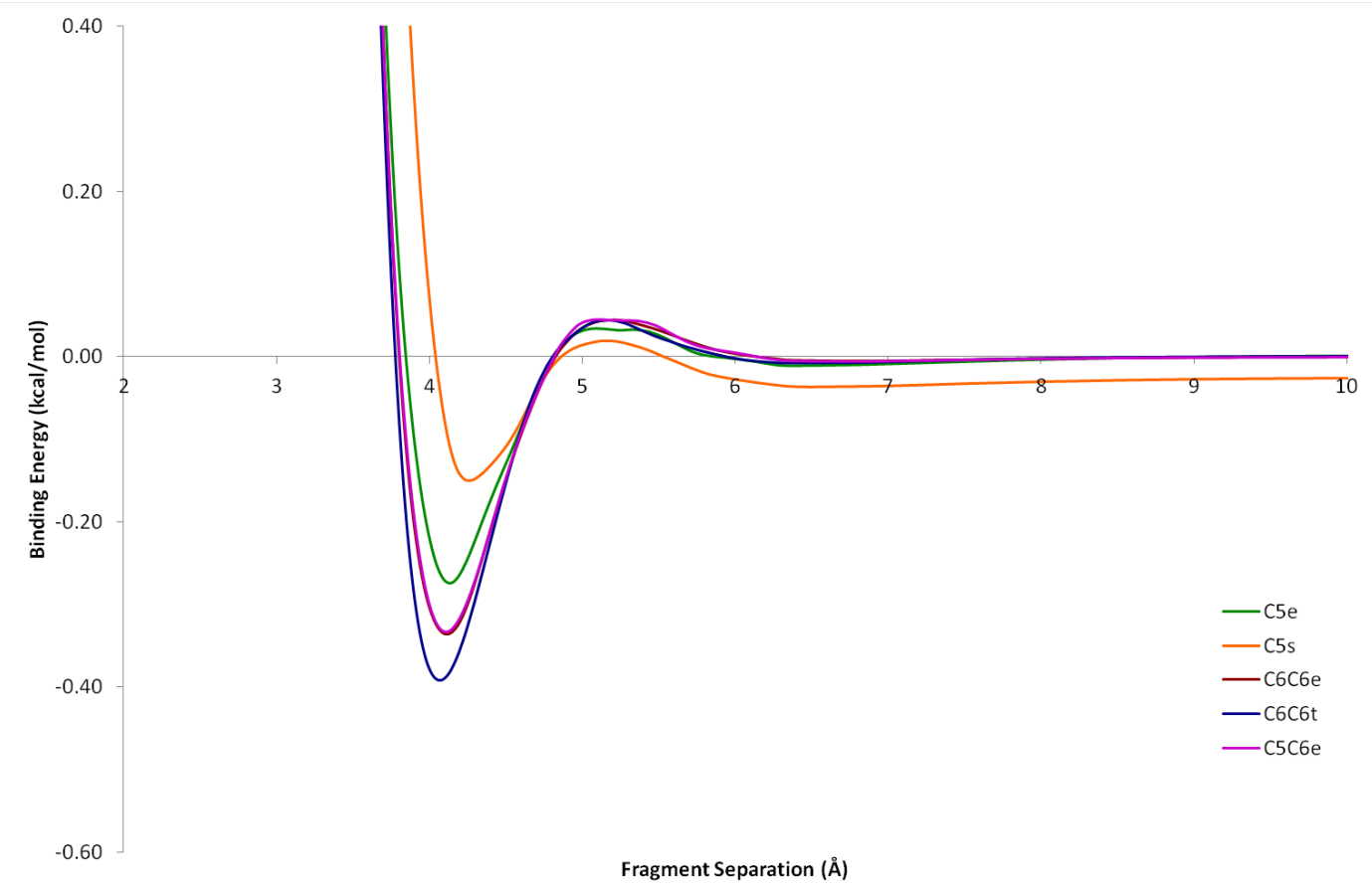

Figure 3.16. Energy profiles generated using the B3LYP functional with the benchmark integration grid. Spiking that was evident in the coarser grids, especially in the C5s geometry, has been eliminated. 


\section{Chapter 4}

\section{Summary of Results}

Across all the functionals evaluated, there was no clearly preferred geometry for the $\mathrm{C}_{60} @$ corannulene complex. As such, at normal experimental temperatures, free rotation of the $\mathrm{C}_{60}$ relative to the corannulene would be expected. This was in accordance with the x-ray crystal structure determination of Dawe et al. where the $\mathrm{C}_{60}$ was found to be disordered and modelled in four distinct geometries. ${ }^{[30}$ Low temperature work could enable geometry selectivity.

\subsection{Functionals}

The functionals evaluated showed a wide range of results. Functionals containing dispersion correction terms, B97-D and $\omega$ B97X-D, provided the best results. They were similar enough that either would be useful in investigating larger systems. $\omega$ B97X-D was chosen in this instance as it was the original functional used. BP86 and B3LYP provided very poor results and neither is recommended for use in the types of systems investigated here. Long-range corrected functionals CAM-B3LYP, M06-2X and $\omega$ B97X were found to have possible use for studying trends, but not absolute energies. Of them, M06-2X was the best. Binding energies obtained with PW91 and $\tau$-HCTH were too low for the functionals to be of use in their current form. Including a dispersion correction term, to give PW91-D and $\tau$-HCTH-D respectively, could provide additional, reliable functionals. 


\subsection{Integration Grid}

Integration grid size was found to have no major effect on the results obtained with good functionals, such as B97-D and $\omega$ B97X-D. Using the computationally cheaper fine grid would be expected to provide acceptable results. Poor functionals, such as B3LYP, BP86 and $\tau$-HCTH, were found to have a strong dependence on integration grid size. The finer grids were required to remove some of the numerically induced errors which were seen to occur. However, as they did not provide good results, this has no bearing on the recommended use of the fine grid. 


\section{Chapter 5}

\section{Functionalised Bowls}

Binding properties and changes in calculated NMR shifts were investigated for a variety of corannulene based bowls. The bowls chosen, shown in Figure 5.1, were: corannulene (5.11), circumcorannulene (5.1f), and pentaindenocorannulene $(\mathbf{5 . 1 g})$ to investigate the effect of increasing the size of the rigid $\pi$-system; mono- 5 5.1a), sympenta- 5.1b), and deca- 5.1c methylcorannulene to investigate the effect of sequential group addition to the rim; sym-pentaphenylcorannulene $5.1 \mathrm{5}$ ) to investigate the effect of having aromatic substituents; sym-pentapropylcorannulene $[\mathbf{5 . 1 k})$, sym-pentakis(propyloxy)corannulene (5.1h), and sym-pentakis(propylthio)corannulene 5.1i) to investigate the effect of changing the linking atom; and sym-pentakis(4-methoxyphenylthio)corannulene $(\mathbf{5 . 1 \mathbf { j }})$, sym-pentakis(2-naphthylthio)corannulene $(\mathbf{5 . 1 \mathrm { m }})$ and pentakis(1,4-benzodithiino)corannulene (5.1e) to investigate the effect of sulfur-linked aromatic substituents.

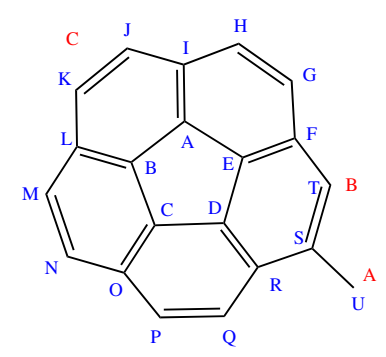

(a)

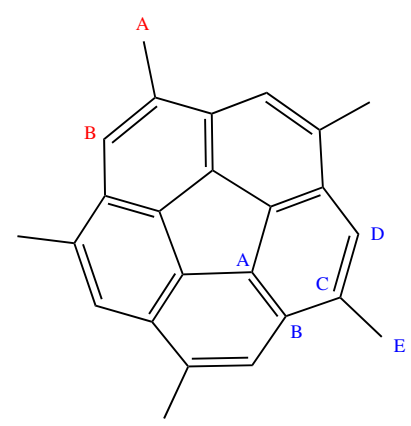

(b)

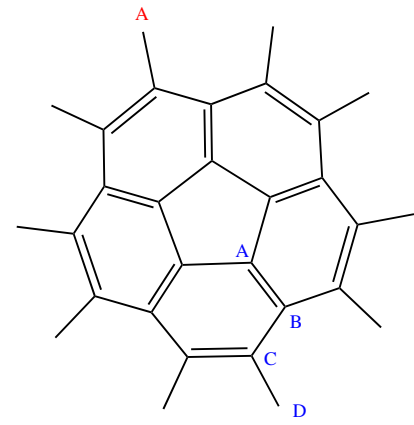

(c)

Figure 5.1. Functionalised bowl structures. Red labels mark the NMR equivalent hydrogens and blue mark the carbons. The bowls are: (a) monomethylcorannulene $\left(\mathrm{H}_{\mathrm{C}}\right.$ includes all hydrogens except $\mathrm{H}_{\mathrm{A}}$ and $\mathrm{H}_{\mathrm{B}}$ ); (b) sym-pentamethylcorannulene; (c) decamethylcorannulene; 


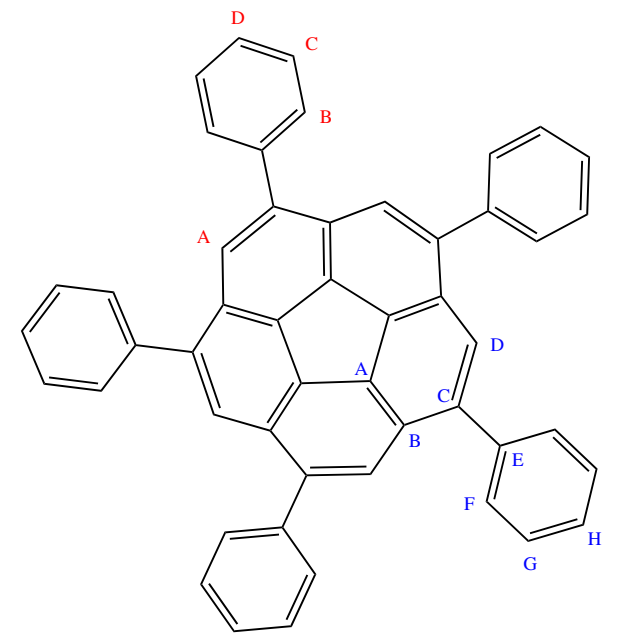

(d)

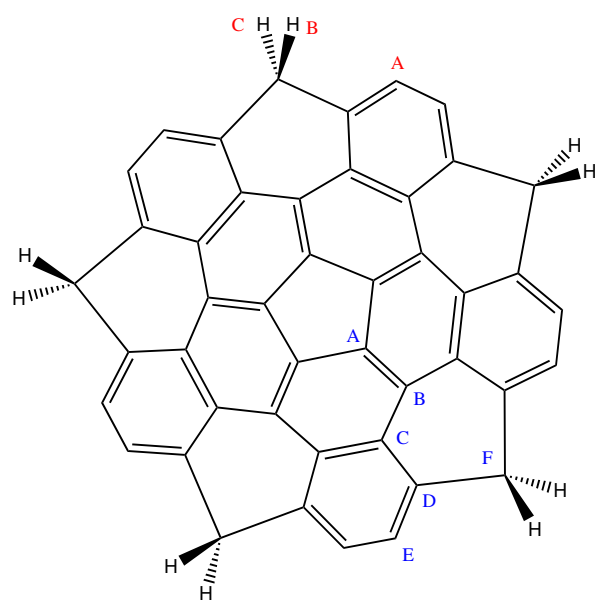

(f)

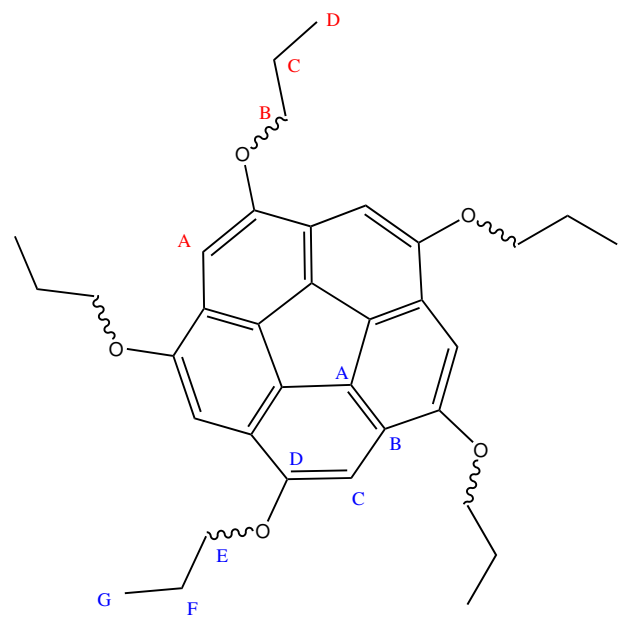

(h)

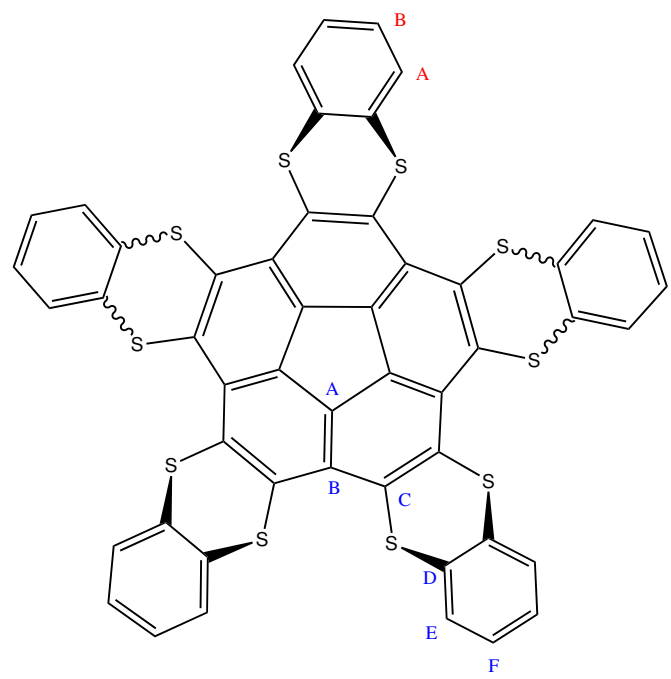

(e)

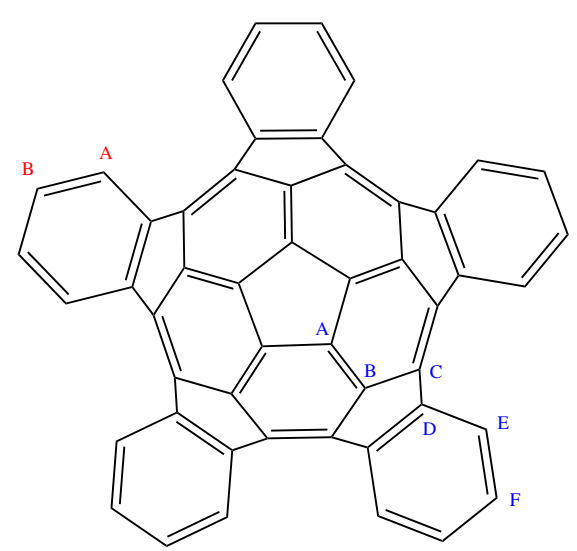

(g)

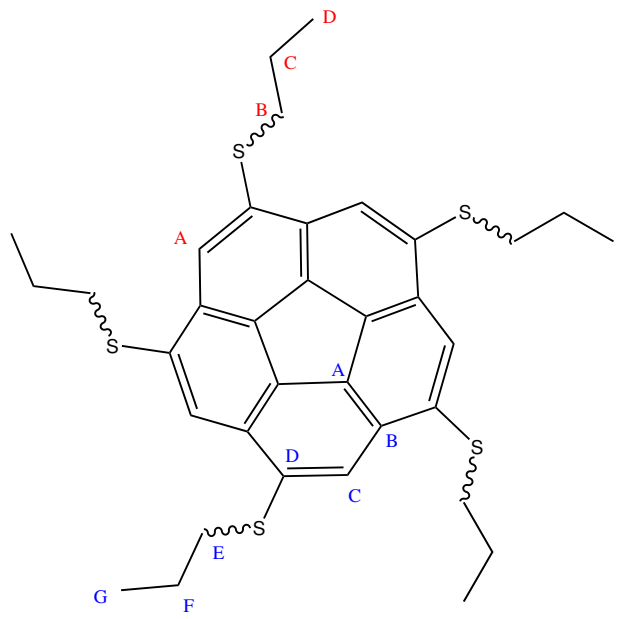

(i)

Figure 5.1 continued. (d) pentaphenylcorannulene; (e) pentakis(1,4-benzodithiino)corannulene, where the flaps or either all up (-AU) or as in the crystal structure of Bancu et al. ${ }^{19}$ (-CS); (f) circumcorannulene; (g) pentaindenocorannulene; (h) sym-pentakis(propyloxy)corannulene; (i) sym-pentakis(propylthio)corannulene; 


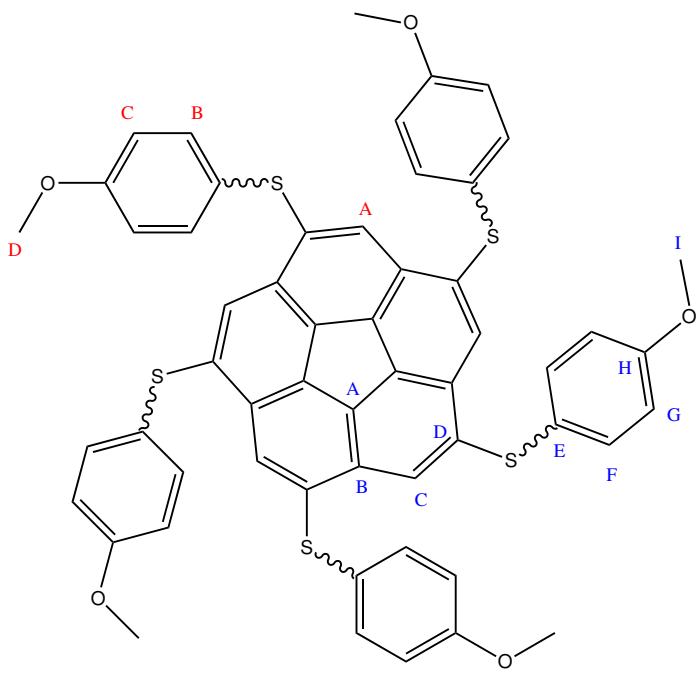

(j)

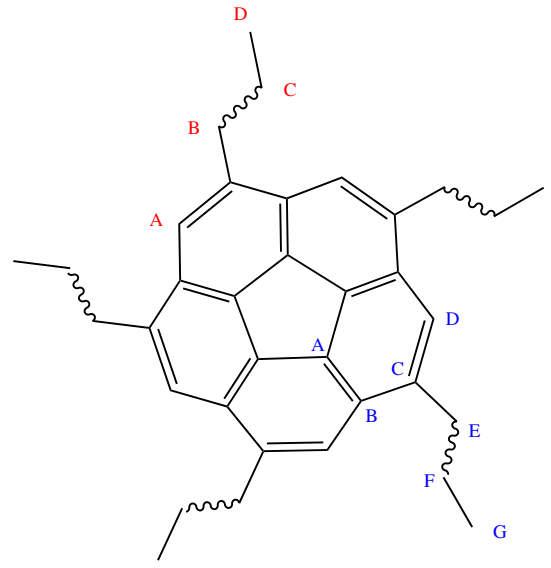

(k)

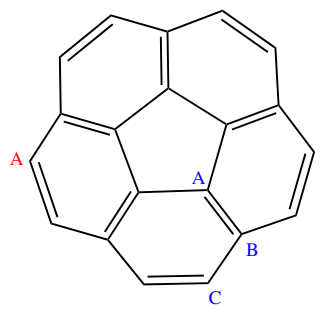

(l)

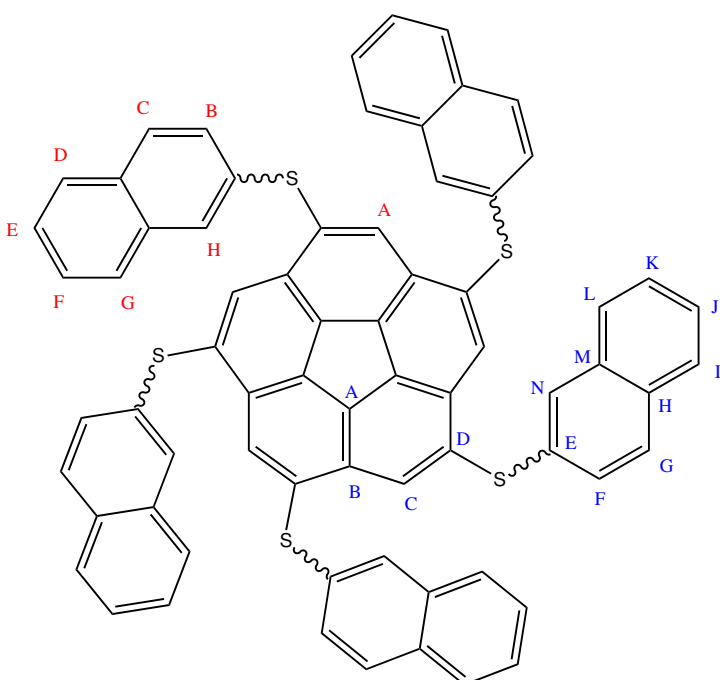

(m)

Figure 5.1 continued. (j) sym-pentakis(4-methoxyphenylthio)corannulene; k sympentapropylcorannulene; (1) corannulene; and (m) sym-pentakis(2-naphthylthio)corannulene.

\subsection{Results}

\subsubsection{Binding Energies}

Binding energies were calculated (Equation 3.1) for the functionalised bowl- $\mathrm{C}_{60} \mathrm{com}$ plexes. The results are presented in Table 5.1. The geometries refer to the input geometry and may not reflect the final geometry obtained through optimisation as rotation of $\mathrm{C}_{60}$ occurred in some instances. Results obtained for $\mathrm{C}_{60} @ \mathbf{5 . 1 1}$ are included for reference. 
Table 5.1. Binding energies of the functionalised bowl complexes. All values are in kcal $\mathrm{mol}^{-1}$.

\begin{tabular}{|c|c|c|c|c|c|}
\hline Bowl & C5C6e & $\mathrm{C} 5 \mathrm{e}$ & $\mathrm{C} 5 \mathrm{~s}$ & C6C6e & C6C6t \\
\hline $\mathrm{C}_{60} @ 5.11$ & -21.299 & -21.172 & -18.036 & -21.256 & -20.912 \\
\hline $\mathrm{C}_{60} @ \overrightarrow{\overline{\mathbf{5 . 1 f}}}$ & -41.009 & -39.412 & -41.698 & -41.026 & -43.401 \\
\hline $\mathrm{C}_{60} @ \overrightarrow{\overline{\mathbf{5 . 1 g}}}$ & -44.120 & -42.240 & -45.053 & -44.262 & -43.546 \\
\hline $\mathrm{C}_{60} @ \overline{\mathbf{5 . 1 a}}$ & -23.017 & -22.467 & -22.474 & -22.867 & -22.659 \\
\hline $\mathrm{C}_{60} @ \overline{\mathbf{5 . 1 b}}$ & -28.448 & -28.346 & -25.443 & -28.671 & -27.757 \\
\hline $\mathrm{C}_{60} @ \overline{\mathbf{5 . 1 c}}$ & -32.972 & -32.799 & -30.298 & -33.106 & -33.171 \\
\hline $\mathrm{C}_{60} @ \overline{\mathbf{5 . 1 d}}$ & -36.669 & -36.239 & -35.522 & -36.504 & -36.619 \\
\hline $\mathrm{C}_{60} @$ 5.1k$-D$ & -30.161 & -30.361 & -29.520 & -30.409 & -30.234 \\
\hline$C_{60} @ \overline{\mathbf{5 . 1 h}}-D$ & -27.876 & -28.236 & -28.825 & -28.395 & -27.947 \\
\hline $\mathrm{C}_{60} @$ 5.1i-D & -27.815 & -28.493 & -28.399 & -27.595 & -27.485 \\
\hline $\mathrm{C}_{60} @ \overline{\mathbf{5 . 1 k}} \cdot \mathbf{U}$ & -33.238 & -30.027 & -29.299 & -32.902 & -32.904 \\
\hline $\mathrm{C}_{60} @ \mathbf{\overline { \mathbf { 5 . 1 h } } \cdot \mathbf { U }}$ & -36.159 & -36.970 & -37.222 & -36.135 & -36.261 \\
\hline $\mathrm{C}_{60} @ \overline{\mathbf{5 . 1 i}-\mathbf{U}}$ & -42.246 & -36.907 & -44.905 & -38.722 & -38.700 \\
\hline $\mathrm{C}_{60} @ \overline{\mathbf{5 . 1 e}}-\mathbf{A U}$ & -57.265 & -57.684 & -56.329 & -56.783 & -56.151 \\
\hline $\mathrm{C}_{60} @ \overline{\mathbf{5 . 1 e}}-\mathbf{C S}$ & -40.057 & -40.368 & -39.862 & -40.980 & -39.238 \\
\hline$C_{60} @ \overline{\mathbf{5 . 1 j}} \cdot \mathbf{D}$ & -28.749 & -29.472 & -26.520 & -29.006 & -28.875 \\
\hline $\mathrm{C}_{60} @ \mathbf{5 . 1 m}-D$ & -28.875 & -30.030 & -26.660 & -29.267 & -29.031 \\
\hline $\mathrm{C}_{60} @ \overline{\mathbf{5 . 1 j} \cdot \mathbf{U}}$ & -61.304 & -66.003 & -65.124 & -61.390 & -58.450 \\
\hline $\mathrm{C}_{60} @ \overline{\mathbf{5 . 1 m}} \cdot \mathbf{U}$ & -71.394 & -71.581 & -69.185 & -70.230 & -68.368 \\
\hline
\end{tabular}

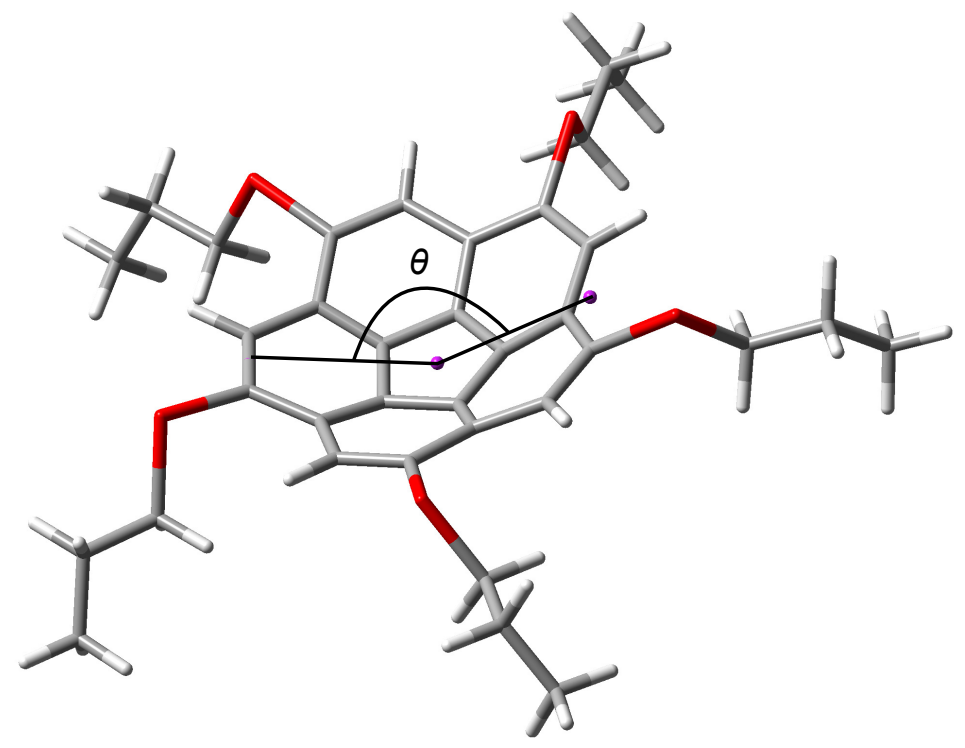

Figure 5.2. The internal angle, $\theta$, is defined as the angle measured between the midpoints opposite sides of the corannulene skeleton and the centre of the hub, as shown on 5.1h.D. 
Table 5.2. Corannulene hub- $\mathrm{C}_{60}$ separation distances and internal bowl angle for the functionalised bowl complexes. All separation distances are in $\AA$ and angles in degrees.

\begin{tabular}{|c|c|c|c|c|c|c|}
\hline Bowl & C5C6e & $\mathrm{C} 5 \mathrm{e}$ & $\mathrm{C} 5 \mathrm{~s}$ & C6C6е & C6C6t & $\theta$ \\
\hline $\mathrm{C}_{60} @ \mathbf{5 . 1 1}$ & 3.252 & 3.247 & 3.324 & 3.251 & 3.290 & $148.4^{\circ}$ \\
\hline $\mathrm{C}_{60} @ \overline{\overline{\mathbf{5 . 1 f}}}$ & 3.489 & 3.471 & 3.496 & 3.488 & 3.447 & $139.3^{\circ}$ \\
\hline $\mathrm{C}_{60} @ \overrightarrow{\overline{\mathbf{5 . 1 g}}}$ & 4.017 & 4.035 & 3.965 & 4.026 & 4.049 & $127.8^{\circ}$ \\
\hline $\mathrm{C}_{60} @ \mathbf{5 . 1 a}$ & 3.249 & 3.245 & 3.245 & 3.248 & 3.283 & $148.4^{\circ}$ \\
\hline $\mathrm{C}_{60} @ \overline{\mathbf{5 . 1 b}}$ & 3.203 & 3.217 & 3.301 & 3.215 & 3.255 & $148.5^{\circ}$ \\
\hline $\mathrm{C}_{60} @$ 5.1c & 3.042 & 3.048 & 3.095 & 3.039 & 3.066 & $158.0^{\circ}$ \\
\hline $\mathrm{C}_{60} @ \overline{\mathbf{5 . 1 d}}$ & 3.257 & 3.286 & 3.278 & 3.256 & 3.256 & $147.8^{\circ}$ \\
\hline$C_{60} @ \overline{\mathbf{5 . 1 k}}-\mathbf{D}$ & 3.208 & 3.200 & 3.245 & 3.206 & 3.202 & $149.0^{\circ}$ \\
\hline $\mathrm{C}_{60} @ \overline{\mathbf{5 . 1 h}} \cdot \mathbf{D}$ & 3.248 & 3.228 & 3.224 & 3.268 & 3.271 & $147.4^{\circ}$ \\
\hline $\mathrm{C}_{60} @ \overline{\mathbf{5 . 1 i}-D}$ & 3.248 & 3.232 & 3.308 & 3.236 & 3.246 & $148.8^{\circ}$ \\
\hline $\mathrm{C}_{60} @ \overline{\mathbf{5 . 1 \mathbf { k }}} \cdot \mathbf{U}$ & 3.251 & 3.685 & 3.757 & 3.238 & 3.233 & $148.4^{\circ}$ \\
\hline $\mathrm{C}_{60} @ \overline{\mathbf{5 . 1 h} \cdot \mathbf{U}}$ & 3.611 & 3.690 & 3.688 & 3.590 & 3.543 & $142.4^{\circ}$ \\
\hline $\mathrm{C}_{60} @ \overline{\mathbf{5 . 1 i}-\mathbf{U}}$ & 3.278 & 3.439 & 3.170 & 3.259 & 3.275 & $146.7^{\circ}$ \\
\hline $\mathrm{C}_{60} @ \overrightarrow{\mathbf{5 . 1 e}}-\mathbf{A U}$ & 3.065 & 3.097 & 3.123 & 3.080 & 3.075 & $158.0^{\circ}$ \\
\hline $\mathrm{C}_{60} @$ 5.1e-CS & 3.068 & 3.088 & 3.090 & 3.073 & 3.071 & $158.8^{\circ}$ \\
\hline$C_{60} @ \mathbf{5 . 1 j} \cdot D$ & 3.213 & 3.186 & 3.286 & 3.236 & 3.239 & $149.9^{\circ}$ \\
\hline$C_{60} @ \overline{\mathbf{5 . 1 m}}-\mathbf{D}$ & 3.240 & 3.199 & 3.217 & 3.207 & 3.216 & $150.1^{\circ}$ \\
\hline $\mathrm{C}_{60} @ \overline{\mathbf{5 . 1 j} \cdot \mathbf{U}}$ & 3.132 & 3.164 & 3.137 & 3.133 & 3.163 & $146.9^{\circ}$ \\
\hline $\mathrm{C}_{60} @ \overline{\mathbf{5 . 1 m}}-\mathbf{U}$ & 3.208 & 3.222 & 3.214 & 3.143 & 3.184 & $148.3^{\circ}$ \\
\hline
\end{tabular}

\subsubsection{Geometric Parameters}

Fragment separation was calculated in the same manner as in $\S 3.1 .2$. The internal angle of the corannulene skeleton within uncomplexed bowls was measured. It was defined as the angle between the midpoints of opposite sides of corannulene and the centre of the corannulene hub (Figure 5.2). The results obtained are shown in Table 5.2. $\mathrm{C}_{60} @ \mathbf{5 . 1 1}$ results are included for reference.

\subsection{3 ${ }^{1}$ H NMR}

${ }^{1} \mathrm{H}$ NMR calculated values for the functionalised bowls were referenced to the calculated absolute TMS shift of $32.203 \mathrm{ppm}$. A scaling factor was determined with a regression analysis of the calculated values and their respective experimental values, and thermally weighted complex and fragment values scaled accordingly. Changes in the chemical shifts upon complexation were calculated as the difference between the scaled thermally weighted complex and fragment values. Results are presented in Table 5.3 . 
Table 5.3. Calculated ${ }^{1} \mathrm{H}$ NMR shifts for the bowls and complexes. Values for the weighted bowl and complex are those of their thermally weighted averages. All values are in ppm.

\begin{tabular}{|c|c|c|c|c|}
\hline $\mathrm{H}$ & Bowl & Weighted Bowl & Weighted Complex & $\Delta \delta$ \\
\hline \multicolumn{5}{|c|}{$\mathrm{C}_{60} @ 5.11$} \\
\hline A & 7.776 & 7.817 & 7.922 & 0.105 \\
\hline \multicolumn{5}{|c|}{$\mathrm{C}_{60} @ \mathbf{5 . 1 f}$} \\
\hline A & 7.468 & 7.501 & 7.534 & 0.033 \\
\hline B & 4.011 & 4.173 & 4.218 & 0.045 \\
\hline $\mathrm{C}$ & 4.914 & 5.067 & 5.105 & 0.037 \\
\hline \multicolumn{5}{|c|}{$\mathrm{C}_{60} @ 5.1 \mathrm{~g}$} \\
\hline A & 8.011 & 8.053 & 8.066 & 0.013 \\
\hline B & 7.351 & 7.398 & 7.400 & 0.001 \\
\hline \multicolumn{5}{|c|}{$\mathrm{C}_{60} @ 5.1 \mathrm{5}$} \\
\hline A & 7.858 & 8.035 & 8.058 & 0.023 \\
\hline B & 7.687 & 7.794 & 7.868 & 0.073 \\
\hline $\mathrm{C}$ & 7.485 & 7.560 & 7.558 & -0.002 \\
\hline $\mathrm{D}$ & 7.427 & 7.491 & 7.492 & 0.002 \\
\hline \multicolumn{5}{|c|}{$\mathrm{C}_{60} @ 5.1 \mathrm{a}$} \\
\hline A & 2.718 & 2.914 & 3.013 & 0.099 \\
\hline B & 7.410 & 7.460 & 7.431 & -0.029 \\
\hline $\mathrm{C}$ & 7.772 & 7.813 & 7.882 & 0.069 \\
\hline \multicolumn{5}{|c|}{$\mathrm{C}_{60} @ \mathbf{5 . 1 b}$} \\
\hline A & 2.648 & 2.856 & 2.886 & 0.029 \\
\hline B & 7.536 & 7.584 & 7.636 & 0.052 \\
\hline \multicolumn{5}{|c|}{$\mathrm{C}_{60} @ 5.1 \mathrm{c}$} \\
\hline A & 2.710 & 2.913 & 2.922 & 0.009 \\
\hline \multicolumn{5}{|c|}{ 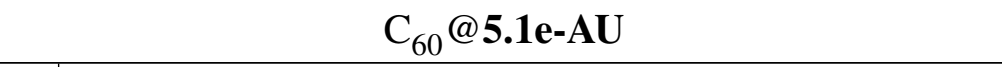 } \\
\hline A & 7.711 & 7.770 & 7.898 & 0.128 \\
\hline B & 7.257 & 7.323 & 7.357 & 0.034 \\
\hline \multicolumn{5}{|c|}{$\mathrm{C}_{60} @ 5.1 \mathrm{e}-\mathrm{CS}$} \\
\hline A & 7.689 & 7.761 & 7.773 & 0.012 \\
\hline B & 7.309 & 7.410 & 7.417 & 0.007 \\
\hline \multicolumn{5}{|c|}{$\mathrm{C}_{60} @ 5.1 \mathrm{~m}-\mathrm{D}$} \\
\hline A & 7.791 & 7.770 & 7.696 & -0.074 \\
\hline
\end{tabular}


Table 5.3 - Continued from previous page

\begin{tabular}{|c|c|c|c|c|}
\hline $\mathrm{H}$ & Bowl & Weighted Bowl & Weighted Complex & $\Delta \delta$ \\
\hline \multicolumn{5}{|c|}{$C_{60} @ 5.1 \mathrm{~m}-\mathrm{D}$} \\
\hline B & 7.050 & 7.219 & 7.156 & -0.063 \\
\hline $\mathrm{C}$ & 7.442 & 7.500 & 7.484 & -0.016 \\
\hline $\mathrm{D}$ & 7.610 & 7.618 & 7.603 & -0.015 \\
\hline $\mathrm{E}$ & 7.458 & 7.511 & 7.497 & -0.014 \\
\hline $\mathrm{F}$ & 7.490 & 7.566 & 7.570 & 0.003 \\
\hline G & 7.808 & 7.834 & 7.827 & -0.006 \\
\hline $\mathrm{H}$ & 8.059 & 8.030 & 8.062 & 0.032 \\
\hline \multicolumn{5}{|c|}{$\mathrm{C}_{60} @ \mathbf{5 . 1 \mathbf { j }} \cdot \mathbf{D}$} \\
\hline A & 8.902 & 7.719 & 7.663 & -0.057 \\
\hline B & 8.048 & 7.486 & 7.472 & -0.014 \\
\hline $\mathrm{C}$ & 6.612 & 6.756 & 6.747 & -0.009 \\
\hline $\mathrm{D}$ & 3.538 & 3.867 & 3.868 & 0.001 \\
\hline \multicolumn{5}{|c|}{$\mathrm{C}_{60} @ 5.1 \mathrm{~m}-\mathrm{U}$} \\
\hline A & 8.794 & 9.159 & 9.131 & -0.029 \\
\hline B & 5.444 & 8.576 & 8.509 & -0.066 \\
\hline $\mathrm{C}$ & 3.851 & 8.037 & 8.040 & 0.003 \\
\hline $\mathrm{D}$ & 7.109 & 7.762 & 7.777 & 0.016 \\
\hline $\mathrm{E}$ & 7.420 & 7.466 & 7.509 & 0.044 \\
\hline $\mathrm{F}$ & 7.253 & 7.495 & 7.490 & -0.005 \\
\hline $\mathrm{G}$ & 7.614 & 7.832 & 7.911 & 0.079 \\
\hline $\mathrm{H}$ & 8.034 & 8.355 & 8.538 & 0.183 \\
\hline \multicolumn{5}{|c|}{$C_{60} @ \mathbf{5 . 1 j} \cdot \mathbf{U}$} \\
\hline A & 8.533 & 8.880 & 8.912 & 0.032 \\
\hline B & 6.209 & 8.019 & 8.097 & 0.079 \\
\hline $\mathrm{C}$ & 6.023 & 6.692 & 6.792 & 0.100 \\
\hline D & 3.464 & 3.735 & 3.667 & -0.068 \\
\hline \multicolumn{5}{|c|}{$\mathrm{C}_{60} @ 5.1 \mathrm{i}-\mathrm{D}$} \\
\hline A & 8.316 & 8.309 & 8.263 & -0.046 \\
\hline B & 3.092 & 3.335 & 3.303 & -0.032 \\
\hline $\mathrm{C}$ & 1.815 & 2.089 & 2.096 & 0.007 \\
\hline $\mathrm{D}$ & 1.117 & 1.397 & 1.403 & 0.006 \\
\hline
\end{tabular}


Table 5.3-Continued from previous page

\begin{tabular}{|c|c|c|c|c|}
\hline $\mathrm{H}$ & Bowl & Weighted Bowl & Weighted Complex & $\Delta \delta$ \\
\hline \multicolumn{5}{|c|}{$C_{60} @ 5.1 h-D$} \\
\hline A & 7.360 & 7.276 & 7.247 & -0.029 \\
\hline B & 4.350 & 4.614 & 4.628 & 0.014 \\
\hline $\mathrm{C}$ & 2.207 & 2.456 & 2.478 & 0.022 \\
\hline D & 1.072 & 1.349 & 1.361 & 0.013 \\
\hline \multicolumn{5}{|c|}{$\mathrm{C}_{60} @ 5.1 \mathrm{k}-\mathrm{D}$} \\
\hline A & 7.539 & 7.584 & 7.633 & 0.049 \\
\hline B & 2.947 & 3.110 & 3.106 & -0.005 \\
\hline $\mathrm{C}$ & 2.191 & 2.481 & 2.491 & 0.009 \\
\hline $\mathrm{D}$ & 1.293 & 1.551 & 1.551 & 0.000 \\
\hline \multicolumn{5}{|c|}{$\mathrm{C}_{60} @ \mathbf{5 . 1 i} \cdot \mathbf{U}$} \\
\hline A & 8.770 & 8.616 & 8.679 & 0.063 \\
\hline B & 2.474 & 2.652 & 2.791 & 0.139 \\
\hline $\mathrm{C}$ & 0.165 & 2.325 & 2.342 & 0.017 \\
\hline $\mathrm{D}$ & 0.360 & 1.226 & 1.181 & -0.045 \\
\hline \multicolumn{5}{|c|}{$\mathrm{C}_{60} @ 5.1 \mathrm{~h}-\mathbf{U}$} \\
\hline A & 7.525 & 7.594 & 7.602 & 0.008 \\
\hline B & 4.165 & 3.872 & 3.950 & 0.079 \\
\hline $\mathrm{C}$ & 0.379 & 2.426 & 2.415 & -0.010 \\
\hline $\mathrm{D}$ & 0.312 & 1.134 & 1.120 & -0.014 \\
\hline \multicolumn{5}{|c|}{$\mathrm{C}_{60} @ 5.1 \mathrm{k}-\mathrm{U}$} \\
\hline A & 7.786 & 7.696 & 7.746 & 0.050 \\
\hline B & 3.192 & 3.354 & 3.381 & 0.026 \\
\hline $\mathrm{C}$ & 1.734 & 2.064 & 2.220 & 0.156 \\
\hline D & 0.223 & 1.499 & 1.484 & -0.015 \\
\hline
\end{tabular}

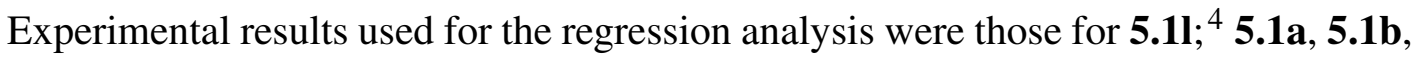

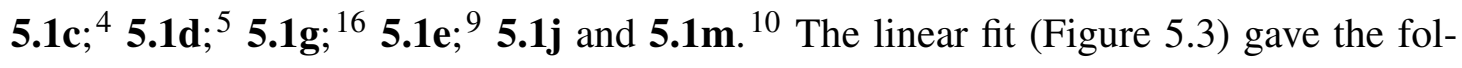
lowing scaling factor

$$
\delta_{\text {scaled }}=0.966 \delta_{\text {calc }}+0.306
$$

with an $r^{2}$ value of 0.995 . 


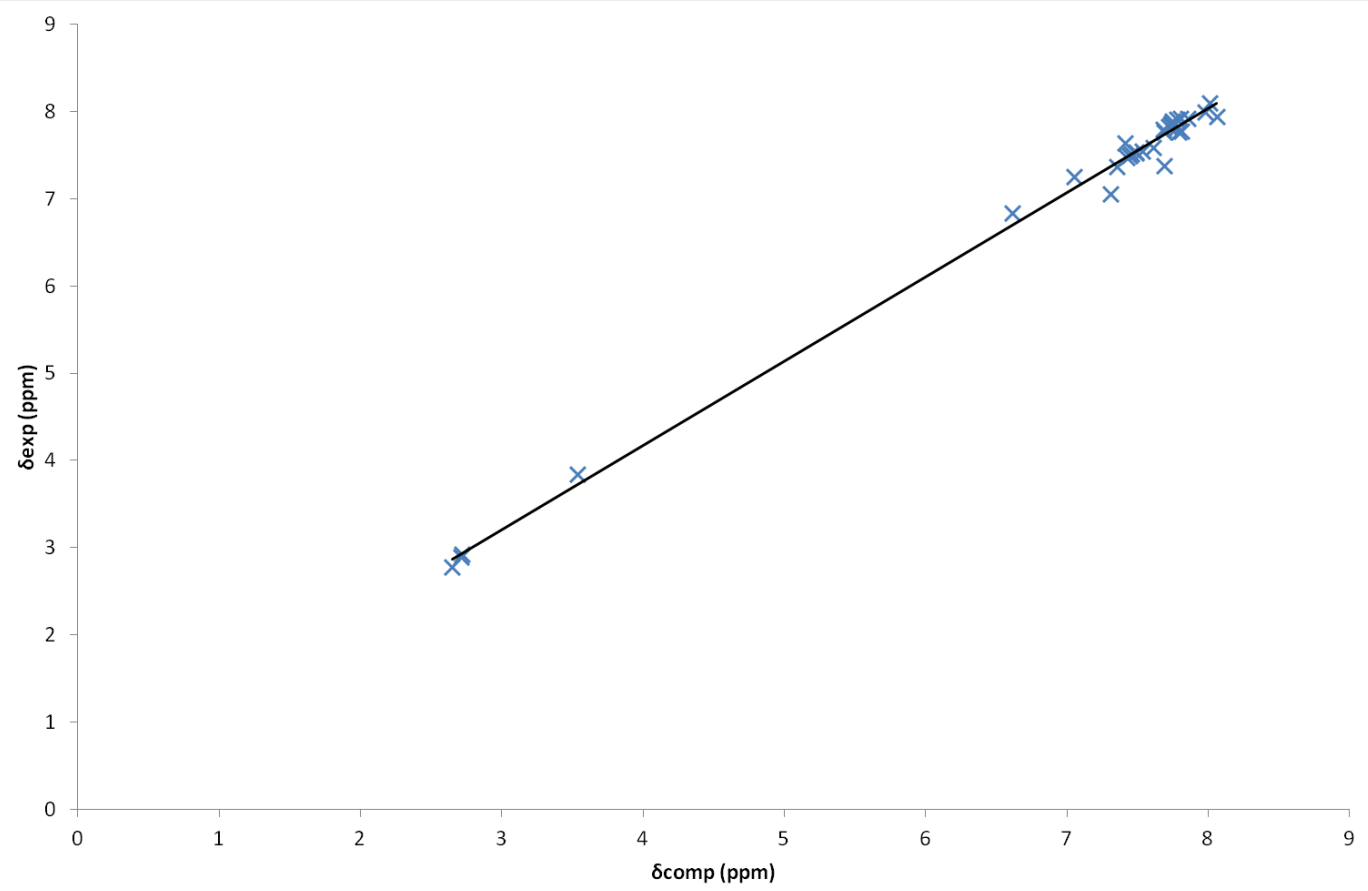

Figure 5.3. Linear regression plot used to determine ${ }^{1} \mathrm{H}$ NMR scaling factor. Linear fit gave $\delta_{\text {scaled }}=0.966 \delta_{\text {calc }}+0.306$ with an $r^{2}$ value of 0.995 .

\subsection{4 ${ }^{13}$ C NMR}

${ }^{13} \mathrm{C}$ NMR calculated values for the functionalised bowls were referenced to the calculated absolute TMS shift of $194.538 \mathrm{ppm}$. Scaling factors and shifts were determined as for ${ }^{1} \mathrm{H}$ NMR in $\S 5.1 .3$. Results are presented in Table 5.4.

Table 5.4. Calculated ${ }^{13} \mathrm{C}$ NMR shifts for the bowls and complexes. Values for the weighted bowl and complex are those of their thermally weighted averages. All values are in ppm.

\begin{tabular}{|c|c|c|c|c|}
\hline $\mathrm{C}$ & Bowl & Weighted Bowl & Weighted Complex & $\Delta \delta$ \\
\hline \multicolumn{5}{|c|}{$\mathrm{C}_{60} @ 5.11$} \\
\hline $\mathrm{C}_{60}$ & 141.397 & 145.894 & 145.005 & -0.889 \\
\hline $\mathrm{A}$ & 130.329 & 134.470 & 134.926 & 0.457 \\
\hline B & 125.069 & 129.232 & 129.794 & 0.562 \\
\hline $\mathrm{C}$ & 122.836 & 126.786 & 127.951 & 1.165 \\
\hline \multicolumn{5}{|c|}{$\mathrm{C}_{60} @ \mathbf{5 . 1 f}$} \\
\hline $\mathrm{C}_{60}$ & 141.397 & 145.824 & 144.008 & -1.816 \\
\hline $\mathrm{A}$ & 135.280 & 139.314 & 139.784 & 0.469 \\
\hline
\end{tabular}


Table 5.4 - Continued from previous page

\begin{tabular}{|c|c|c|c|c|}
\hline $\mathrm{C}$ & Bowl & Weighted Bowl & Weighted Complex & $\Delta \delta$ \\
\hline \multicolumn{5}{|c|}{$\mathrm{C}_{60} @ 5.1 \mathrm{5.1f}$} \\
\hline B & 128.266 & 132.336 & 132.660 & 0.324 \\
\hline $\mathrm{C}$ & 125.708 & 129.823 & 130.648 & 0.825 \\
\hline $\mathrm{D}$ & 128.553 & 132.717 & 133.413 & 0.696 \\
\hline $\mathrm{E}$ & 121.647 & 125.623 & 126.957 & 1.334 \\
\hline $\mathrm{F}$ & 36.092 & 36.370 & 36.402 & 0.032 \\
\hline \multicolumn{5}{|c|}{$\mathrm{C}_{60} @ \mathbf{5 . 1 g}$} \\
\hline $\mathrm{C}_{60}$ & 141.397 & 145.855 & 144.220 & -1.635 \\
\hline A & 135.415 & 139.472 & 139.841 & 0.369 \\
\hline B & 144.263 & 148.594 & 148.597 & 0.004 \\
\hline $\mathrm{C}$ & 135.375 & 139.717 & 140.818 & 1.102 \\
\hline $\mathrm{D}$ & 134.788 & 139.038 & 139.885 & 0.847 \\
\hline $\mathrm{E}$ & 120.990 & 124.649 & 125.794 & 1.144 \\
\hline $\mathrm{F}$ & 122.900 & 126.719 & 127.502 & 0.783 \\
\hline \multicolumn{5}{|c|}{$\mathrm{C}_{60} @ 5.1 \mathrm{a}$} \\
\hline $\mathrm{C}_{60}$ & 141.397 & 145.895 & 144.885 & -1.010 \\
\hline A & 130.508 & 134.739 & 135.481 & 0.743 \\
\hline B & 130.637 & 134.621 & 135.278 & 0.658 \\
\hline $\mathrm{C}$ & 130.192 & 134.484 & 135.055 & 0.571 \\
\hline $\mathrm{D}$ & 130.605 & 134.869 & 135.414 & 0.545 \\
\hline $\mathrm{E}$ & 129.509 & 133.672 & 134.350 & 0.679 \\
\hline $\mathrm{F}$ & 125.834 & 130.128 & 130.552 & 0.424 \\
\hline G & 122.506 & 126.480 & 127.769 & 1.290 \\
\hline $\mathrm{H}$ & 122.859 & 126.810 & 128.239 & 1.429 \\
\hline I & 124.768 & 128.860 & 129.433 & 0.573 \\
\hline $\mathrm{J}$ & 123.045 & 126.945 & 128.156 & 1.211 \\
\hline $\mathrm{K}$ & 122.388 & 126.280 & 126.970 & 0.690 \\
\hline $\mathrm{L}$ & 125.239 & 129.370 & 129.889 & 0.519 \\
\hline M & 122.836 & 126.786 & 128.189 & 1.402 \\
\hline $\mathrm{N}$ & 122.743 & 126.686 & 127.682 & 0.995 \\
\hline $\mathrm{O}$ & 124.637 & 128.782 & 129.175 & 0.394 \\
\hline $\mathrm{P}$ & 122.766 & 126.713 & 127.864 & 1.151 \\
\hline
\end{tabular}


Table 5.4 - Continued from previous page

\begin{tabular}{|c|c|c|c|c|}
\hline $\mathrm{C}$ & Bowl & Weighted Bowl & Weighted Complex & $\Delta \delta$ \\
\hline \multicolumn{5}{|c|}{$\mathrm{C}_{60} @ \mathbf{5 . 1 a}$} \\
\hline Q & 120.964 & 124.941 & 126.380 & 1.439 \\
\hline $\mathrm{R}$ & 125.278 & 129.723 & 130.307 & 0.584 \\
\hline $\mathrm{S}$ & 131.745 & 136.087 & 137.053 & 0.966 \\
\hline $\mathrm{T}$ & 122.193 & 126.203 & 127.813 & 1.610 \\
\hline $\mathrm{U}$ & 20.755 & 20.186 & 20.913 & 0.727 \\
\hline \multicolumn{5}{|c|}{$\mathrm{C}_{60} @ \mathbf{5 . 1 b}$} \\
\hline $\mathrm{C}_{60}$ & 141.397 & 145.901 & 144.867 & -1.034 \\
\hline A & 129.998 & 134.333 & 134.886 & 0.553 \\
\hline B & 125.289 & 129.756 & 130.351 & 0.596 \\
\hline $\mathrm{C}$ & 131.372 & 135.699 & 136.785 & 1.086 \\
\hline $\mathrm{D}$ & 119.916 & 123.823 & 125.398 & 1.576 \\
\hline $\mathrm{E}$ & 20.815 & 20.237 & 21.040 & 0.803 \\
\hline \multicolumn{5}{|c|}{$\mathrm{C}_{60} @ 5.1 \mathrm{c}$} \\
\hline $\mathrm{C}_{60}$ & 141.397 & 145.909 & 144.793 & -1.115 \\
\hline A & 126.056 & 130.988 & 131.618 & 0.629 \\
\hline B & 124.887 & 129.901 & 131.070 & 1.168 \\
\hline $\mathrm{C}$ & 130.209 & 134.266 & 135.556 & 1.290 \\
\hline $\mathrm{D}$ & 23.115 & 23.067 & 23.544 & 0.477 \\
\hline \multicolumn{5}{|c|}{$\mathrm{C}_{60} @ \mathbf{5 . 1 d}$} \\
\hline $\mathrm{C}_{60}$ & 141.397 & 145.864 & 144.812 & -1.051 \\
\hline A & 131.403 & 135.344 & 135.974 & 0.629 \\
\hline B & 125.197 & 128.815 & 129.169 & 0.354 \\
\hline $\mathrm{C}$ & 138.584 & 142.744 & 143.361 & 0.618 \\
\hline $\mathrm{D}$ & 122.840 & 126.262 & 127.327 & 1.065 \\
\hline $\mathrm{E}$ & 134.798 & 138.601 & 138.020 & -0.581 \\
\hline $\mathrm{F}$ & 125.096 & 128.926 & 129.979 & 1.052 \\
\hline $\mathrm{G}$ & 123.340 & 127.284 & 127.236 & -0.047 \\
\hline $\mathrm{H}$ & 122.078 & 125.844 & 126.091 & 0.247 \\
\hline \multicolumn{5}{|c|}{$\mathrm{C}_{60} @ \mathbf{5 . 1 e - A U}$} \\
\hline $\mathrm{C}_{60}$ & 141.397 & 145.788 & 143.732 & -2.056 \\
\hline A & 126.812 & 131.266 & 132.156 & 0.889 \\
\hline
\end{tabular}


Table 5.4 - Continued from previous page

\begin{tabular}{|c|c|c|c|c|}
\hline $\mathrm{C}$ & Bowl & Weighted Bowl & Weighted Complex & $\Delta \delta$ \\
\hline \multicolumn{5}{|c|}{$\mathrm{C}_{60} @ \mathbf{5 . 1 e - A U}$} \\
\hline B & 126.825 & 130.841 & 132.188 & 1.347 \\
\hline $\mathrm{C}$ & 137.312 & 141.488 & 141.975 & 0.487 \\
\hline $\mathrm{D}$ & 136.785 & 140.705 & 140.924 & 0.219 \\
\hline $\mathrm{E}$ & 123.985 & 127.867 & 129.454 & 1.587 \\
\hline $\mathrm{F}$ & 122.326 & 126.235 & 127.252 & 1.016 \\
\hline \multicolumn{5}{|c|}{$\mathrm{C}_{60} @ 5.1 \mathrm{e}-\mathrm{CS}$} \\
\hline $\mathrm{C}_{60}$ & 141.397 & 145.818 & 144.518 & -1.300 \\
\hline A & 126.358 & 130.369 & 130.974 & 0.605 \\
\hline B & 126.485 & 129.387 & 130.916 & 1.528 \\
\hline $\mathrm{C}$ & 139.192 & 143.108 & 143.650 & 0.542 \\
\hline $\mathrm{D}$ & 134.856 & 138.714 & 139.034 & 0.320 \\
\hline $\mathrm{E}$ & 124.319 & 128.032 & 128.609 & 0.578 \\
\hline $\mathrm{F}$ & 122.550 & 126.499 & 126.981 & 0.482 \\
\hline \multicolumn{5}{|c|}{$\mathrm{C}_{60} @ 5.1 \mathrm{~m}-\mathrm{D}$} \\
\hline $\mathrm{C}_{60}$ & 141.397 & 145.873 & 145.053 & -0.821 \\
\hline A & 130.524 & 135.061 & 135.729 & 0.668 \\
\hline B & 127.277 & 131.913 & 132.518 & 0.605 \\
\hline $\mathrm{C}$ & 127.950 & 131.889 & 132.647 & 0.758 \\
\hline $\mathrm{D}$ & 134.325 & 138.418 & 139.426 & 1.008 \\
\hline $\mathrm{E}$ & 133.560 & 137.865 & 137.637 & -0.228 \\
\hline $\mathrm{F}$ & 124.639 & 128.223 & 128.189 & -0.034 \\
\hline G & 124.260 & 128.315 & 128.186 & -0.129 \\
\hline $\mathrm{H}$ & 125.548 & 129.397 & 129.308 & -0.088 \\
\hline I & 123.192 & 127.181 & 127.064 & -0.116 \\
\hline $\mathrm{J}$ & 121.137 & 124.789 & 124.784 & -0.005 \\
\hline K & 121.472 & 125.341 & 125.382 & 0.041 \\
\hline $\mathrm{L}$ & 123.423 & 127.260 & 127.355 & 0.095 \\
\hline M & 126.454 & 130.707 & 130.771 & 0.064 \\
\hline $\mathrm{N}$ & 125.258 & 128.995 & 129.128 & 0.133 \\
\hline \multicolumn{5}{|c|}{$\mathrm{C}_{60} @ 5.1 \mathrm{j}-\mathrm{D}$} \\
\hline $\mathrm{C}_{60}$ & 141.397 & 145.900 & 144.947 & -0.953 \\
\hline
\end{tabular}


Table 5.4 - Continued from previous page

\begin{tabular}{|c|c|c|c|c|}
\hline $\mathrm{C}$ & Bowl & Weighted Bowl & Weighted Complex & $\Delta \delta$ \\
\hline \multicolumn{5}{|c|}{$\mathrm{C}_{60} @ 5.1 \mathrm{j}-\mathrm{D}$} \\
\hline A & 129.979 & 134.895 & 135.601 & 0.706 \\
\hline B & 127.232 & 131.338 & 131.898 & 0.560 \\
\hline $\mathrm{C}$ & 130.948 & 131.391 & 132.277 & 0.886 \\
\hline $\mathrm{D}$ & 136.733 & 139.477 & 140.438 & 0.961 \\
\hline $\mathrm{E}$ & 125.224 & 130.237 & 129.975 & -0.262 \\
\hline $\mathrm{F}$ & 132.866 & 133.011 & 133.039 & 0.027 \\
\hline G & 108.582 & 112.318 & 112.312 & -0.006 \\
\hline $\mathrm{H}$ & 152.036 & 156.081 & 156.129 & 0.106 \\
\hline I & 52.199 & 53.81 & 53.100 & 0.019 \\
\hline \multicolumn{5}{|c|}{$\mathrm{C}_{60} @ 5.1 \mathrm{~m}-\mathbf{U}$} \\
\hline $\mathrm{C}_{60}$ & 141.397 & 145.716 & 142.710 & -3.005 \\
\hline A & 130.861 & 131.897 & 132.221 & 0.324 \\
\hline B & 128.348 & 130.207 & 131.759 & 1.552 \\
\hline $\mathrm{C}$ & 134.995 & 134.520 & 134.790 & 0.270 \\
\hline $\mathrm{D}$ & 132.264 & 138.435 & 138.412 & -0.022 \\
\hline $\mathrm{E}$ & 131.678 & 134.497 & 134.510 & 0.013 \\
\hline $\mathrm{F}$ & 123.516 & 131.798 & 132.269 & 0.471 \\
\hline G & 123.433 & 127.662 & 128.706 & 1.044 \\
\hline $\mathrm{H}$ & 125.338 & 130.390 & 131.279 & 0.888 \\
\hline I & 123.256 & 126.855 & 127.774 & 0.919 \\
\hline $\mathrm{J}$ & 120.706 & 125.455 & 126.310 & 0.855 \\
\hline $\mathrm{K}$ & 121.312 & 124.892 & 125.468 & 0.577 \\
\hline $\mathrm{L}$ & 124.552 & 127.691 & 129.431 & 1.740 \\
\hline M & 126.339 & 130.062 & 131.324 & 1.262 \\
\hline $\mathrm{N}$ & 125.227 & 135.595 & 136.986 & 1.392 \\
\hline \multicolumn{5}{|c|}{$\mathrm{C}_{60} @ 5.1 \mathrm{j} \cdot \mathbf{U}$} \\
\hline $\mathrm{C}_{60}$ & 141.397 & 145.747 & 143.872 & -1.875 \\
\hline A & 131.693 & 131.586 & 131.852 & 0.266 \\
\hline B & 127.852 & 130.256 & 132.117 & 1.861 \\
\hline $\mathrm{C}$ & 135.533 & 137.522 & 138.396 & 0.875 \\
\hline D & 132.697 & 138.352 & 138.240 & -0.113 \\
\hline
\end{tabular}


Table 5.4 - Continued from previous page

\begin{tabular}{|c|c|c|c|c|}
\hline $\mathrm{C}$ & Bowl & Weighted Bowl & Weighted Complex & $\Delta \delta$ \\
\hline \multicolumn{5}{|c|}{$\mathrm{C}_{60} @ 5.1 \mathrm{j} \cdot \mathbf{U}$} \\
\hline $\mathrm{E}$ & 125.951 & 126.849 & 126.275 & -0.574 \\
\hline $\mathrm{F}$ & 127.605 & 137.691 & 138.741 & 1.050 \\
\hline $\mathrm{G}$ & 109.516 & 111.559 & 113.862 & 2.303 \\
\hline $\mathrm{H}$ & 149.797 & 157.251 & 158.136 & 0.885 \\
\hline I & 53.624 & 53.112 & 53.050 & -0.062 \\
\hline \multicolumn{5}{|c|}{$\mathrm{C}_{60} @ 5.1 \mathrm{i}-\mathrm{D}$} \\
\hline $\mathrm{C}_{60}$ & 141.397 & 145.873 & 144.885 & -0.988 \\
\hline A & 131.032 & 135.714 & 136.384 & 0.671 \\
\hline B & 127.866 & 132.503 & 132.988 & 0.485 \\
\hline $\mathrm{C}$ & 128.497 & 132.465 & 133.608 & 1.143 \\
\hline $\mathrm{D}$ & 135.110 & 139.629 & 140.757 & 1.129 \\
\hline $\mathrm{E}$ & 41.529 & 42.068 & 41.987 & -0.080 \\
\hline $\mathrm{F}$ & 22.143 & 21.787 & 21.821 & 0.033 \\
\hline $\mathrm{G}$ & 15.689 & 14.875 & 14.854 & -0.021 \\
\hline \multicolumn{5}{|c|}{$\mathrm{C}_{60} @ 5.1 \mathrm{~h}-\mathrm{D}$} \\
\hline $\mathrm{C}_{60}$ & 141.397 & 145.883 & 144.943 & -0.940 \\
\hline A & 129.556 & 134.554 & 135.042 & 0.488 \\
\hline B & 123.431 & 128.348 & 129.145 & 0.796 \\
\hline $\mathrm{C}$ & 152.599 & 157.858 & 158.425 & 0.567 \\
\hline $\mathrm{D}$ & 109.180 & 111.312 & 112.423 & 1.111 \\
\hline $\mathrm{E}$ & 75.100 & 76.251 & 76.229 & -0.022 \\
\hline $\mathrm{F}$ & 20.040 & 24.042 & 24.042 & 0.000 \\
\hline $\mathrm{G}$ & 11.316 & 10.190 & 10.145 & -0.045 \\
\hline \multicolumn{5}{|c|}{$\mathrm{C}_{60} @ 5.1 \mathrm{k}-\mathrm{D}$} \\
\hline $\mathrm{C}_{60}$ & 141.397 & 145.880 & 144.810 & -1.070 \\
\hline A & 130.392 & 135.246 & 135.766 & 0.521 \\
\hline B & 124.070 & 129.065 & 129.589 & 0.524 \\
\hline $\mathrm{C}$ & 136.973 & 141.344 & 142.422 & 1.078 \\
\hline $\mathrm{D}$ & 118.710 & 122.986 & 124.502 & 1.515 \\
\hline $\mathrm{E}$ & 37.422 & 37.674 & 38.693 & 1.019 \\
\hline $\mathrm{F}$ & 28.039 & 27.266 & 27.209 & -0.056 \\
\hline
\end{tabular}


Table 5.4 - Continued from previous page

\begin{tabular}{|c|c|c|c|c|}
\hline $\mathrm{C}$ & Bowl & Weighted Bowl & Weighted Complex & $\Delta \delta$ \\
\hline \multicolumn{5}{|c|}{$C_{60} @ 5.1 k-D$} \\
\hline $\mathrm{G}$ & 16.481 & 15.730 & 15.696 & -0.034 \\
\hline \multicolumn{5}{|c|}{$\mathrm{C}_{60} @ 5.1 \mathrm{i} \cdot \mathbf{U}$} \\
\hline $\mathrm{C}_{60}$ & 141.397 & 145.766 & 144.958 & -0.808 \\
\hline A & 130.708 & 131.732 & 132.298 & 0.566 \\
\hline B & 131.139 & 130.112 & 131.058 & 0.946 \\
\hline $\mathrm{C}$ & 131.405 & 138.654 & 139.158 & 0.504 \\
\hline $\mathrm{D}$ & 132.583 & 135.628 & 136.130 & 0.502 \\
\hline $\mathrm{E}$ & 40.722 & 38.095 & 37.728 & -0.367 \\
\hline $\mathrm{F}$ & 23.786 & 26.290 & 26.705 & 0.416 \\
\hline G & 15.451 & 14.011 & 15.129 & 1.117 \\
\hline \multicolumn{5}{|c|}{$\mathrm{C}_{60} @ 5.1 \mathrm{~h}-\mathbf{U}$} \\
\hline $\mathrm{C}_{60}$ & 141.397 & 145.877 & 145.259 & -0.618 \\
\hline A & 130.532 & 131.802 & 132.186 & 0.384 \\
\hline B & 128.636 & 125.940 & 126.279 & 0.340 \\
\hline $\mathrm{C}$ & 151.375 & 158.305 & 158.548 & 0.243 \\
\hline $\mathrm{D}$ & 107.643 & 115.172 & 116.217 & 1.045 \\
\hline $\mathrm{E}$ & 71.537 & 78.113 & 80.596 & 2.483 \\
\hline $\mathrm{F}$ & 21.942 & 23.043 & 23.493 & 0.450 \\
\hline $\mathrm{G}$ & 10.575 & 10.320 & 11.751 & 1.431 \\
\hline \multicolumn{5}{|c|}{$\mathrm{C}_{60} @ 5.1 \mathrm{k}-\mathbf{U}$} \\
\hline $\mathrm{C}_{60}$ & 141.397 & 145.827 & 145.010 & -0.817 \\
\hline $\mathrm{A}$ & 129.097 & 131.587 & 132.317 & 0.729 \\
\hline B & 127.256 & 127.254 & 127.768 & 0.514 \\
\hline $\mathrm{C}$ & 135.514 & 140.894 & 141.578 & 0.684 \\
\hline $\mathrm{D}$ & 120.266 & 123.373 & 124.055 & 0.682 \\
\hline $\mathrm{E}$ & 31.927 & 37.849 & 37.871 & 0.022 \\
\hline $\mathrm{F}$ & 27.562 & 27.052 & 30.363 & 3.310 \\
\hline $\mathrm{G}$ & 14.313 & 15.553 & 15.496 & -0.057 \\
\hline
\end{tabular}


Experimental results used for the regression analysis were those for $\mathrm{C}_{60}$, 81 5.11:4 5.1a 5.1b 5.1c, 5.1d $, 5,5.16$ and 5.1j ${ }^{10}$ The linear fit (Figure 5.4) gave the following scaling factor

$$
\delta_{\text {scaled }}=1.043 \delta_{\text {calc }}-1.463
$$

with an $r^{2}$ value of 0.995 .

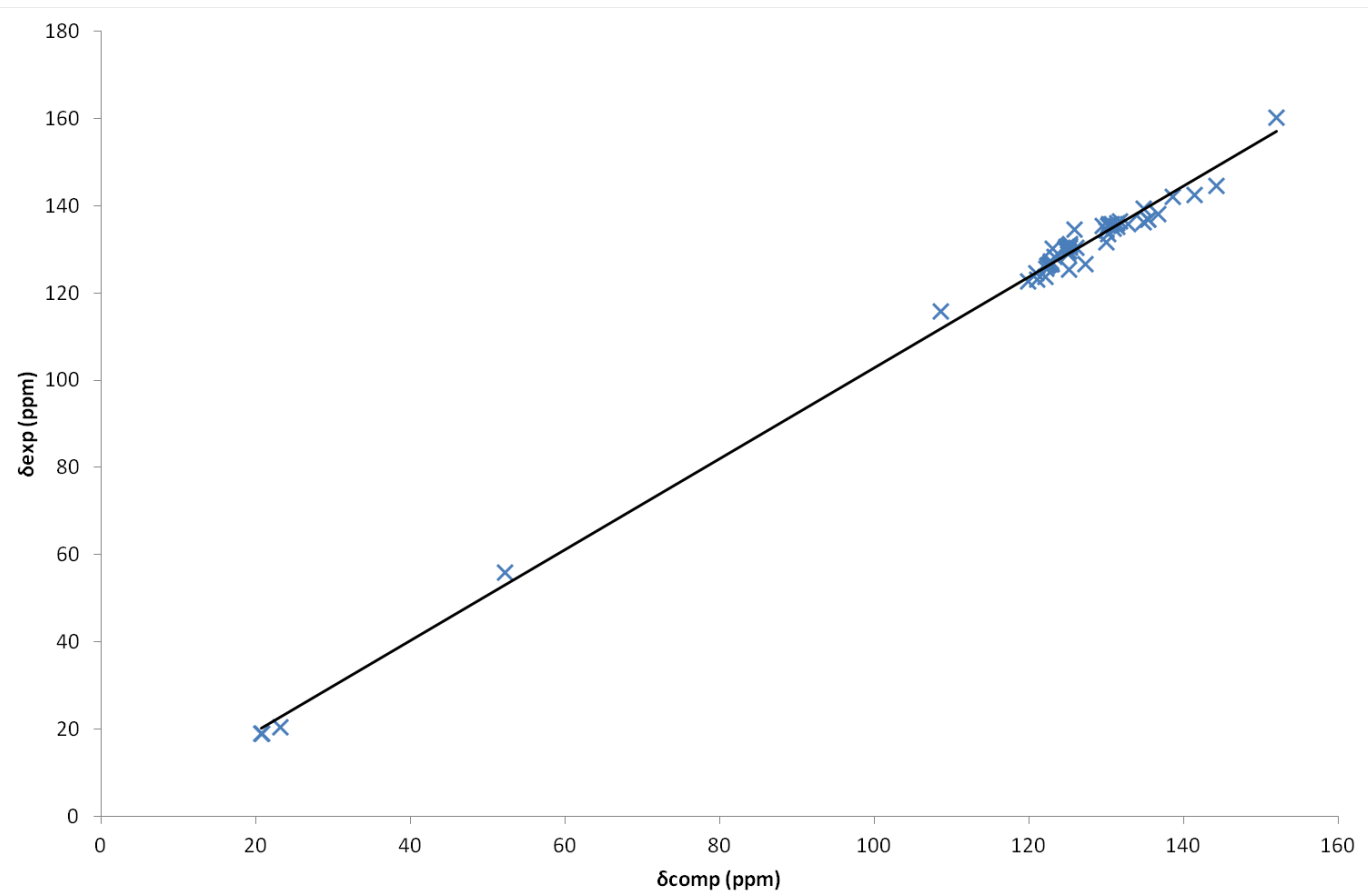

Figure 5.4. Linear regression plot used to determine ${ }^{13} \mathrm{C}$ NMR scaling factor. Liner fit gave $\delta_{\text {scaled }}=1.043 \delta_{\text {calc }}-1.463$ with an $r^{2}$ value of 0.995 .

\subsection{Discussion}

\subsubsection{Binding Energies}

\subsubsection{Effects of increased $\pi$-system size}

Increasing the size of the rigid $\pi$-system from 5.11 to 5.1f to 5.1g has a marked effect on the binding properties of the $\mathrm{C}_{60} @$ bowl complex. 5.11 is the smallest bowl, consisting of a rigid framework of 20 carbon atoms with an internal angle of $148.4^{\circ}$. It had the weakest binding of the three bowl sizes, as well as the shortest $\mathrm{C}_{60}$-hub separation distance. 5.1f is a rigid framework of 45 carbon atoms. The internal angle across the corannulene skeleton is $139.3^{\circ}$, indicating an increase in the curvature of the bowl. 
$\mathrm{C}_{60}$-hub separation distance and binding energy are also increased relative to 5.11 5.19 $\mathrm{s}$ framework consists of 50 carbon atoms and the internal angle of the corannulene skeleton decreased to $127.8^{\circ}$. There is further increase in both binding energy and $\mathrm{C}_{60}$-hub separation distance over that of $\mathbf{5 . 1 f}$. The corannulene moiety within $\mathrm{C}_{60}$ had an internal angle of $125.1^{\circ}$, which is complementary to that of the corannulene skeleton of the bowls. Binding energies in relation to these internal angles indicated that stronger bonding is achieved when the corannulene skeleton has an internal angle closer to that of $\mathrm{C}_{60}$.

\subsubsection{Effects of sequential methyl addition to the rim}

Sequential addition of methyl groups to the rim of corannulene had a regular effect on the binding energies obtained. Each additional methyl group, from $\mathbf{5 . 1 1}$ with zero, increases the binding energy of the complex by $1.2 \mathrm{kcal} \mathrm{mol}^{-1}$. There was also a slight flattening of the corannulene skeleton as methyl groups were added, most noticeably with 5.1c As the skeleton flattened, the $\mathrm{C}_{60}$-hub separation distance decreased, further confirming the correlation between internal angle and complex separation distance. Even though there was a flattening of the corannulene skeleton, binding energy increased with additional methyl groups. This was due ti increased methyl- $\pi$ interactions.

\subsubsection{Effects of phenyl group rim addition}

Phenyl groups provide further binding stabilisation over alkyl substituents. The internal bowl angle and fragment separation distances of 5.1d complexes were similar to those of $\mathbf{5 . 1 b}$ and $\mathbf{5 . 1 1}$ complexes. This indicated that the additional stabilisation was due to the $\pi$-systems providing additional $\pi-\pi$ interactions with the $C_{60}$. Steric repulsion means the $\pi$ systems are slightly rotated with respect to the $\mathrm{C}_{60}$ surface, away from parallel. As such the stabilisation increase is not as large as systems where the phenyl ring is rigidly held, such as in $\mathbf{5 . 1 9}$.

\subsubsection{Effects of resonance-stabilising substituents}

Increasing the electron-donating ability of the corannulene substituents enhanced the binding strength of the complexes formed. In the complexes with appendages positioned upwards, sulfur-containing bowls (5.1i) bound the strongest, followed by oxygen $\mathbf{5 . 1 h}$ ) and finally pure hydrocarbon bowls $(\mathbf{5 . 1 k})$. Sulfur and oxygen form resonance struc- 
tures with the corannulene skeleton, increasing the electron-rich nature of the concave bowl face. There is an additional inductive effect present for the oxygen-containing bowls. Sulfur's electronegativity is very similar to that of carbon so the inductive effect does not play a large role in the binding. Oxygen's high electronegativity draws electron density to it through the attached propyl chain, causing the propyl group to be slightly electron deficient. This destabilises the complex bonding as the arms do not embrace the electron deficient $\mathrm{C}_{60}$ to the same extent. Binding energies of the downwards positioned complexes were similar across the three bowls, indicating that electronic differences within the propyl chains provide the main source of complex stabilisation when positioned upwards.

\subsubsection{Effects of sulfur-linked, aromatic substituents}

Binding energies of the sulfur-linked aromatic ring containing functionalised bowl complexes were much greater than those of pure hydrocarbon and propyl chain containing bowls. Complexes in which all five appendages were positioned upwards, surrounding the $\mathrm{C}_{60}$ molecule, had stronger binding than their downwards positioned counterparts. Binding energies of 5.1m-D and 5.1j-D were similar to those of 5.1k-D, 5.1h-D and 5.1i-D. This provided further evidence that the nature of the arms has the strongest influence on binding strength. In a few cases, upwards positioned appendages for some input geometries had one appendage rotate down; for example the C5C6e input of 5.1j.U. The relative strengths of binding were inversed with respect to the experimentally reported $K_{\text {assoc }}$ values of Scott's group. $\frac{910}{5.1 \mathrm{~m}}$. U was found to have the strongest binding, followed by 5.1j.U and finally 5.1e-AU. In solution, the loose substituents of $\mathbf{5 . 1 m}$ and $\mathbf{5 . 1 j}$ could easily be rotated away from the $\mathrm{C}_{60}$ surface, thereby diminishing $\pi-\pi$ interactions. In this situation, the rigidly help 5.1e would have the strongest binding as the $\pi-\pi$ interactions are fixed. The additional electron density provided to the benzene ring of $\mathbf{5 . 1 j}$ by the methoxy group would enhance the strength of any $\pi-\pi$ interactions. This could cause $\mathrm{C}_{60} @ \mathbf{5 . 1 \mathbf { j }}$ complexes to be near in strength, or even stronger, than $\mathrm{C}_{60} @ \mathbf{5 . 1 \mathrm { m }}$ complexes. The trend in binding energy was matched by the increasing curvature of the bowls. Those with an internal angle closer to that of $\mathrm{C}_{60}$ had stronger binding. 


\subsection{2 ${ }^{1}$ H NMR}

Correlation between $\Delta \delta$ values for ${ }^{1} \mathrm{H}$ NMR and binding energies of the complex were dependent on the type of system investigated. Increasing the $\pi$-system size of the bowl showed no correlation between binding energy and $\Delta \delta$ values. 5.11 had the largest downfield shift, indicating strongest deshielding from the $\mathrm{C}_{60}$ which was consistent with the close proximity of $\mathrm{C}_{60}$. 5.1f showed minor downfield shifts for all hydrogens. $\mathbf{5 . 1 g}$ showed slight downfield shifts for $\mathrm{H}_{\mathrm{A}}$ and negligible shifts for $\mathrm{H}_{\mathrm{B}}$. The varying nature of the hydrogen environments meant that though a general concept of closer $\mathrm{C}_{60}$-hub separation distances resulted in larger degrees of deshielding, no qualitative conclusions could be drawn.

${ }^{1} \mathrm{H}$ NMR $\Delta \delta$ values of methyl substituted corannulenes provided a possible qualitative means of measuring binding energy. $\mathrm{C}_{60}$ deshielding of the methyl hydrogens decreased by a regular amount as additional methyl groups were added to the complex, with the methyl hydrogens of 5.1c showing the least effect of $\mathrm{C}_{60}$ deshielding. As there was a linear relationship between the number of methyl groups and binding energy, these regular changes in $\Delta \delta$ values could be used to directly estimate the binding energies of the complexes.

The corannulene bound hydrogens of 5.1d showed decreased deshielding effect when compared with the corresponding hydrogens on 5.11 and 5.1b. This decrease in deshielding correlates with an increase in binding energy of the complex. $\mathrm{H}_{\mathrm{B}}$ shows the largest $\Delta \delta$ value, as the tilt of the phenyl group with respect to the $\mathrm{C}_{60}$ means that it is closest to $\mathrm{C}_{60}$, experiencing the largest deshielding effect. As such, in complexes with bowls of a similar nature, the ortho hydrogens would provide the best means of experimentally monitoring complex formation due to their larger $\Delta \delta$ values.

The increased strength of complexes formed with appendages positioned upwards as opposed to downwards indicated that these geometries would be preferred. Complexes containing propyl chains $5 \mathbf{5 . 1 k}, \mathbf{5 . 1 h}$, and $\mathbf{5 . 1 i}$ showed ${ }^{1} \mathrm{H} \Delta \delta$ values which were related to the binding energies. In all cases, the hydrogens 'beta' to the corannulene $\left(\mathrm{H}_{\mathrm{B}}\right.$ on 5.1k and $\mathrm{H}_{\mathrm{A}}$ on the chalcogen containing bowls) showed the strongest effect from $\mathrm{C}_{60}$ complexation. As the binding strength increased, deshielding of the corannulene bound and $\alpha$ and $\beta$ methylene hydrogens increased. This is consistent with the $\mathrm{C}_{60}$ being held closer to the corannulene hub. 
Calculated ${ }^{1} \mathrm{H}$ NMR $\Delta \delta$ values for three experimentally reported complexes $[\mathbf{5 . 1 j}$ $5.1 \mathrm{~m}, 10$ and $\mathbf{5 . 1 e}^{9}$ ) were of similar magnitudes to those reported in the literature. 5.1m-U was calculated to be the strongest binding complex of the three, though had the lowest experimental $K_{\text {assoc }}$ value. Mizyed et al. found that only $\mathrm{H}_{\mathrm{H}}$ had any significant deshielding and hypothesised that this could be due to "edge-to-face" interactions with the $\mathrm{C}_{60}$. Optimisation of such a complex resulted in the napthyl groups rotating to provide face-to-face $\pi-\pi$ interactions. However, a similar effect was noticed in the calculated $\Delta \delta$ values, whereby $\mathrm{H}_{\mathrm{H}}$ and $\mathrm{H}_{\mathrm{G}}$ showed more significant deshielding than any other hydrogens on the napthyl group. Optimised structures showed that there was very slight rotation of the napthyl groups to position these hydrogens closer to the $\mathrm{C}_{60}$. This rotation could be amplified if a solvent was included. Strong deshielding of $\mathrm{H}_{\mathrm{B}}$ and $\mathrm{H}_{\mathrm{C}}$ on 5.1j-U was evident in the calculated $\Delta \delta$ values, which was in accordance with the literature. ${ }^{10}$ Calculations disagreed with regards to $\mathrm{H}_{\mathrm{A}}$ and $\mathrm{H}_{\mathrm{D}}$. Corannulene bound $\mathrm{H}_{\mathrm{A}}$ was found to be lightly deshielded and the methyl group $\mathrm{H}_{\mathrm{D}}$ was fairly shielded. These inconsistencies could be due to lack of solvent inclusion. The calculated $\Delta \delta$ values of 5.1e-AU were similar to those reported by Georghiou et al. ${ }^{9}$ Combined with the larger binding energy, this indicated that the $\mathrm{C}_{60} @$ 5.1e complex has all five flaps positioned upwards, as opposed to the positioning in the crystal structure of Bancu et al. ${ }^{19}$

\subsection{3 ${ }^{13} \mathrm{C}$ NMR}

${ }^{13} \mathrm{C}$ NMR experiments take at least five times as long to run as ${ }^{1} \mathrm{H}$ NMR experiments, meaning that they are not as attractive for use in monitoring complexation reactions. However, reasonable shifts in the calculated $\delta$ values are obtained upon complexation of $\mathrm{C}_{60}$ with a bowl molecule. As such, they could provide an additional means of monitoring such reactions. $\Delta \delta$ values obtained for the $\mathrm{C}_{60}$ carbons are found to always indicate that the $\mathrm{C}_{60}$ is shielded. There was no overall general relationship between the binding energy and $\Delta \delta$ values obtained. Within similar complexes, such as with $5.1 \mathrm{i}$ and $\mathbf{5 . 1 h}$ the stronger binding complex shows stronger shielding of the $\mathrm{C}_{60}$. This could be used as a means of determining relative strengths of binding in similar complexes.

Besides changes to the $\mathrm{C}_{60}$ shifts, methyl carbons provide the best means of using ${ }^{13} \mathrm{C}$ NMR to monitor complexation reactions. Though there is no overall trend linking binding energy and $\Delta \delta$ values, the shifts can be related to the binding energies if the complexes are similar. Methyl carbons have much smaller relative shifts than aromatic carbons, the $\Delta \delta$ values are much larger percentages and would be more noticeable. 


\section{Chapter 6}

\section{Conclusions}

\subsection{Binding Energies}

The binding energy of the functionalised bowl complexes was found to be strongly dependent on the type of bowl complexed. Bowls containing larger, rigid $\pi$-systems showed stronger binding as $\pi-\pi$ interactions were increased. Closer matching of the degree of curvature of the bowl $\pi$ with that of $\mathrm{C}_{60}$ also showed increased binding energies. Sequential addition of functional groups to the rim of corannulene was found to increase the binding energy with $\mathrm{C}_{60}$ by a regular amount, giving a linear relationship between binding energy and number of substituents. This effect may be limited when larger groups are added due to steric hindrance. Aromatic groups with free rotation provided additional complex stabilisation over pure alkyl substituents. The $\pi$-system is slightly rotated with respect to the $\mathrm{C}_{60}$ so full face-to-face interaction is not achieved, this increased stabilisation is not as great as those systems where the additional aromatic groups are held rigid.

Addition of electron donating atoms, such as oxygen or sulfur, to the rim of corannulene increases the binding energy of the complex formed. Stronger complexes were formed with those bowls where the appendages or flaps were all positioned upwards, embracing the $\mathrm{C}_{60}$. In solution, these may be in a rapid equilibrium whereby not all of the appendages or flaps are positioned upwards at the same time. Complexes where the appendages were all positioned downwards showed very similar binding energies, indicating that the nature of the embracing arms provides the main source of binding stabilisation between the bowls. 


\subsection{NMR}

Reasonable $\Delta \delta$ values for the chemical shift were obtained with ${ }^{13} \mathrm{C}$ NMR of complexed bowls. Across all the bowls investigated, there was not a general trend to relate binding energy to the $\Delta \delta$ of a particular type of carbon. However, bowls with similar electronic properties, such as the methyl substituted bowls or $\mathbf{5 . 1 h}$ and $\mathbf{5 . 1 i}$, showed a degree of shielding of the $\mathrm{C}_{60}$ related to the complex binding energy. Stronger bound complexes showed greater shielding effects, indicating that shifts in the $\mathrm{C}_{60} \delta$ value could be used to determine relative strength of binding between complexes.

${ }^{1} \mathrm{H}$ NMR results also showed no general trend between binding energy and $\Delta \delta$ values, though trends within similar types of bowls were present. A linear relationship was found to exist between the calculated ${ }^{1} \mathrm{H}$ NMR $\Delta \delta$ values of methyl hydrogens and the binding energy of methyl substituted bowl complexes, providing a possible means of determining binding energies. Penta- substituted bowls with the same type of atom in the 'ipso' position showed stronger shielding of the corannulene bound hydrogens as the binding strength increased. This relationship was not found to be linear so would be unable to provide estimates of the absolute, as opposed to relative, binding energy of a complex. Lack of solvent inclusion meant calculated ${ }^{1} \mathrm{H}$ NMR $\Delta \delta$ values for the complexes of 5.1j 5.1m and 5.1e were unable to replicate those reported in the literature. Some of the results were similar indicating that the gas-phase calculations provided results which could be used as a basis for predicting experimental results. 


\section{Glossary}

BSSE Basis set superposition error. An error present in the calculation of binding energies due to there being more basis functions employed in the calculation of the complex than in either of the monomers.

GGA Generalised gradient approximation. A functional which depends on both the electron density and the gradient of the density.

indeno group The $\mathrm{C}_{9} \mathrm{H}_{8}$ group composed of $\mathrm{a}_{5}$ and $\mathrm{C}_{6}$ ring fused together (below).

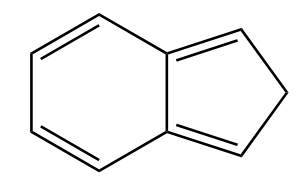

'ipso' position In substituted corannulene molecules, refers to the atom of the substituent group directly bonded to the corannulene framework.

Job plot A graphical method used to determine the stoichiometry of a binding event.

sym-penta substituted In substituted corannulene molecules, the five substituents are attached to the $1,3,5,7$, and 9 positions of corannulene, forming a $\mathrm{C}_{5}$ symmetric molecule.

TMS Tetramethylsilane, $\mathrm{Si}\left(\mathrm{CH}_{3}\right)_{4}$. Commonly used as an internal reference in ${ }^{1} \mathrm{H}$ and ${ }^{13} \mathrm{C}$ NMR experiments. 


\section{Appendix A}

\section{Energy Profiles}

Additional energy profiles of the $\mathrm{C}_{60} @$ corannulene complex. All ultrafine and the remaining $(96,32,64)$ benchmark integration grid results are displayed for the nine density functionals.

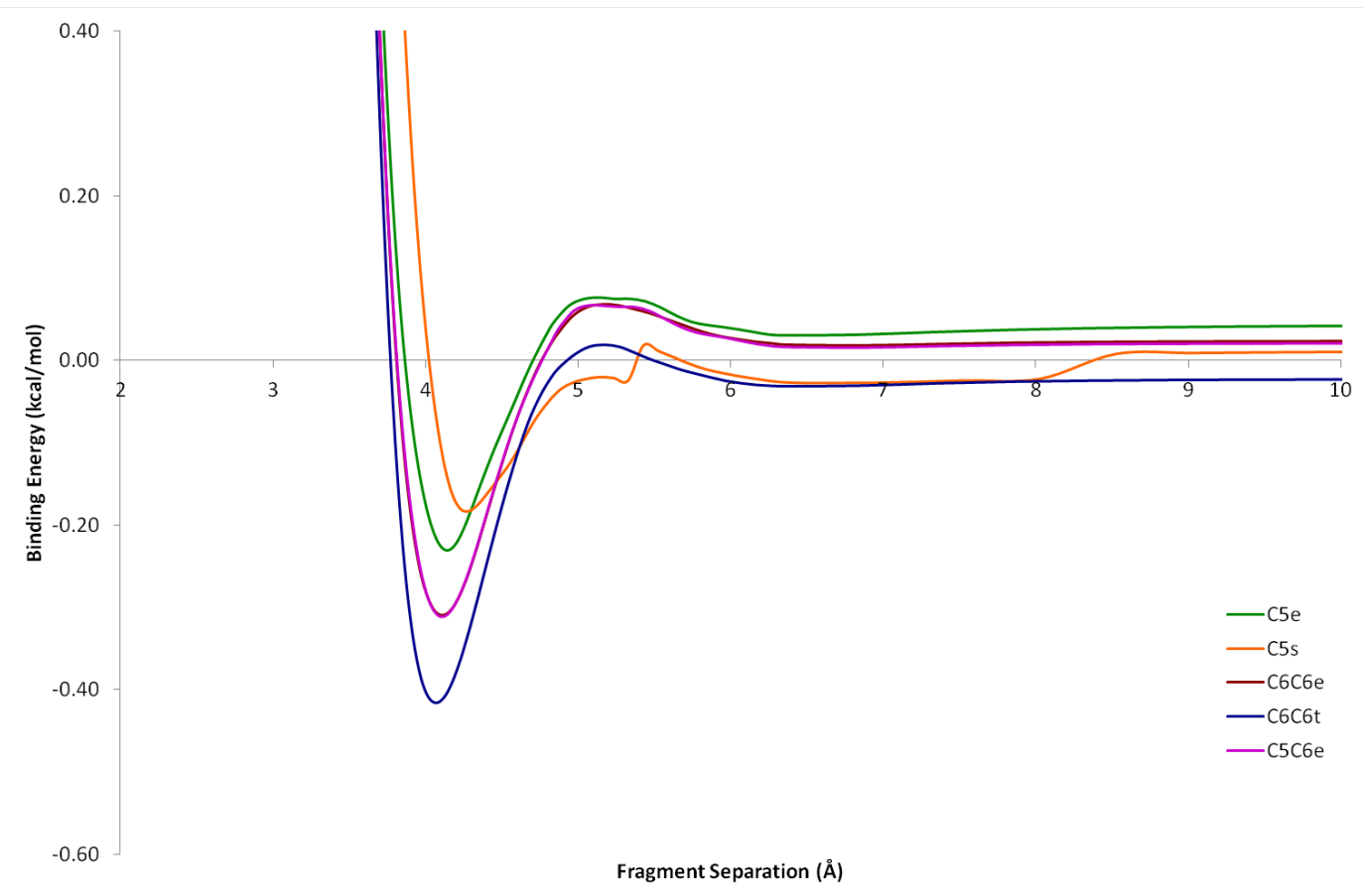

Figure A.1. B3LYP energy profiles generated using the ultrafine integration grid. 


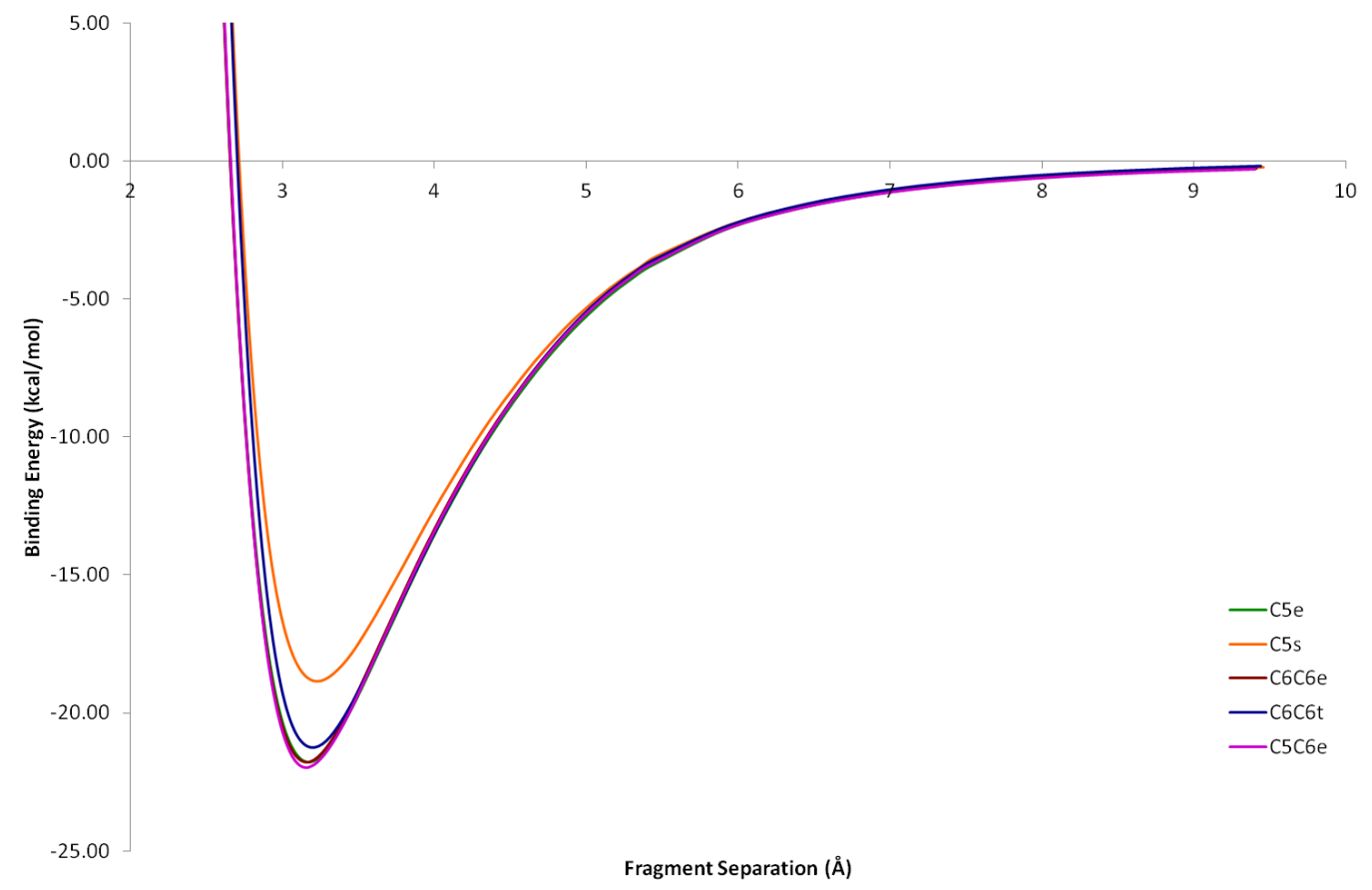

Figure A.2. B97-D energy profiles generated using the ultrafine integration grid.

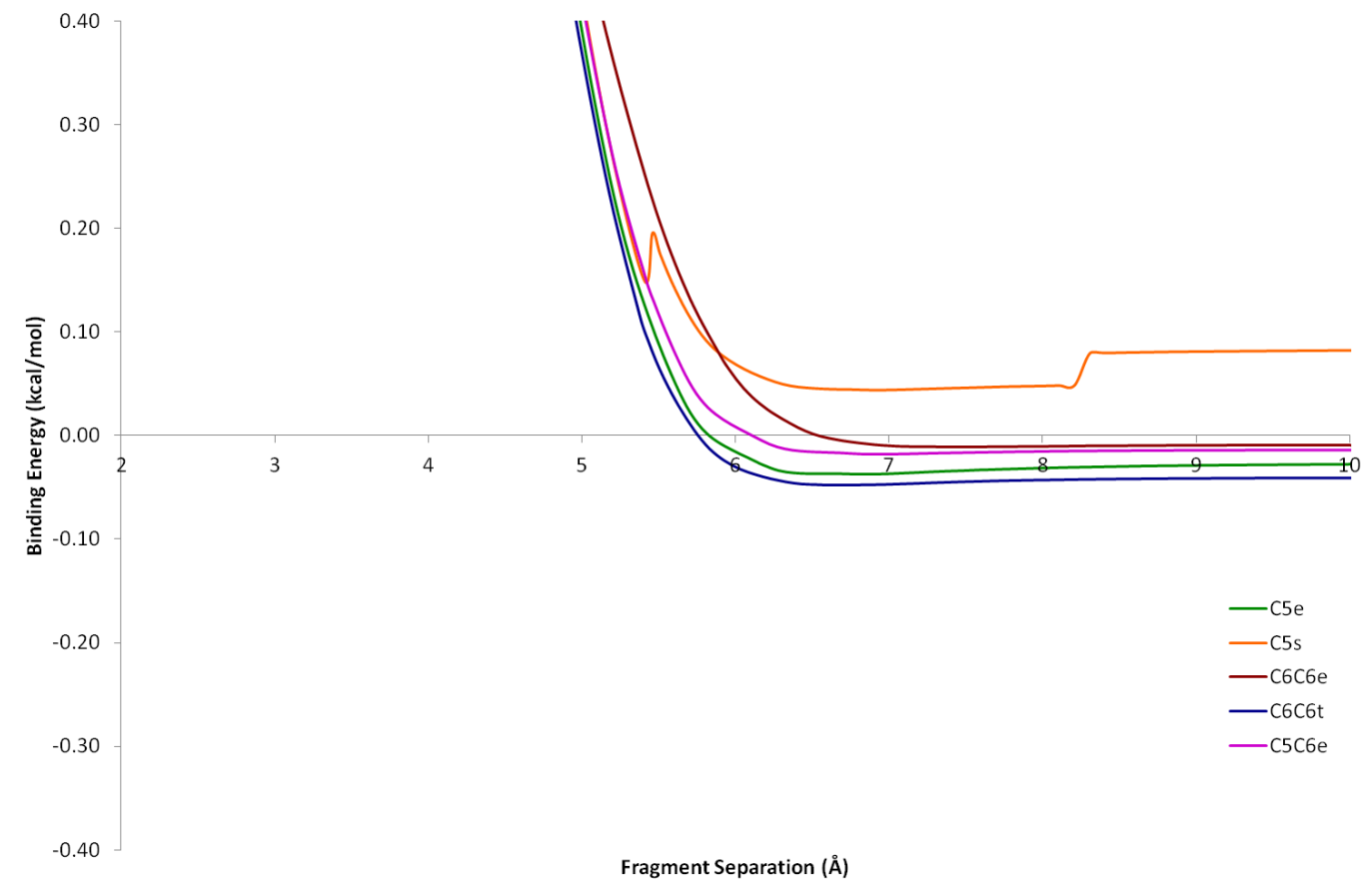

Figure A.3. BP86 energy profiles generated using the ultrafine integration grid. 


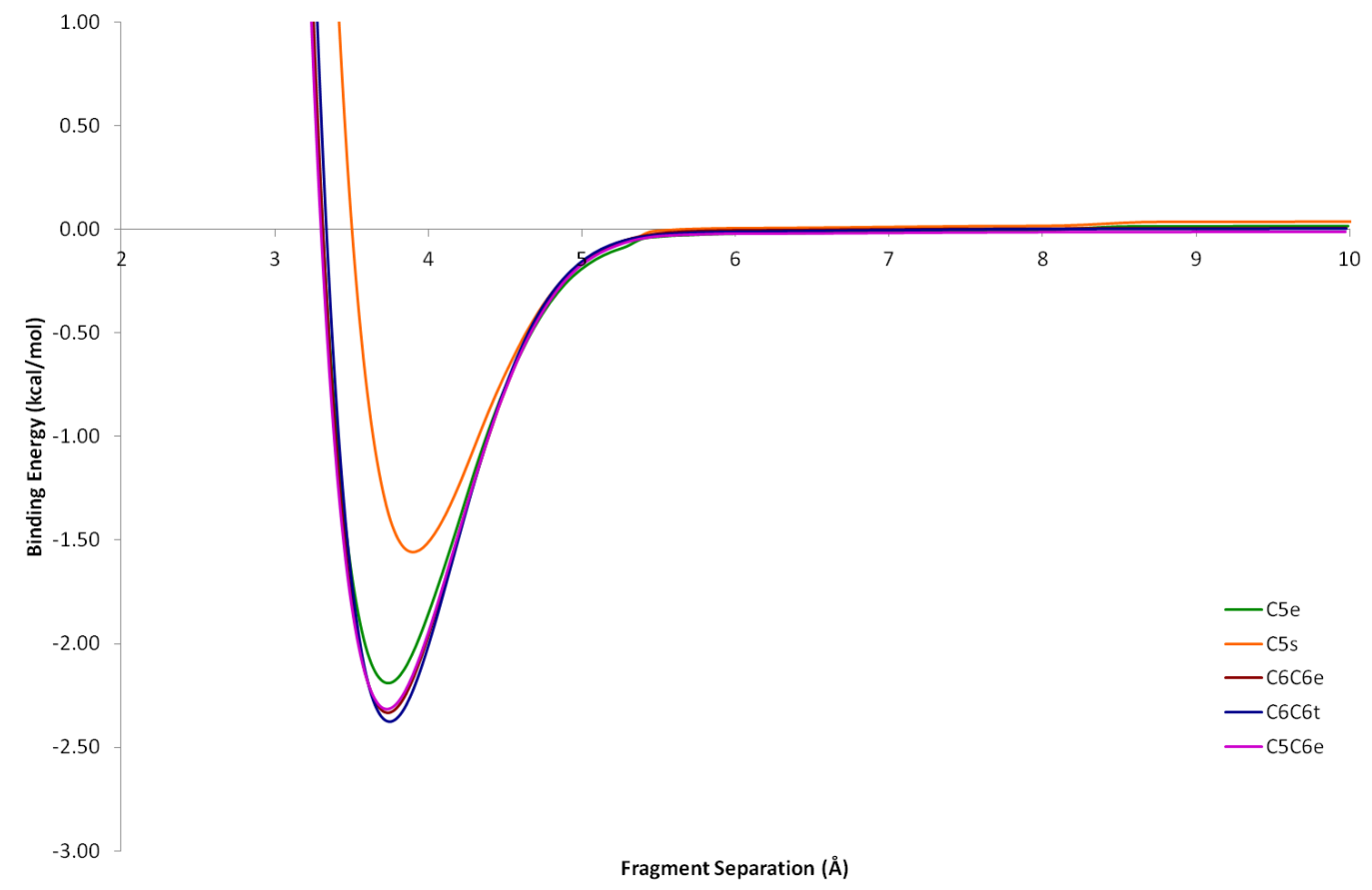

Figure A.4. CAM-B3LYP energy profiles generated using the ultrafine integration grid.

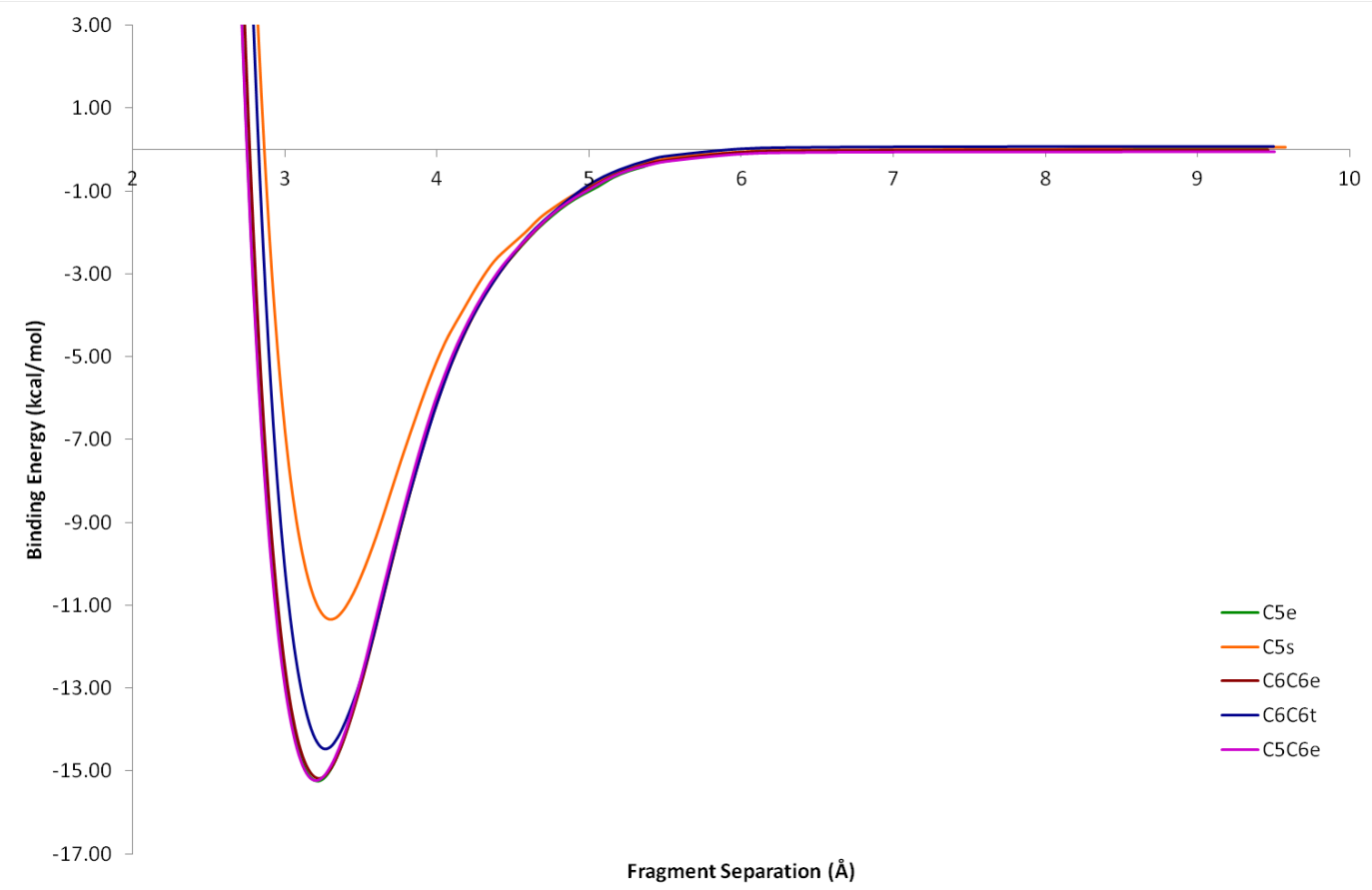

Figure A.5. M06-2X energy profiles generated using the ultrafine integration grid. 


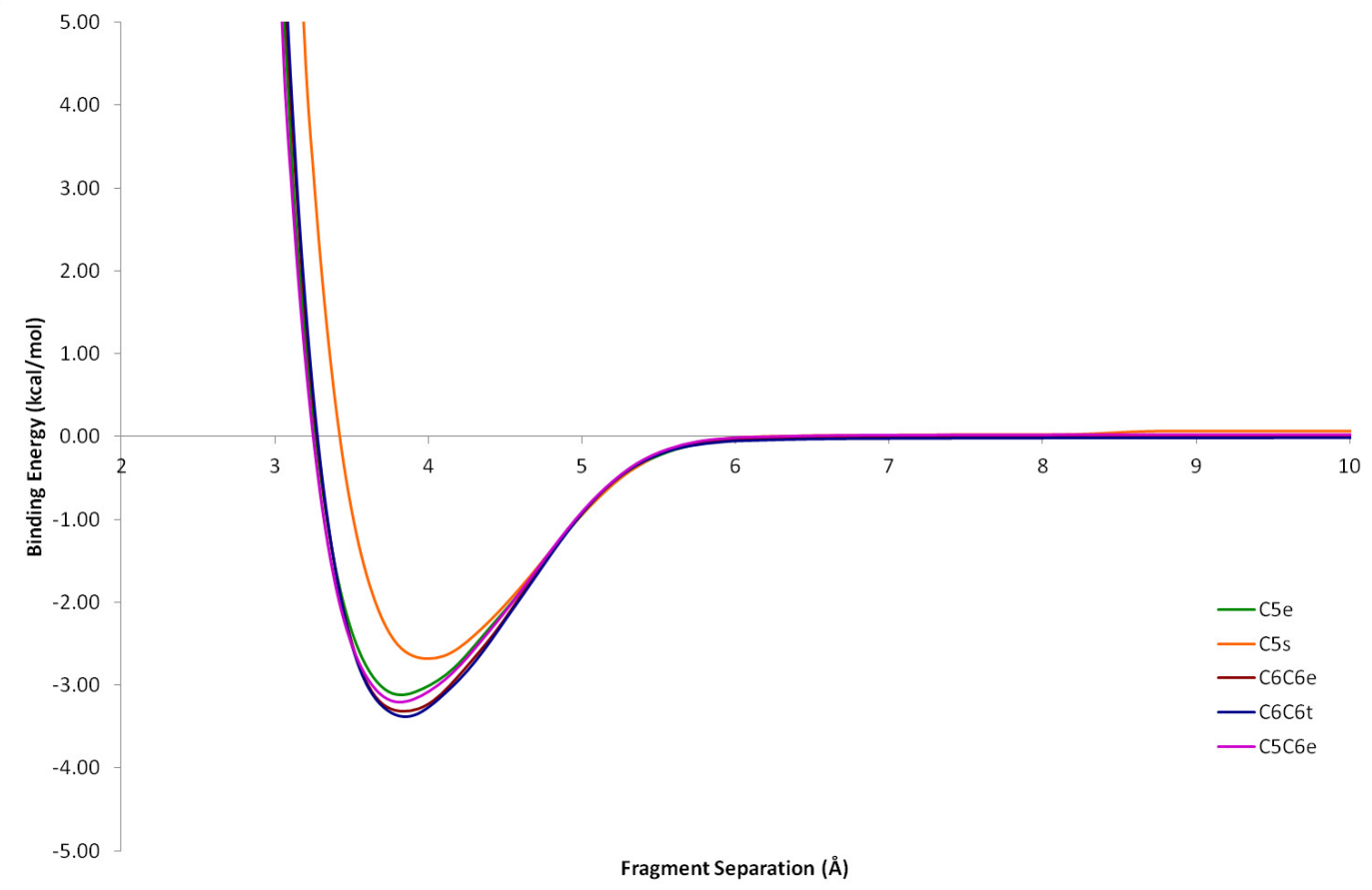

Figure A.6. PW91 energy profiles generated using the ultrafine integration grid.

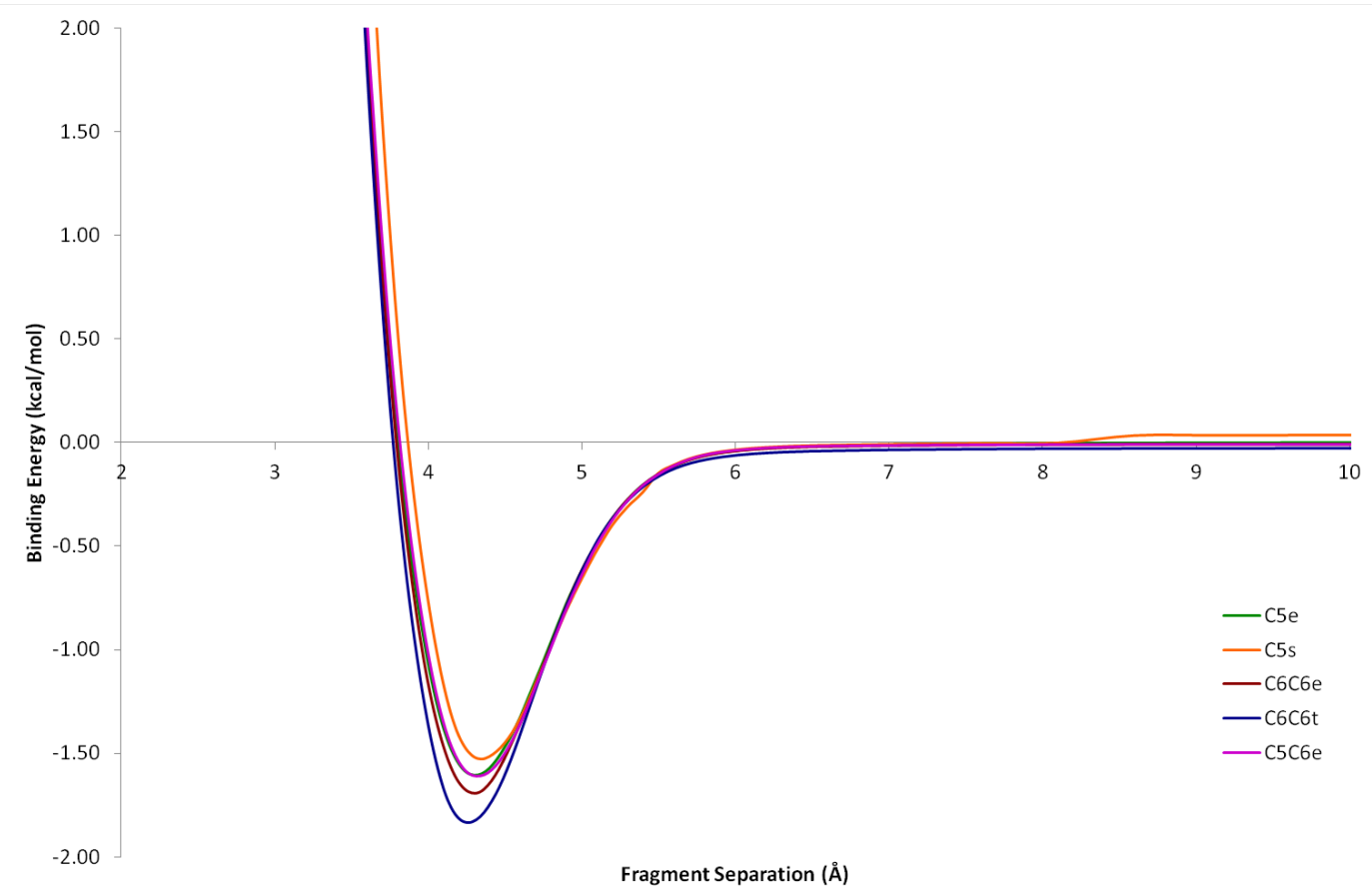

Figure A.7. $\tau$-HCTH energy profiles generated using the ultrafine integration grid. 


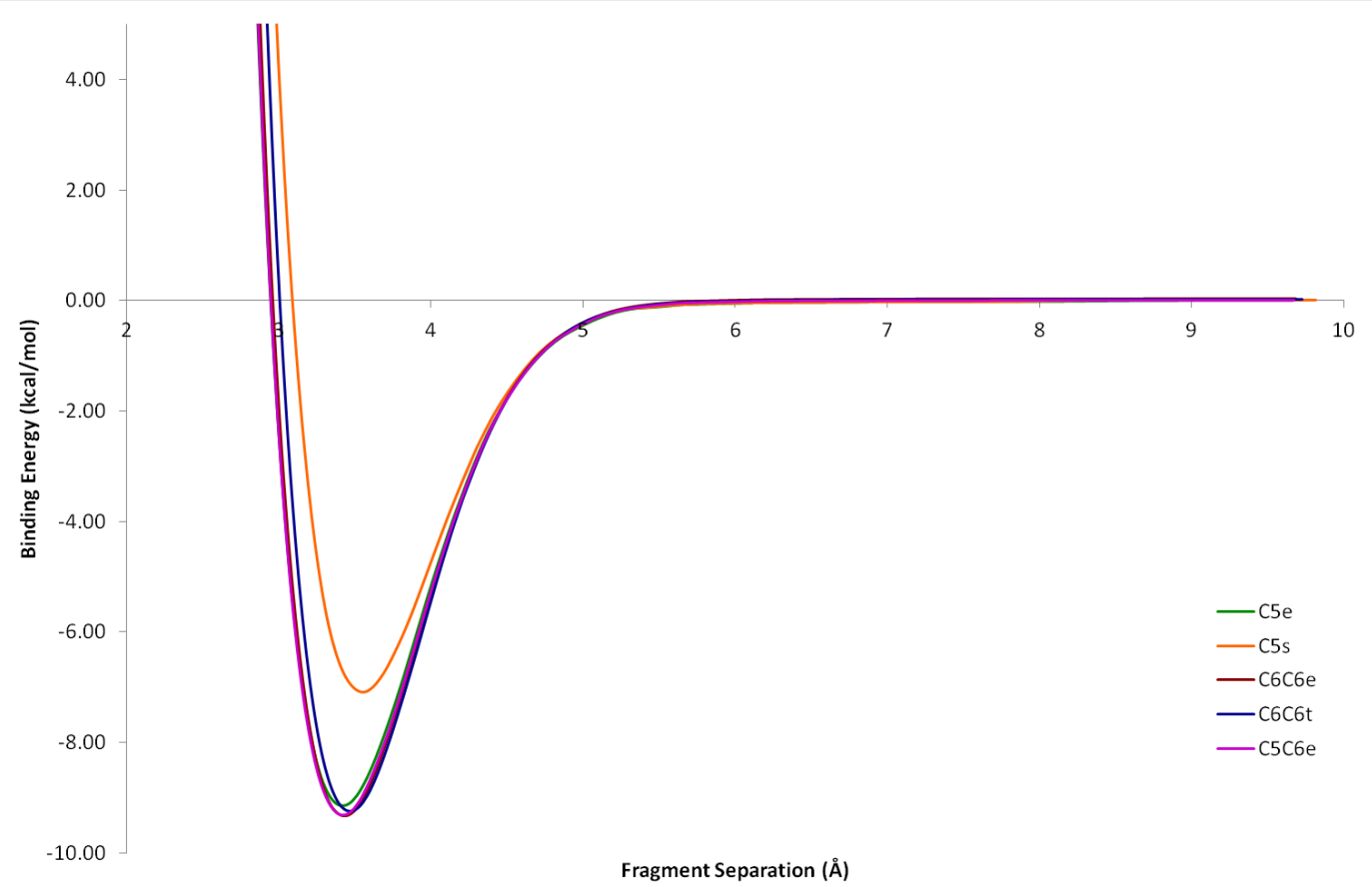

Figure A.8. $\omega \mathrm{B} 97 \mathrm{X}$ energy profiles generated using the ultrafine integration grid.

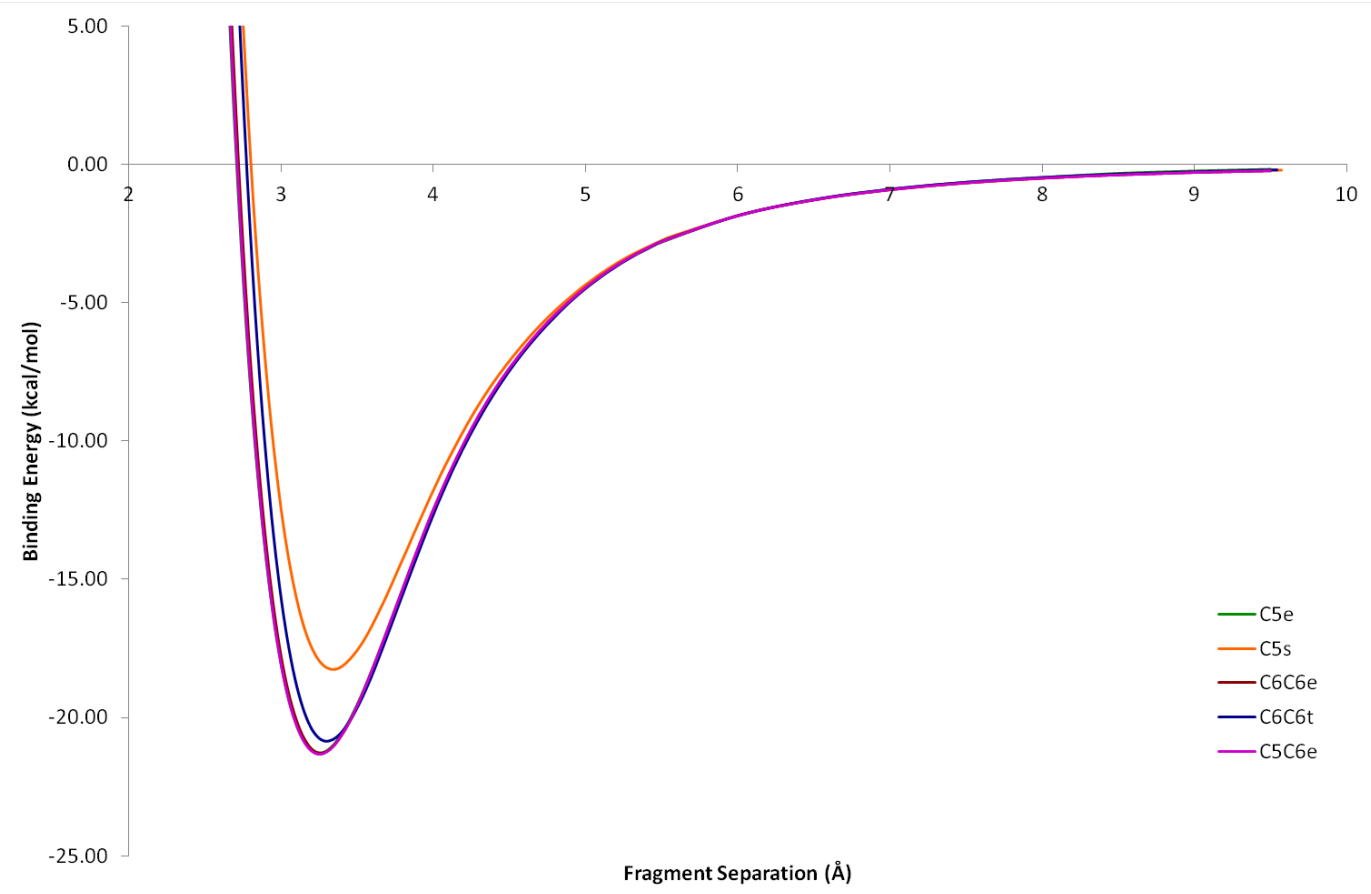

Figure A.9. $\omega \mathrm{B} 97 \mathrm{X}-\mathrm{D}$ energy profiles generated using the ultrafine integration grid. 


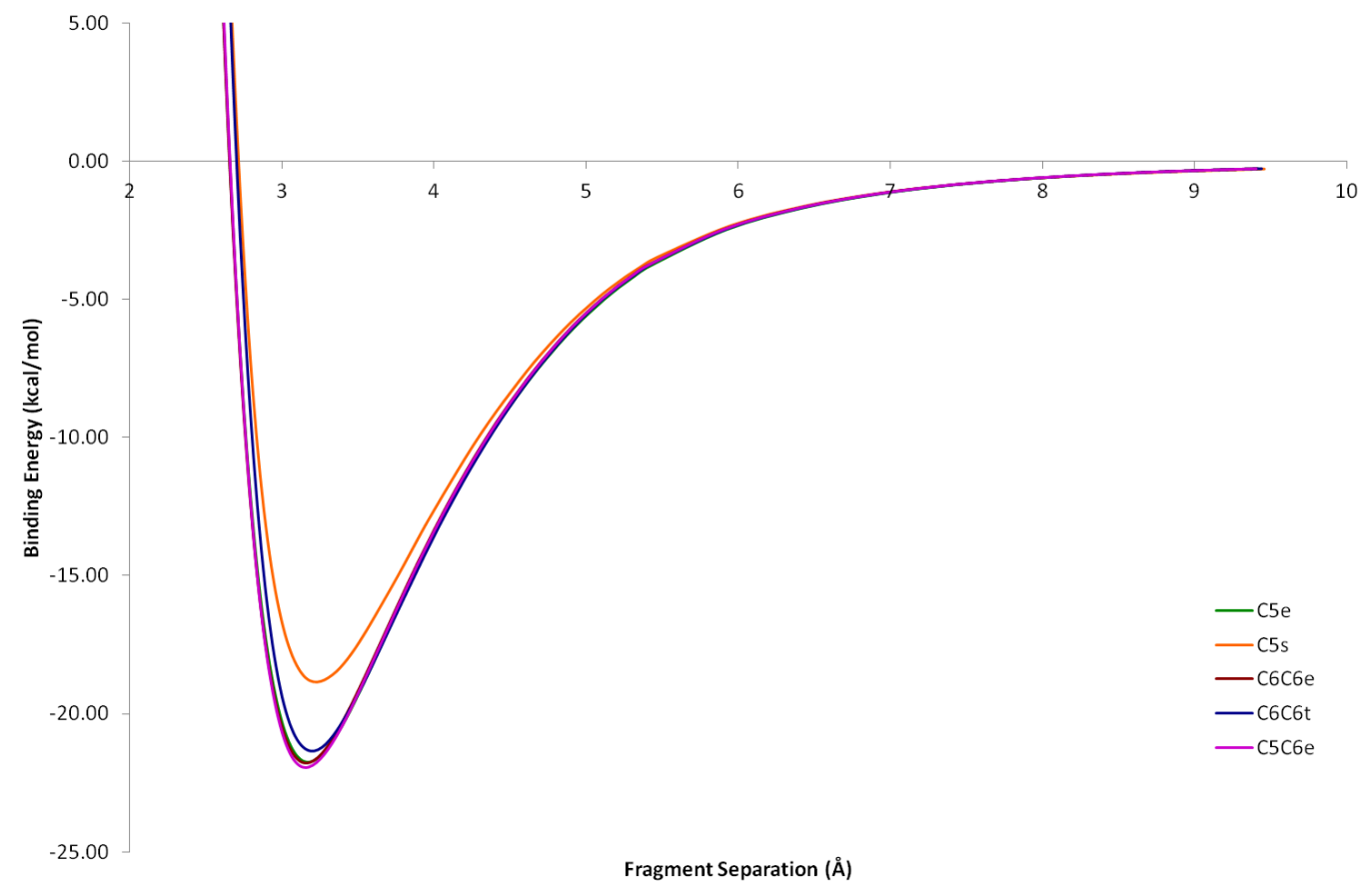

Figure A.10. B97-D energy profiles generated using the benchmark integration grid.

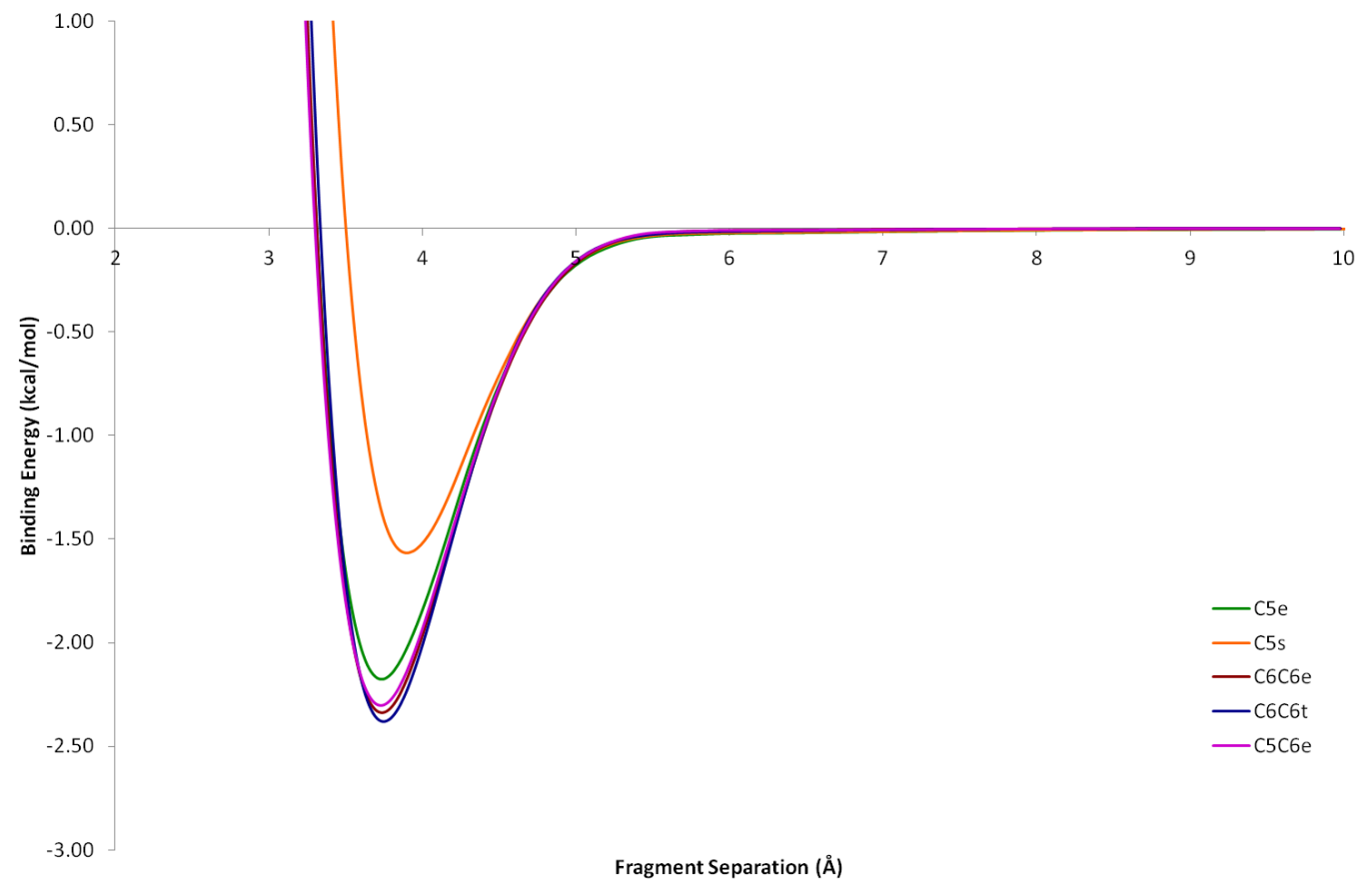

Figure A.11. CAM-B3LYP energy profiles generated using the benchmark integration grid. 


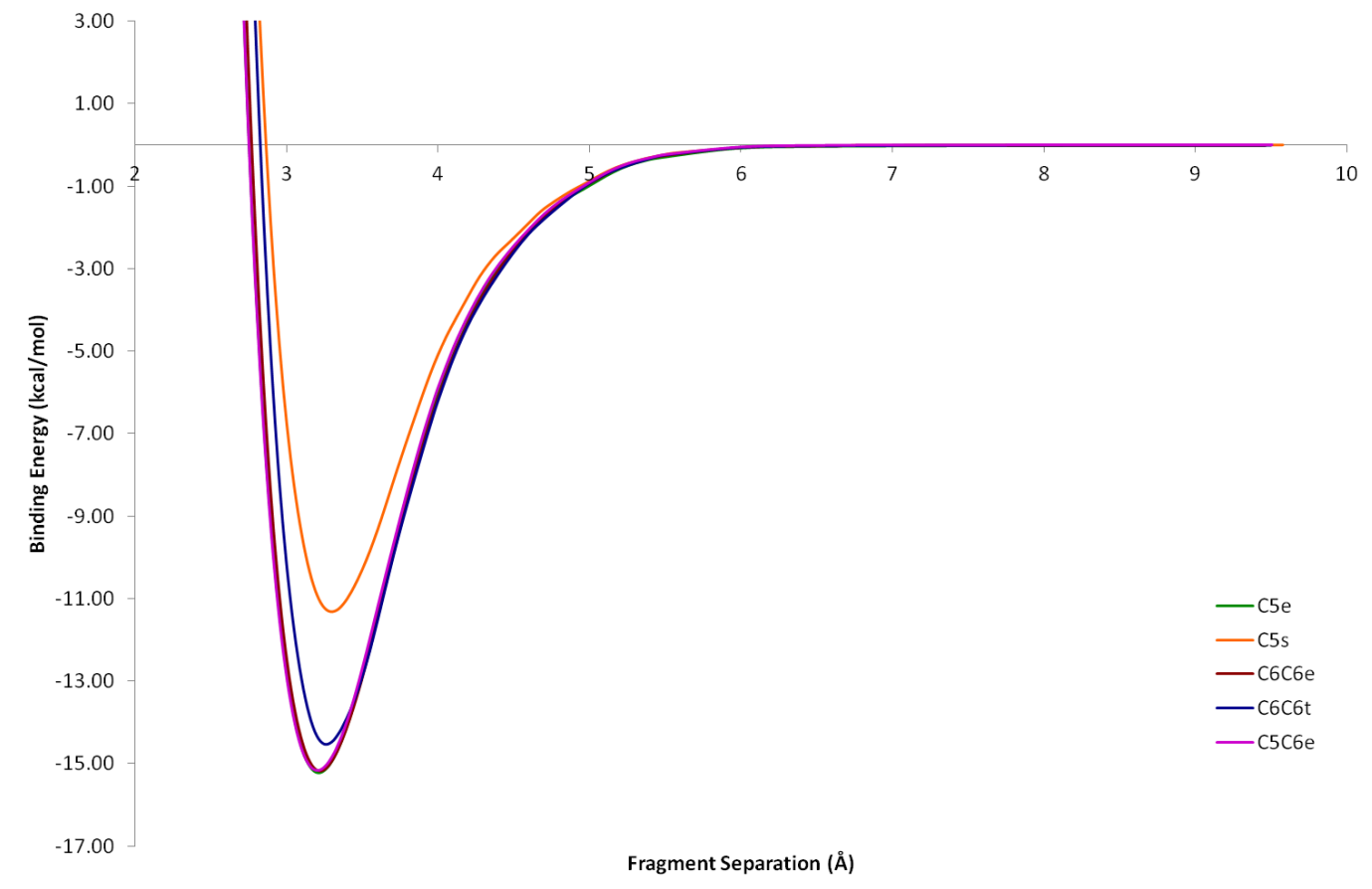

Figure A.12. M06-2X energy profiles generated using the benchmark integration grid.

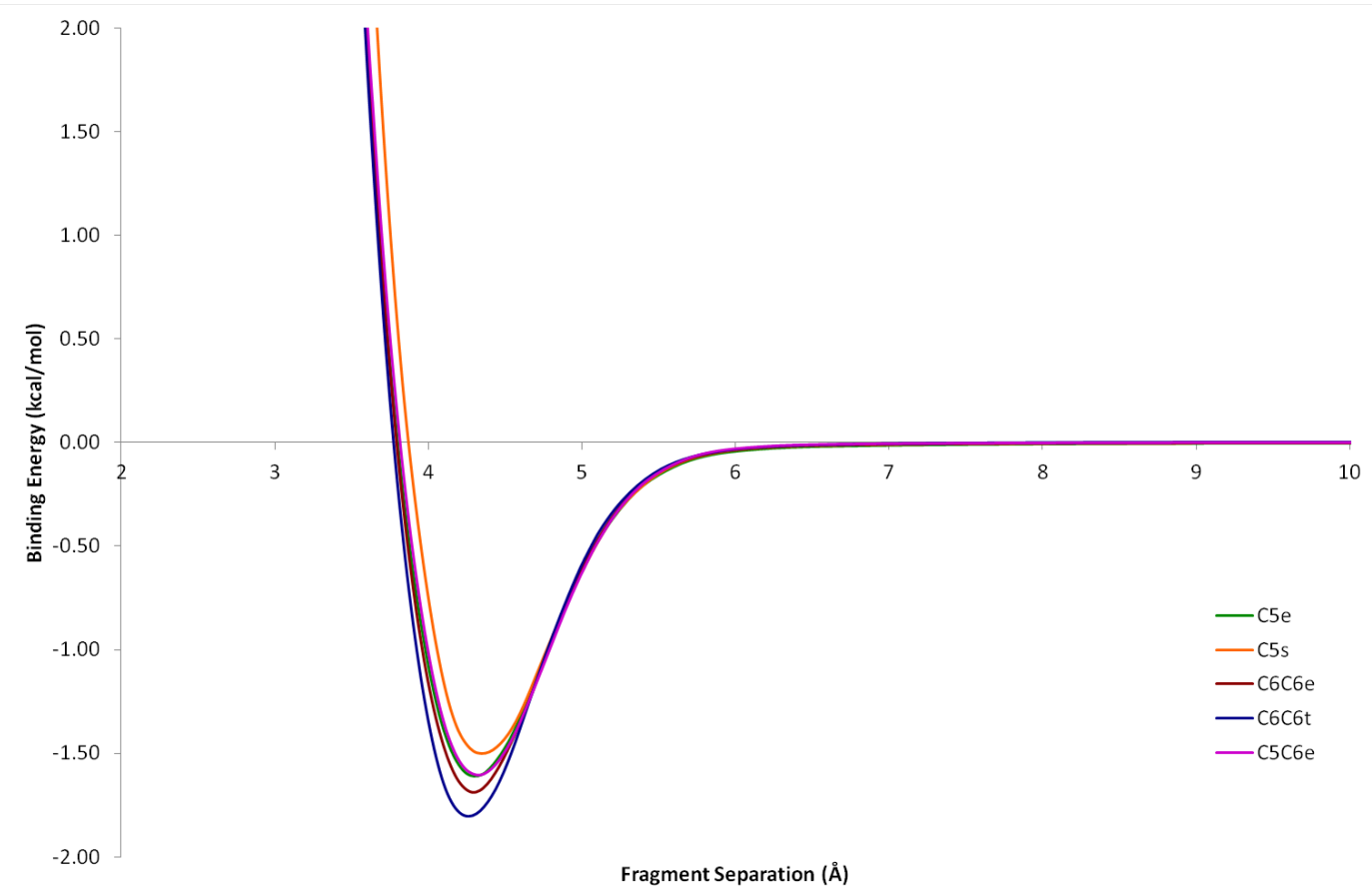

Figure A.13. $\tau$-HCTH energy profiles generated using the benchmark integration grid. 


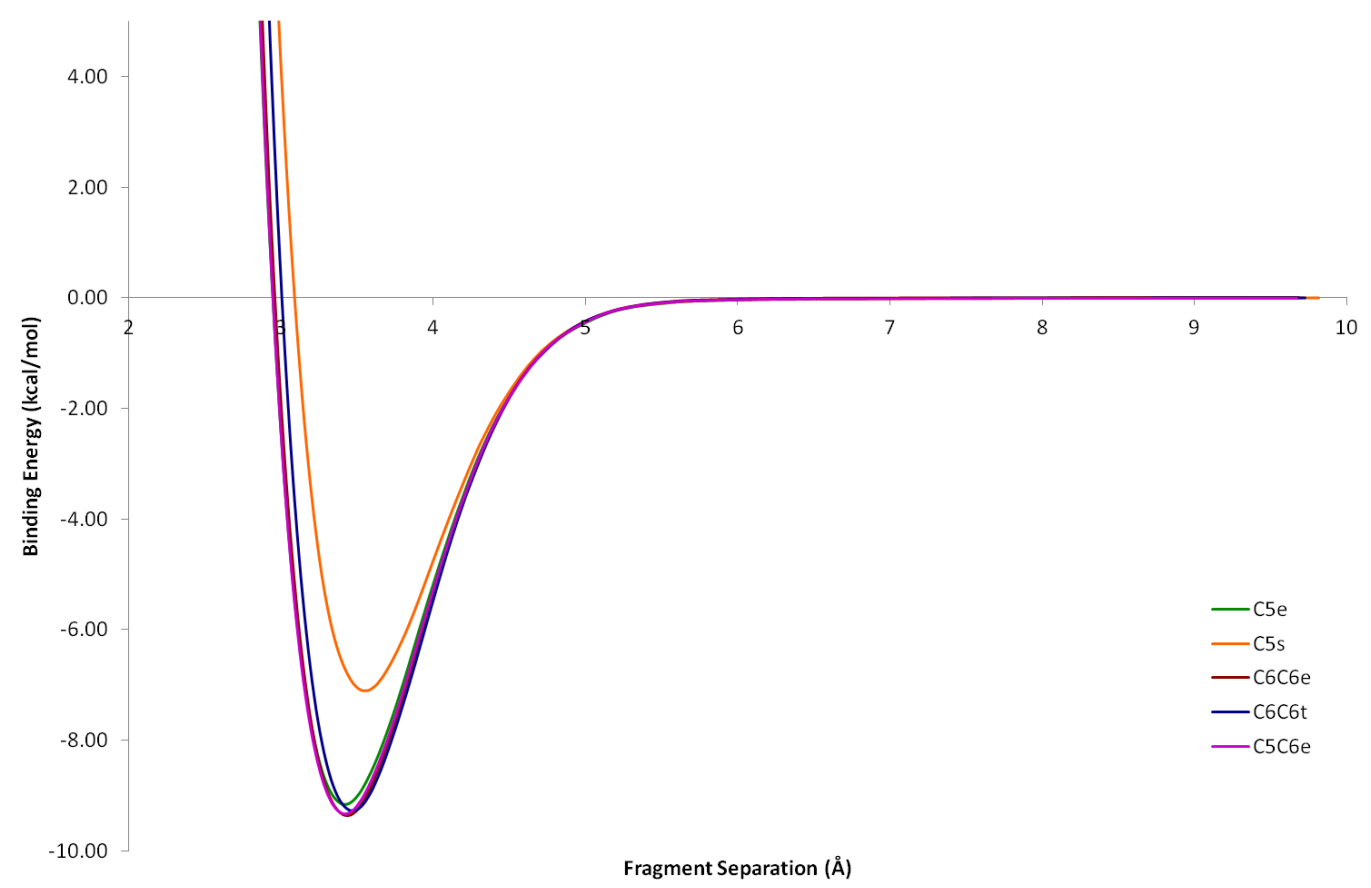

Figure A.14. $\omega \mathrm{B} 97 \mathrm{X}$ energy profiles generated using the benchmark integration grid.

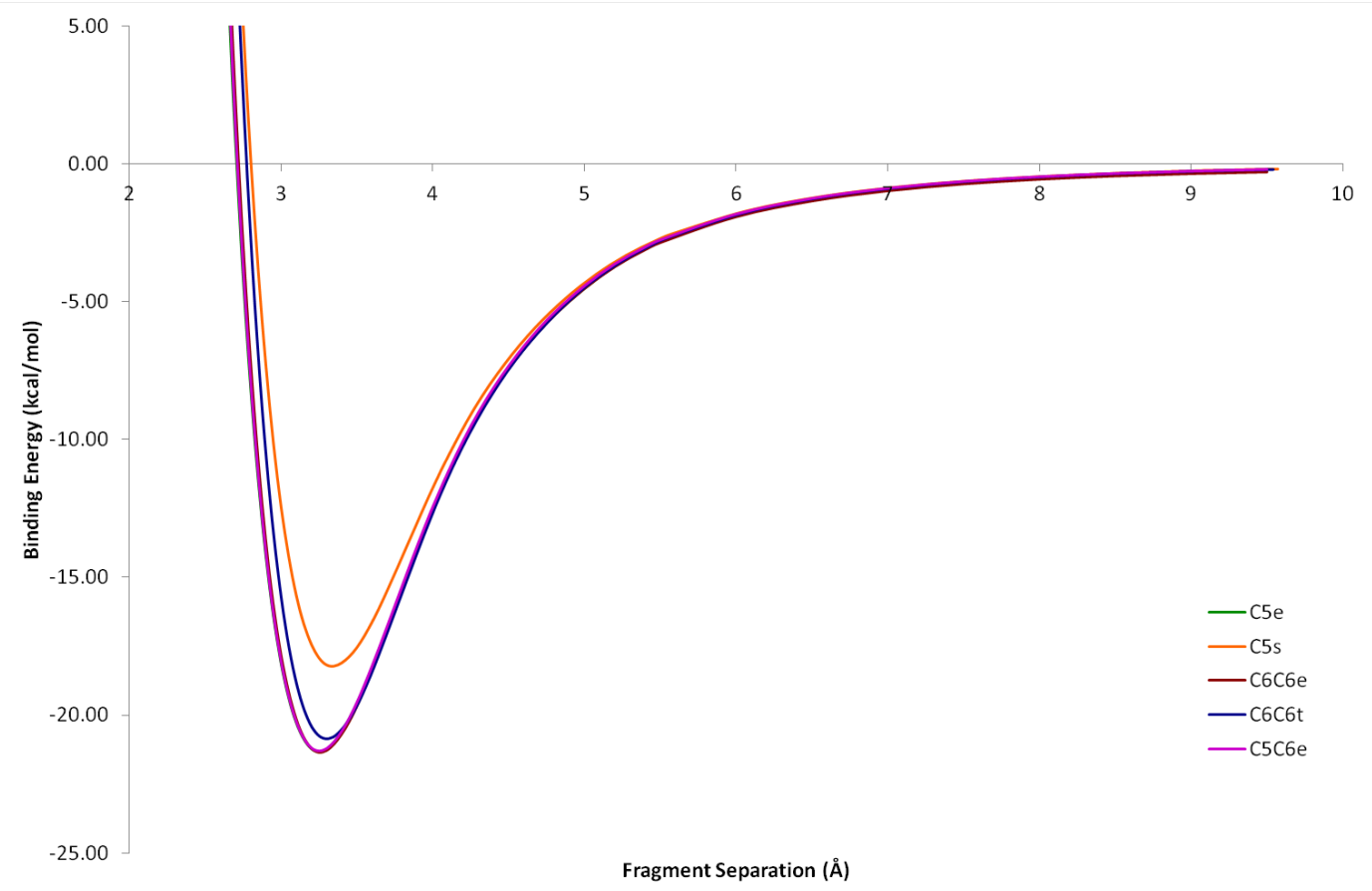

Figure A.15. $\omega$ B97X-D energy profiles generated using the benchmark integration grid. 


\section{Bibliography}

(1) Barth, W. E.; Lawton, R. G. J. Am. Chem. Soc. 1966, 88, 380-381.

(2) Wu, Y.-T.; Siegel, J. S. Chem. Rev. 2006, 106, 4843-4867.

(3) Mehta, G.; Prakash Rao, H. S. Tetrahedron 1998, 54, 13325-13370.

(4) Seiders, T. J.; Elliott, E. L.; Grube, G. H.; Siegel, J. S. J. Am. Chem. Soc. 1999, $121,7804-7813$.

(5) Grube, G. H.; Elliott, E. L.; Steffens, R. J.; Jones, C. S.; Baldridge, K. K.; Siegel, J. S. Org. Lett. 2002, 5, 713-716.

(6) Sevryugina, Y.; Rogachev, A. Y.; Jackson, E. A.; Scott, L. T.; Petrukhina, M. A. J. Org. Chem. 2006, 71, 6615-6618.

(7) Pappo, D.; Mejuch, T.; Reany, O.; Solel, E.; Gurram, M.; Keinan, E. Org. Lett. 2009, 11, 1063-1066.

(8) Wu, Y.-T.; Bandera, D.; Maag, R.; Linden, A.; Baldridge, K. K.; Siegel, J. J. Am. Chem. Soc. 2008, 130, 10729-10739.

(9) Georghiou, P. E.; Tran, A. H.; Mizyed, S.; Bancu, M.; Scott, L. T. J. Org. Chem. 2005, 70, 6158-6163.

(10) Mizyed, S.; Georghiou, P. E.; Bancu, M.; Cuadra, B.; Rai, A. K.; Cheng, P.; Scott, L. T. J. Am. Chem. Soc. 2001, 123, 12770-12774.

(11) Miyajima, D.; Tashiro, K.; Araoka, F.; Takezoe, H.; Kim, J.; Kato, K.; Takata, M.; Aida, T. J. Am. Chem. Soc. 2009, 131, 44-45.

(12) Baldridge, K. K.; Hardcastle, K. I.; Seiders, T. J.; Siegel, J. S. Org. Biomol. Chem. 2010, 8, 53-55.

(13) Gershoni-Poranne, R.; Pappo, D.; Solel, E.; Keinan, E. Org. Lett. 2009, 11, 51465149.

(14) Reisch, H. A.; Bratcher, M. S.; Scott, L. T. Org. Lett. 2000, 2, 1427-1430.

(15) Wu, T. C.; Hsin, H. J.; Kuo, M. Y.; Li, C. H.; Wu, Y. T. J. Am. Chem. Soc. 2011, $133,16319-16321$. 
(16) Jackson, E. A.; Steinberg, B. D.; Bancu, M.; Wakamiya, A.; Scott, L. T. J. Am. Chem. Soc. 2007, 129, 484-485.

(17) Steinberg, B. D.; Jackson, E. A.; Filatov, A. S.; Wakamiya, A.; Petrukhina, M. A.; Scott, L. T. J. Am. Chem. Soc. 2009, 131, 10537-10545.

(18) Steffens, R. J.; Baldridge, K. K.; Siegel, J. S. Helv. Chim. Acta 2000, 83, 2644 2654.

(19) Bancu, M.; Rai, A. K.; Cheng, P.; Gilardi, R. D.; Scott, L. T. Synlett 2004, 173176.

(20) Toivonen, T.; Hukka, T.; Cramariuc, O.; Rantala, T.; Lemmetyinen, H. J. Phys. Chem. A 2006, 110, 12213-12221.

(21) Liao, J., M.-S.and Watts; Huang, M. Phys. Chem. Chem. Phys. 2009, 11, 43654374.

(22) Kawase, T.; Kurata, H. Chem. Rev. 2006, 106, 5250-5273.

(23) Mizyed, S.; Ashram, M.; Miller, D. O.; Georghiou, P. E. J. Chem. Soc., Perkin Trans. 2 2001, 1916-1919.

(24) Becker, H.; Javahery, G.; Petrie, S.; Cheng, P.-C.; Schwarz, H.; Scott, L. T.; Bohme, D. K. J. Am. Chem. Soc. 1993, 115, 11636-11637.

(25) Benesi, H. A.; Hildebrand, J. H. J. Am. Chem. Soc. 1949, 71, 2703-2707.

(26) Foster, R.; Fyfe, C. A. Chem. Commun. (London) 1965, 642.

(27) Sygula, A.; Fronczek, F. R.; Sygula, R.; Rabideau, P. W.; Olmstead, M. M. J. Am. Chem. Soc. 2007, 129, 3842-3843.

(28) Fielding, L. Tetrahedron 2000, 56, 6151-6170.

(29) Xiao, W.; Passerone, D.; Ruffieux, P.; Aït-Mansour, K.; Gröning, O.; Tosatti, E.; Siegel, J.; Fasel, R. J. Am. Chem. Soc. 2008, 130, 4767-4771.

(30) Dawe, L. N.; AlHujran, T. A.; Tran, H.-A.; Mercer, J. I.; Jackson, E. A.; Scott, L. T.; Georghiou, P. E. Chem. Commun. 2012, 48, 5563-5565.

(31) Peverati, R.; Baldridge, K. K. J. Chem. Theory Comput. 2008, 12, 2030-2048.

(32) Hobza, P.; Selzle, H. L.; Schlag, E. W. J. Phys. Chem. 1996, 100, 18790-18794.

(33) Špirko, V.; Engkvist, O.; Soldán, P.; Selzle, H. L.; Schlag, E. W.; Hobza, P. J. Chem. Phys. 1999, 111, 572-582.

(34) Mück-Lichtenfeld, C.; Grimme, S.; Kobryn, L.; Sygula, A. Phys. Chem. Chem. Phys. 2010, 12, 7091-7097. 
(35) Josa, D.; Otero, J. R.; Cabaleiro Lago, E. M. Phys. Chem. Chem. Phys. 2011, 13, 21139-21145.

(36) Janowski, T.; Pulay, P.; Karunarathna, A. A. S.; Sygula, A.; Saebø, S. Chem. Phys. Lett. 2011, 512, 155-160.

(37) Denis, P. A. Chem. Phys. Lett. 2011, 516, 82-87.

(38) Vijay, D.; Sakurai, H.; Sastry, G. N. Int. J. Quant. Chem. 2011, 111, 1893-1901.

(39) Sygula, A.; Saebø, S. Int. J. Quantum Chem. 2009, 109, 65-72.

(40) Riley, K. E.; Pitoňák, M.; Černý, J.; Hobza, P. J. Chem. Theory Comput. 2010, 6, 66-80.

(41) Sherrill, C. D.; Takatani, T.; Hohenstein, E. G. J. Phys. Chem. A 2009, 113, 1014610159.

(42) Wong, B. J. Comput. Chem. 2009, 30, 51-56.

(43) Zhao, Y.; Truhlar, D. Phys. Chem. Chem. Phys. 2008, 10, 2813-2818.

(44) Becke, A. J. Chem. Phys. 1993, 98, 5648-5652.

(45) Lee, C.; Yang, W.; Parr, R. Phys. Rev. B 1988, 37, 785-789.

(46) Vosko, S. H.; Wilk, L.; Nusair, M. Can. J. Phys. 1980, 58, 1200-1211.

(47) Stephens, P.; Devlin, F.; Chabalowski, C.; M.J., F. J. Phys. Chem. 1994, 98, 11623 11627.

(48) Grimme, S. J. Comput. Chem. 2006, 27, 1787-1799.

(49) Becke, A. Phys. Rev. A 1988, 38, 3098-3100.

(50) Perdew, J. Phys. Rev. B 1986, 33, 8822-8824.

(51) Yanai, T.; Tew, D.; Handy, N. Chem. Phys. Lett. 2004, 393, 51-57.

(52) Zhao, Y.; Truhlar, D. Theor. Chem. Acc. 2008, 120, 215-241.

(53) Perdew, J.; Chevary, J.; Vosko, S.; Jackson, K.; Pederson, M.; Singh, D.; Fiolhais, C. Phys. Rev. B 1992, 46, 6671-6687.

(54) Perdew, J.; Burke, K.; Wang, Y. Phys. Rev. B: Condens. Matter Mater. Phys. 1996, $54,16533-16539$.

(55) Boese, A.; Handy, N. J. Chem. Phys. 2002, 116, 9559-9569.

(56) Chai, J.-D.; Head-Gordon, M. J. Chem. Phys. 2008, 128, 084106. 
(57) Chai, J.-D.; Head-Gordon, M. Phys. Chem. Chem. Phys. 2008, 10, 6615-6620.

(58) Boese, A. D.; Handy, N. C. J. Chem. Phys. 2001, 114, 5497-5503.

(59) Becke, A. D. J. Chem. Phys. 1997, 107, 8554-8560.

(60) Perdew, J.; Burke, K.; Ernzerhof, M. Phys. Rev. Lett. 1996, 77, 3865-3868.

(61) Zhang, Y.; Truhlar, D. G. J. Phys. Chem. A 2006, 110, 13126-13130.

(62) Tawada, Y.; Tsuneda, T.; Yanagisawa, S.; Yanai, T.; Hirao, K. J. Chem. Phys. 2004, $120,8425-8433$.

(63) Møller, C.; Plesset, M. Phys. Rev. 1934, 46, 618-622.

(64) Frisch, M.; Head-Gordon, M.; Pople, J. Chem. Phys. Lett. 1990, 166, 275-280.

(65) Frisch, M.; Head-Gordon, M.; Pople, J. Chem. Phys. Lett. 1990, 166, 281-289.

(66) Head-Gordon, M.; Pople, J.; Frisch, M. Chem. Phys. Lett. 1988, 153, 503-506.

(67) Head-Gordon, M.; Head-Gordon, T. Chem. Phys. Lett. 1994, 220, 122-128.

(68) Sæbø, S.; Almlöf, J. Chem. Phys. Lett. 1989, 154, 83-89.

(69) Grimme, S. J. Chem. Phys. 2003, 118, 9095-9102.

(70) Cheeseman, J. R.; Trucks, G. W.; Keith, T. A.; Frisch, M. J. J. Chem. Phys. 1996, 104, 5497-5509.

(71) Wolinski, K.; Hinton, J. F.; Pulay, P. J. Am. Chem. Soc. 1990, 112, 8251-8260.

(72) Ditchfield, R. Mol. Phys. 1974, 27, 789-807.

(73) Friedrich, K.; Seifert, G.; Großmann, G. Z. Phys. D 1990, 17, 45-46.

(74) Schreckenbach, G.; Ziegler, T. J. Phys. Chem. 1995, 99, 606-611.

(75) Paranhos Costa, F. L.; Ferreira de Albuquerque, A. C.; Martins dos Santos Jr., F.; Barbose de Amorim, M. J. Phys. Org. Chem. 2010, 23, 972-977.

(76) Rablen, P. R.; Pearlman, S. A.; Finkbiner, J. J. Phys. Chem. A 1999, 103, 73577363.

(77) Jain, R.; Bally, T.; Rablen, P. R. J. Org. Chem. 2009, 74, 4017-4023.

(78) Wu, A.; Zhang, Y.; Xu, X.; Yan, Y. J. Comput. Chem. 2007, 28, 2431-2442. 
(79) Frisch, M. J.; Trucks, G. W.; Schlegel, H. B.; Scuseria, G. E.; Robb, M. A.; Cheeseman, J. R.; Scalmani, G.; Barone, V.; Mennucci, B.; Petersson, G. A.; Nakatsuji, H.; Caricato, M.; Li, X.; Hratchian, H. P.; Izmaylov, A. F.; Bloino, J.; Zheng, G.; Sonnenberg, J. L.; Hada, M.; Ehara, M.; Toyota, K.; Fukuda, R.; Hasegawa, J.; Ishida, M.; Nakajima, T.; Honda, Y.; Kitao, O.; Nakai, H.; Vreven, T.; Montgomery, J. A., Jr.; Peralta, J. E.; Ogliaro, F.; Bearpark, M.; Heyd, J. J.; Brothers, E.; Kudin, K. N.; Staroverov, V. N.; Kobayashi, R.; Normand, J.; Raghavachari, K.; Rendell, A.; Burant, J. C.; Iyengar, S. S.; Tomasi, J.; Cossi, M.; Rega, N.; Millam, J. M.; Klene, M.; Knox, J. E.; Cross, J. B.; Bakken, V.; Adamo, C.; Jaramillo, J.; Gomperts, R.; Stratmann, R. E.; Yazyev, O.; Austin, A. J.; Cammi, R.; Pomelli, C.; Ochterski, J. W.; Martin, R. L.; Morokuma, K.; Zakrzewski, V. G.; Voth, G. A.; Salvador, P.; Dannenberg, J. J.; Dapprich, S.; Daniels, A. D.; Farkas, .; Foresman, J. B.; Ortiz, J. V.; Cioslowski, J.; Fox, D. J. Gaussian 09 Revision B.01. Gaussian Inc. Wallingford CT 2009.

(80) Kleingeld, R.; Lein, M. personal correspondence.

(81) Taylor, R.; Hare, J. P.; Abdul-Sada, A. K.; Kroto, H. W. J. Chem. Soc., Chem. Commun. 1990, 1423-1425. 